\title{
THERMAL AND DYNAMIC EFFECTS IN ELECTRON BEAM WELDING CAVITIES
}

Dale A. Schauer

(Ph.D. Thesis)

August, 1977

Prepared for U.S. Energy Research \& Development Administration under contract No. W-7405-Eng-48

\section{UL LAWRENCE INERMORE IABORATORY}




\title{
近 \\ LAWRENCE LIVEPMORE LABORATORY \\ University of Caltomia Livermore,California 94550
}

\section{UCRI-52331 \\ Thesis \\ THERMAL AND DYNAMIC EFFECTS IN ELECTRON BEAM WELDING CAVITIES}

\author{
Dale A, Schauer \\ (Ph.D. Thesis) \\ August, 1977
}

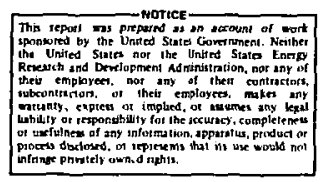




\section{ABSTRACT}

An experimental and analytical study of the temperature distributions along the molten metal surface in an electron beam welding cavity is described. Surface temperature distributions in cavities were measured with a narrow band infrared radiation pyrometer. The availability of the cavity temperature measurements allowed estimates to be made for the vapor pressure and surface energy forces as a functi on of cavity position. The results indi ated a force imbalance occirred in the cavity. It is postulated $t$. at at the location of the foi se imbalance a liquid material projection forms periodically and moves into the path of the electron beam. The liquid in this projection is driven towards the bottom, partially filling the cavity. This action is followed by the electron beam pushing the liquid aside to form a maximum depth cavity. This process is then repeated.

An analysis for predicting cavity oscillation frequency shows reasonable agreement with frequencies measured at the weld root determined from weld sections. A study of the measured temperature distributions in cavities of varying depth combined with the force imbalance observations led to an interpretation of when spiking might occur. A procedure is proposed for determining the spiking tendency for a given set of weld parameters. The results of this study permit a designer to select apriori the best set of weld parameters to achieve a weld of predictable quality. 
TABLE OF CONTENTS

Page

Abstract

Summary

Nomenclature

Introduction

Experimentâl Program

Equipment

Experimental Procedure

Liquid Metal Spectral Emittance as a Function of Pyrometer Temperature

Experimental Determination of Spectral Emittance Values

Cavity Effect on Temperature Measurements

Experimenta1 Measurements

EB Welding Cavity Peak Temperatures

Fusion Zone Werd Sections

EB Welding Cavity Temperature Distributions

Material Composition Change of Alloy in Weld Region

Analysis and Interpretation of Welding Process

Introduction

Calculations of Forces in Cavity

Cavity Dynamics

Size Estimation of Liquid Projection 
Estimate of Time to Fill Cavity Bottom

Estimate of Time Required to Reopen

Cavity

Cavity Oscillation Frequency

Cavity Oscillation Frequency Calculation for Weld in Pure Aluminum

Vapor Pressure-Temperature Relationship for Alloy Cavity

Surface Tension of Liquid in Alloy Cavity

Alloy Effects on Cavity Jscillation Frequency

Cavity Oscillation Frequency Calculation for Alloy

Formation of Freeze-Ring Pattern on Weld Bead Surface

Discussion

Interpretation of the Electron Beam Welding Process

Proposed Dynamic EB Welding Model

Prediction of Spiking Tendency

Dimensionless Temperature Profile Stability Parameter

Conclusions

Recommendations

References

Appendix A - Reflected Radiation Entering Probe from Dther Cavity Surface Elements

Appendix B - Frequency of : veld Bead Ripples 
Appendix C - Vapor Pressure - Surface Tension Pressure Relationship at the Cavity Bottom ...........

Appendix D - Stability Parameter Calculations ..... 


\section{ACKNOWLEDGMENTS}

Sincere appreciation is extended to the many people who have helped bring this seemingly eternal undertaking to a fruitful end. Gratitude is expressed to my parents, Dave and Helen Schauer, who provided me with the educational opportunity that they themselves were denied. I thank my wife, Carlotta, who perservered while consuming many hours wondering when this dissertation would be finished. Special thanks are extended to Mildred Rundquist who persisted in typing rough draft after rough draft as well as the final version. Appreciation of the special efforts of $W$. H. Giedt are also in order. His unique approach to the direction of graduate students and research work provided an excellent atmosphere for the efforts of this thesis and the development of this student. The discussions with Z. A. Munir on the possible types of interactions in the weid cavity were instrumental in the development of the proposed dynamic model. The constructive criticism offered by $\mathrm{H}$. Tong led to the development of the means for predicting spiking. F. Drabnik is to be complimented on the outstanding job of designing and building the hardware that made these temperature measurements possible. Many early fail-

ures were later overcome by following his design suggestions. R. E. Armstrong and G. L. Mara gave of their expertise in EB welding to offer many ideas on what might be happening during the weld process. Finally, I thank G. A. Broadman, R. G. Stone, and R. B. Carr for supporting this research effort.

This work was performed under the auspices of the United States Energy Research and Development Administration. 


\section{ACKNOWLEDGMENTS}

Sincere appreciation is extended 0 the many people who have helped bring this seemingly eternal undertaking tc a fruitful end. I thank my wife, Carlotta, who perservered while consuming many hours wondering when this dissertation would be finished. Special thanks are extended to Mildred Rundquist who persisted in typing rough draft after rough draft as well as the final version. Appreciation of the special efforts of $W$. H. Giedt are also in order. His unique approach to the direction of griduate students and research work provided an excellent atmosphere for the efforts of this thesis and the development of this student. The discussions with

2. A. Munir on the possible types of interactions in the weld cavity were instrumental in the development of the proposed dynamic model. The constructive criticism offered by $\mathrm{H}$. Tong led to the development of the means for predicting spiking. F. Drobnik is to be complimented on the outstanding job of designing and building the hardware that made these temperature measurements possible. Many early failures were later overcome by following his design suggestions. R. E. Armstrong and G. L. Mara gave of their expertise in EB welding to orfer many ideas on what might be rappening during the weld process. Finally, I thank G. A. Broadman, R. G. Stone, and R. B. Carr for supporting this research effort.

This work was done under the auspices of the United States Energy Research and Development Administration. 


\section{SUMMARY}

A review of recent studies of electron beam we!ding clearly indicates that the fundamental mechanisms and their interactions are extremeiy complex. Although the importance of the pressure produced by evaporating meta $l$ in the cavity is generally recugnized, no definitive information has as yet been obtained to validate this hypothesis. Since the vapor pressure will be determined by the surface temperature of the molten metal, an experimental program was undertaken to measure local temperatures in the cavities produced during electron beam welding. The results obtained were utilized in providing an improved interpretation of the governing forces and their interactions.

The experimental part of the program utilized a narrow band infrared radiation pyrometer to measure the surface temperature in the cavity which forms during electron beam welding. The location of the pyrometer measurement spot was controllable frum outside the vacuum weld chamber during welding. Temperature distribution measurements were obtained both perpendicular and parallel to the welding direction. For shallow welds, measurements could be obtained at the cavity bottom. The interreflections occurring in the welding cavity were found to effect the measured pyrometer output. The temperature measurements indi-. cate that a temperature gradient exists in the cavity with the temperature highest at the bottom.

Many investigators have suggested that a vapor filled cavity is formed in the path of the electron beam during welding and that the molten metal oscillates. The analytical part of the program starts by 
showing that a relationship exists in the cavity between the vapor pressure, surface energy, and the hydrostatic head. The availability of the cavity temperature measurements, allowed estimates to be made for the vapor pressure and surface energy forces as a function of cavity position. A region of force imbalance was found to exist in the cavity above which the surface energy force was greater than the local surface vapor pressure force.

It is postulated that at the location of the force imbalance, a liquid material projection moves into the path of the electron beam, is then driven towards the cavity bottom, thus partially filling the cavity. This is followed by the electron beam pushing this liquid aside to form a maximum depth cavity. An analysis based on the cavity geometry, surface energy, and the vapor recoil force acting on the liquid projection is presented. This allows the time to push the liquid projection to the cavity bottom tu be determined. This time is used to calculate a cavity oscil?ation frequency which shows reasonable agreement with measured frequencies at the weld root determined from weld sections. A separate analysis relates the freeze ridge patterns observed at the weld bead surface to a dynamiz behavior of the liquid metal at the cavity top. Estimated ridge frequencies agree well with the experimentally measured frequencies, but are nat necessarily the same as the base frequencies.

Indicated general conclusions are triat for a specific material the peak cavity temperature measured does not depend on electron beam power settings or on weld speeds. A typical cavity temperature distribution results in a large local vapor pressure at the cavity bottom and neg- 
ligible pressure near the cavity top. Because of the importance of vapor pressure, the amount of volatile elements in an alloy can have a dramatic effect on the behavior of the cavity during welding. Temperature measurements of an alloy cavity after repeated weld passes indicate that as very small amounts of highly volatile elements are evaporated and leave the cavity there is a substantial increase in temperature. The analysis, which is based on knowing the temperature distribution in the cavity, provides a possible interpretation of the cavity oscillations diring welding. The measured temperature distributions were observed to exhibit a characteristic behavior as a furiction of weld depth. This observation was combined with the occurrerice of the cavity force imbalance to develop a general method which can be used to assess spiking. Without performirig a single test weld a set of weld parameters can be selected and it can be determined whether spiking will be a problem or not. 
NOMENCLATURE

a

A

$A_{E}$

$A_{\mathrm{s}}$

A

C

$\mathrm{C}_{2}$

$\mathrm{C}_{\mathrm{p}}$

dA

${ }^{d E_{d}} A_{j}-d A_{j}$

$d \gamma / d T$

e

$e_{\lambda}$

$e_{\lambda b}$

E

f

$f_{n}$

$F_{\mathrm{H}}$

Fv

$F_{\text {S }}$

g

h

$\mathrm{h}_{\mathrm{fg}}$
Representative cavity radius

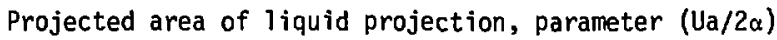

Effective cavity exit area

Cone surface area

Effective cavity evaporation area

Weld depth at which weld root area changes from a relatively smooth 1 ine to a more wavy line

Second PTanck constant $\left(1.4387 \times 10^{4} \mu \mathrm{m}-{ }^{\circ} \mathrm{K}\right)$

Specific heat capacity

Incremental area

Radiation exchange factor

Surface tension temperature coefficient

Emissive power

Hemispherical spectral emissive power per unit area

Hemispherical spectral emissive power per unit area of a blackbody

Beam voltage

Frequency

Diffuse angle factor

Hydrostatic inead force

Vapor pressure force

Surface tension force

Acceleration due to gravity

Cavity penetration depth

Heat of fusion 
Distance between force imbalance and cavity bottom

Radiation intensity

$i_{\lambda}$

Spectral intensity

Beam current

Rate of Evaporation per unit area

k

$m(t)$

Thermal conductivity

$\dot{\mathrm{m}}_{\mathrm{e}}$

Mass of vapor in cavity at time $t$

Mass evaporation rate in cavity

$\dot{m}_{v}$

Mass rate exiting cavity

$M$

Atomic weight

N

Atomic fraction of species

$\mathrm{P}$

Average cavity pressure, exponent

$P_{\text {IN }}$

Equivalent inward pressure

P S.T. $_{\text {. }}$

Pressure due to surface tension

ex

External pressure

$P_{v}$

$\mathbf{p}^{0}$

${ }^{\mathrm{q}}$ IN,S

Vapor pressure

Vapor pressure of pure species

Incoming radiation to $d A_{i}$ by reflection from $A_{S}$

$q_{R}$

Sum of radiation leaving $\mathrm{dA}_{i}$

$R$

Averaye cavity radius

$R_{B}$

Cavicy base radius of curvature

$\mathrm{R}_{\mathrm{C}}$

Effective radius of evaporation at cavity bottom

$R_{T}$

Top cavity radius

$\mathbf{R}_{\mathbf{u}}$

Universal gas constant

$S$

Stability parameter $(H / h)$

t

Time

Temperature, average temperature of cavity vapor 


$\begin{array}{ll}T_{B} & \text { Temperature at cavity bottom } \\ T_{T} & \text { Temperature at cavity top } \\ T_{m} & \text { Melting temperature } \\ T_{r} & \text { Radiant (brightness) temperature } \\ T_{S} & \text { Temperature at which } r \text { is known } \\ T_{Y} & \text { Welding speed } \\ U & \text { Cavity volume } \\ V & \text { Vertical position in cavity, liquid metal movement } \\ X & \text { distance }\end{array}$

GREEK SYMBOLS

$\alpha$

$\beta$

$\gamma$

$\delta$

$\varepsilon_{a}$

$\varepsilon_{\lambda}$

$\varepsilon_{\lambda a}$

$n$

$\lambda$

$\lambda_{e}$

$\theta$

p

$\sigma$

Evaporation coefficient, themal diffusivity, dimensionless cavity location parameter

Angle of probe line of sight relative to cavity surface $(\theta+\phi)$

Surface tension, activity coefficient of species in alloy

Thickness of liquid material projection

Apparent emissivity

Spectral emittance

Apparent spectral emittance

Fraction of $E B$ energy

Wavelength

Effective wavelength of pyrometer

Cone angle of assumed conical cavity, dimensionless cavity temperature variable

Reflectivity, density

Stefan-Boltzmann constant 
$\Delta \tau$

$\tau$

$\tau_{2}$

$\phi$

Time increment

Time required to push liquid projection to cavity bottom

Cavity penetration time

Angle of probe line of sight relative to work piece surfáce 


\section{INTRODUCTION}

Electron beam welding is the fusion joining of materials by bombardment of the interface region with a well defined stream of high energy electrons. Due to scattering of $\cdots+0^{+}$ons at atmospheric pressure the process is usually done in a :...... chamber at pressures on the order of $10^{-5}$ Torr, even though it is possibie to achieve successful welds at slightly higher chamber pressures. Electrons emitted from a hot filament at a high voltage are accelerated towards and focused on the material surface. The impinging electron beam is capable of penetrating only a very short distance into a material surface. The energy absorbed is sufficient to melt a thin layer of material and raise the molten temperature of the liquid to values at which a substantial vapor pressure is produced. 1,2

Although relatively recent, $E B$ welding has earned a place of promise as a joining process in the field of welding. However, successful electron beam welds are presently being obtained by many weld trials combined with electron beam welding experience. The problem is that the welding mechanisms are not fully understood, al though much effort has been expended. Extensive studies on the effects of such factors as beam current, power, focus current, and part motion have been made. However, they have not been sufficiently successful in explaining the interaction of these parameters. It still is not possible to specify the appropriate parameter values to use for making a weld in a new material or when the joint or other conditions are changed. 
WELDING PRACTICE

In order to use the electron beam for welding purposes, it must be focused at or near the workpiece surface. During this focusing process due to imperfect electron optics, the beam current distribution distorts gradually as the degree of focusing is increased. It can be readily appreciated that a beam which focuses to an elongated spot would have different fusion zone features depending on the direction of the weld pass. It can also be expected that smaller and more concentrated beams will produce larger depth to width ratios. It might then be concluded that the best welding beam is a small and highly concentrated one; that is, one of high power concentration. But it has been observed that this is the condition which is conducive to the formation of welding defects such as porosity, cold shuts, or spiking.

A spike is a sudden increase in penetration beyond what might be called the average penetration line. Many spikes have voids in their lower portions because molten metal does not fill in completely. In some cases the molten metal will fill a spike but will not fuse to the sides of the hole which is a condition similar to a cold shut in a casting. These cold shuts seriously reduce the strength of the weld at the root. They are quite difficult to find by radiography but can usually be detected by ultrasonic inspection. It has been suggested ${ }^{3}$ that spiking is inherent in the hole boring mode of electron bean welding and cannot be eliminated by any parameter adjustment on commercially available machines without sacrificing penetration.

As the beam moves along the work, a cavity is formed and molten metal flows from behind and fills this cavity. Although, there are a number of theories and interpretations, it is not known for certain 
just what is happening in the cavity. The cavity is filled with metal vapors and gases liberated from the base metal and there is a constantly changing pressure in the cavity, as shown by violent eruptions of molten metal or weld spatter. In a full penetration weld these gases and vapors are vented through the bottom of the weld and the conditions in the cavity are reasonably constant. In a partial penetration weld these gases and vapors must vent back through the cavity in opposition to the beam and the electrons must pass through this constantly changing composition plasma to reach the base metal. If the material surges into the cavity and interrupts the beam at fairly regular intervals, then the focal point of the beam is constantly changing. This may be caused by electron deflection as the electrons strike metal atoms in and above the cavity. This interaction may alter the electron space charge and cause a change in focal point which will modify the power concentration in the beam at the workpiece. Consequently with these fluctuations in the beam and the instabilities in the weld cavity it is not surprising that the root of the weld is so irregular.

Also possibly important is the actual distribution of energy in the beam. Measurements of the distribution at low energy display a ragged appearance with many localized energy peaks. At high power levels large differences in energy density throughout the beam might be expected. Furthermore, these localized peaks in the energy distribution may appear in some random manner for short periods of time possibly even more accentuated. Therefore, even for a beam that is not highly focused, it has been suggested that the potential exists for spiking if a localized peak occurs with an extremely high energy density for sufficient duration. ${ }^{4}$ 
FUNDAMENTAL STUDIES OF ELECTRON BEAM WELD PROCESS

Recent work has shed considerable light on the electron beam weld process. Although a detailed physical model of the electron beam interaction with the material is still lacking, observations of several investigators suggests a general mechanism. The forces acting in the cavity have been assessed. ${ }^{5}$ The cavity shape and oscillations have been observed by several investigators using $x$-ray photography. It is suggested that a fundamental difference exists between low and high voltage welding. The weld cavity is believed to experience a deep closure for low voltage welding and a surface and deep closure for high voltage welding. A flash $x$-ray technique has been used to observe the oscillation of a cavity filling and opening. ${ }^{6,7,8}$ A pinhole $x$-ray source combined with a movie camera has allowed the beam impingement to be monitored during welding. 9,10 The results suggest the cavity is alternately opened and filled. A continuous $x$-ray fiuoroscopic technique was used to photograph the cavity oscillating in width and depth. 11,12 Cavity oscillations have also been observed by use of high speed photographic techniques. ${ }^{13}$ Evidence has been presented suggesting that surface tension can induce cavity oscillations. ${ }^{14}$ The reaction force during welding has been measured by mounting the workpiece on a balance ${ }^{5}$; and the vapor reactions in the cavity have been detected by measurements made using a piezoelectric sensing element attached to the workpiece surface. ${ }^{15}$ Important results of these studies will now be reviewed in more detail. 
Forces Acting in Cavity:- As part of their early studies on EB welding, Hashimoto and Matsuda ${ }^{5}$ estimated the magnitude of the various forces associated with welding. They concluded that the forces due to the beam impulse of the electrons on the material surface, and the electromagnet :ce effect of the beam current, are small. Only the repulsive force due to evaporation of metal was significant.

Calculations for the various forces acting on the liquid surface in the cavity during welding revealed that some balancing must occur to maintain the cavity. The repulsive force due to metal evaporation acts to both push aside the molten metal, thus preventing it from falling back into the cavity, and to expose a fresh surface of base metal. During steady state welding conditions, this excess metal seems to skirt around both sides of the cavity and is pushed up into a near-by pool at the cavity rear and top. The diameter of the hole seems to be about equal to that of the beam, and it is assumed that it penetrates deeply into the material surface with nearly the same cross sectional area.

The vapor pressure force acts to push the hotter metal from the cavity bottom towards the top since it is believed that the liquid temperature and consequently the vapor pressure at the bottom is much higher. The surface tension trys to constrict the size of the cavity since it is trying to create a liquid surface of minimum energy. Finally, the hydrostatic head of the molten metal liquid maintains a constant tendency for the metal to flow into the cavity. It is concluded that some sort of balance exists between the forces which act to form the cavity, and those which act to fill it. 
Observed Cavity Shape and Oscillations Using Flash X-Ray Technique. Tong and Giedt, ${ }^{6}$ utilizing a radiographic technique, conducted an investigation of the shape of the cavity which forms during electron beam welding. The radiographs revealed that the shape of the cavity was continually changing in an oscillating fashion. The varying shape of the cavity during one period of oscillation was proposed to be analogous to the cavity which developed behind projectiles entering into water at high speeds. 7,8 This analogy served to formulate an analytical model predicting the penetration rates of the cavity as a function of a vapor pressure of the melt and the maximum depth of penetration. Since vapor pressure is a function of surface temperature, a heat transfer analys is was performed to relate surface temperature with cavity penetration rate. The combination of this surface temperature analysis with the analysis of the analog yielded an iterative scheme for predicting the oscillation frequency of the cavity as a function of the depth of penetration and welding parameters. The predicted frequencies were compared with the spiking frequencies abserved from microsections of welds for both high and low voltage welders.

The basic feature of the model proposed in Reference $\delta$ was that the cavity was aiternately filled with liquid metal and then the electron beam bored a deep hole in the material forcing the liquid out of the way, and in some instances, actually drilling into new unmelted material. The alternate filling and emptying in the cavity region can be used to explain how porosity can develop in the weld region. As the molten metal flows into the cavity it can trap bubbles of gases at the base of the weld, and if the cooling rate is sufficiently rapid, fluid may freeze before the gases can be convected to the surface. Also, if 
the cooling rate is sufficiently rapid when the melted material falls into the cavity, the walls of the spike maj already be frozen, so that the fluid upon falling into the spike might not bond thus forming a cold shut or a crack. The periodic penetration and closing of the cavity are also very efficient in mixing the melt and result in a very homogeneous fusion zone.

Early heat transfer solutions represent the deposition of the $E B$ energy as a steady line source. ${ }^{16,17}$ Experimental evidence, however, shows that due to an oscillating flow of the molten material, the EB energy is deposited on a surface which varies from close to horizontal to the sides of a cone-shaped cavity. To account for this a cylindrical constant-temperature boundary condition was also proposed by Tong and Giedt. ${ }^{18}$ A prediction method was formulated for the depth of penetration based on this model. Results were found to agree favorably with available experimental data.

Observed Cavity Oscillations Using Pinhole X-Ray Source. Mara ${ }^{9}$ conducted a study to develop a more accurate description of the events occurring during electron beam welding with special attention being directed to the spiking phenomenon. T'e experimental tool used to evaluate the proposed model of electron beam penetration was a pinhole $x$-ray movie camera which monitored the points of beam impingement. The proposed model and their experimental evidence suggest that the mode of penetration in the engineering materials examined proceeds by an oscillation of the beam within a cavity at frequencies of several hundred cycles per second, and that the beam infrequently maintains an equilibrium state. Results further suggest that during these periods of equilibrium attainment the cavity forces maintain a relatively open and deep 
hole. Then the EB can act directly on the cavity botton and thus produce a spike. Mara believed that the mechanism in electron beam penetration proceeds by a sequence of events in which the cavity is alternately cleared and filled, and the forces acting within the cavity rever attain a well defined state of equilibrium. He believes that the spiking phenomena occurs when the cavity maintaining and cavity closing forces begin to approach the equilibrium state. It is during these pel iods that a pressure bottle exists and the beam is aliowed to work at the base of the cavity with a possible increase in power density due to gas focusing. This action results in the formation of a spike. Weber ${ }^{10}$ using the same experimental approach interpreted the $x$-ray pictures to reveal that the EB electrons collide with the material in regions along the cavity wall. At one time the beam may be striking half way up the cavity or near the surface, and a few milliseconds later it may be striking the cavity bottom. Since the beam is observed to strike material at various locations, this suggests that material has been inserted into the path of the beam. This material must be liquid metal falling into the cavity from the surrounding cavity walls. These events were termed "closures" and were observed to occur repetitively from 50 to 200 cycles/sec.

The $x$-ray pictures are very interesting and allow a reasonable interpretation to be made of the dynamics in the cavity during welding. However, sufficient detail is lacking at the bottom of the weld where the spiking actually occurs. The photographs suggest that the beam spends most of its time in the cavity, and the cavity stays open most of the time. While some weld sections definitely show a spike, the photographs do not. Therefore, one can only speculate as to what is really happening in the bottom of the cavity. 
Cavity Oscillations Observed Using Continuous X-Ray Fluroscopic Technique. Arata et a1. ${ }^{11}$ and Kernish ${ }^{12}$ used a photographic fluoroscopic technique to record a continuous $x$-ray emission from the weld cavity region. By means of this technique combined with metal tracers, a direct observation of the beam hole and the movement of molten metal during electron beam welding can be recorded on movie film. The beami hole generally does not hold a steady shape and oscillated in width and depth.

Arata et al. 11 studied the dynamic mechanism in aluminum al loys during $E B$ welding and observed a strong wall fluctuation to occur frequently and give rise to wall formations resembling caves and knobs (projections). They move upward at the rapid rate of 20-30 centimeters per second. This molten metal flow up and down the wall of the beam hole accounts for the favorable homogeneity of the fusion zone caused by the metal mixing. Their observations provide grounds for maintaining that the spiking can be formed without assuming the existence of such complete closure events as proposed by Tong and Giedt.

They suggest that the formation of spiking is a result of the breakdown of the balance between the vapor pressure and the hydrostatic head of the melt. In addition, the dynamic force of the molten fluid is revealed to have an intimate relation with the occurrence of the wall caves and wall knobs in the beam hole. Spiking was observed to be suppressed when a stable beam hole is produced. This was accomplished by inserting an alloy foil which contains a highly volatile element in the upper portions of the weld joint. The addition of certain elenents into the weld cavity could significantly alter the surface tension force. However, they feel that additional experiments are necessary to clarify 
the mechanism more precisely because of the different phenomenon observed in the specimens of various pure metals and alloys.

Cavity Oscillations Observed Using High Speed Photographic Technique. Ryzhkov and Bashkatov ${ }^{13}$ investigated the mechanism of formation of electron beam welds using high speed photography. Examination of the film at low speed revealed the hydrodynamic nature of the liquid weld surface. They noted that ripples and waves at the surface of the weld form as a result of the molten metal moving in waves beyond the channel in the weld pool. It was also observed that the waves at the surface and at the weld root are the same length and they are sometimes shifted into phase to different degrees. Finally, in the lower portion of the cavity, periodic wave form fluctuations were seen which seemed to be related to a curving of the channel as a result of inertia.

Careful examination of high speed photography of the cavity during EB welds of aluminum alloys did not allow detail to be detected in the depths of the cavity. It was observed that the molten pool surrounded the beam hole and oscillated dynamically. The size of the cavity opening periodically changed diameter. As the diameter ciecreased near the cavity opening a large bubble appeared on the surface. This suggests a cavity pressure buildup. This could be possible if the rate of metal vapor leaving is reduced as the opening gets smaller. The opening never disappears which suggests that the cavity does not collapse and completely fill in during welding.

*Provided by Mr. R. E. Armstrong of the Lawrence Livermore Laboratory, Livermore, California 
Surface Tension Induced Cavity Oscillations. 01 'Shanski $i^{14}$ examined the movement of metal in the cavity during electron beam welding. He explained how thermocapillary forces can develop on the surface of the liquid metal because of nonuniform distribution of temperature in the cavity. These forces can then cause a homogeneous mixing of the material as the weld process takes place. It was shown that the material is transferred in a direction opposite to the beam travel to a distance of from 5 to 8 millimeters. The main transfer of the liquid metal into the solidification zone apparently takes place along the side walls of the cavity.

When there is relative movement of the workpiece the electron beam causes a substantial temperature gradient to develop in the cavity. On the front wall of the ravity which is subject to the action of the electron beam, the temperature on the surface layer may reach the boiling point; but on the rear wall of the cavity it is close to the freezing point. It is argued that the cause of metal transfer must be sought in the disturbance of the thermodynamic equilibrium caused by an apparent asymmetrical heat source in the cavity. The surface tension of a liquid depends on the temperature; the higher the temperature of the liquid, the lower the surface tension. Since the temperature in the cavity varies there is variation of the surface tension from point to point. The postulated temperature gradient causes a thermocapillary tension force to develop on the liquid surface. This force causes flow of the liquid metal in the direction from places with lower surface tension to places with higher surface tension; that is, the liquid metal must move in the direction of decreasing temperature. 
An equation was developed which shows that the thermocapillary tension force component directed along the cavity axis will cause a flow of liquid metal from the front of the cavity slirface to the rear. It is apparent that in real welding processes there are other directions of liquid metal flow caused by the action of the forces of gravity, and as a result of a nonuniform vertical temperature distribution in the cavity which makes the movement of the metal inside the cavity more complex. The phenomenon of metal transfer within the cavity is extremely complex and it largely depends on the welding process variables, the properties of the metals, etc. Therefore, the question of metal transfer in electron beam welding requires further study.

Reaction Force During Welding. Hashimoto and Matsuda ${ }^{5}$ conducted studies on the penetration mechanism of the weld bead in the electron beam welding. The evaporation rate was estimated based on the weight difference before and after a weld pass was made on a small specimen. They also measured the temperature of the molten weld pool by inserting a thermocouple into the molten metal. This temperature and the corresponding saturated pressure of the molten metal were substituted into Langmuir's equilibrium equation ${ }^{19}$ and a value calculated for the evaporation rate. Their results showed reasonable agreement of the evaporation rate determined by both approaches.

During their studies the workpiece was mounted on a balance and the reaction force was measured during welding. A repulsion force was estimated by assuming that the pressure in the hole reaches the saturated value corresponding to the liquid surface temperature and acts on a small area related to the hole diameter. General agreement was obtained between the measured and estimated force values for both steel 
and aluminum. Therefore, they concluded that the forces measured are due mainly from the repulsion force of evaporated metal during welding. Leskov, Turnov, and Zhivada ${ }^{15}$ investigated the special features of electron beam welding in the deep and narrow vapor channels in the weld pool by making measurements with a piezoelectric sensing element attached to the workpiece surface. The basic oscillations in the cavity varied from 10 to $4000 \mathrm{Hertz}$. It was suggested that these oscillations were related to the vapor reactions in the bottom of the cavity during welding. Low oscillation amplitudes were obtained for defocused beams and high amplitudes for focused beams.

They believe that the electron beam acts basically on the front wall of the channel down its entire length. Intensive vaporization takes place at the weld root only. As a jet of vapor moves upward it interacts with the molten metal in the pool causing nonuniform upward movement of the latter with waves and liquid projections forming on the walls of the pool. If a projection forms at the melting front, the interaction between the beam and the metal will increase substantially. This will cause a local increase in the concentration of beam power at the forward wall, the vaporization of a proportion of the metal, formation of a stream of vapor and the reaction of its recoil. The stream will cause local movement in the rear part of the pool, while the reaction will cause the projection to move downwards and along the walls of the pool. Possibly instability of penetration is associated with the formation of projections and their movement towards the weld root caused by the vapor reaction. The formation of cavities in the weld is associated with local disturbances of the pool by the vapor streams. 
An attempt was made to explain these phenomena in terms of ripple of two different types of oscillations. It was argued that the 600 Hertz frequency was due to the power source voltage frequency. The oscillations of the molten pool with a frequency of 30 to 75 Hertz seemed to correspond to the small surface ripples that are observed on the weld bead after welding. The number of ripples is in accordance with indicated frequency of oscillations of the lower frequencies. They concluded that the dominant effect of the formation of metal vapors in the cavity is to develop a vapor reaction along the leading wall at the cavity bottom. Further, they believe that the frequency of the top bead ripples corresponds to the frequency of metal movement caused by these vapor reactions.

INTERPRETATION OF ELECTRON BEAM WELDING PROCESS

In conclusion, it has been suggested by many investigators that a vapor filled cavity is formed in the path of an electron beam during welding. This cavity is filled with molten metal and the molten metal oscillates. There is no general agreement on the type of oscillations in the cavity. Some investigators propose that the metal oscillates up and down. Others propose that there is an alternate filling and emptying of the cavity. Still others propose that the metal moves from the front of the cavity to the rear portion of the cavity by surface tension forces. Most investigators argue that the action is very unpredictable. Therefore, the actual mechanism which determines the size and shape of the cavity during welding is still unknown. This is becalise of the many difficulties with any technique to observe diifectly the dynamic behavior of the metal and the vapor in the cavity during welding. While 
there have been many attempts to observe the behavior in the cavity using both $x$-ray pinhole camera or a fluoroscopic technique in each case the method does not define in detail what is happening at the bottom portion of the cavity. Therefore investigators can only make general conclusions as to what is happening in the cavity.

A detailed physical model of the electron beam interaction with the material surface is lacking. However, the most reasonable current interpretation is that the metal vapor pressure maintains an open cavity surrounded by liquid metal which periodically flows into the cavity due to the liquid hydrostatic head while the higher surface tension of the cooler metal, near the top of the cavity pulls up some of the molten metal. It is generally believed that the interaction of these three forces allow deep penetration. It has been estimated that in order to get any significant cavity penetration, the surface temperature at the base of the cavity must be such that the local vapor pressure must be greater than the sum of the constriction force due to the surface tension and the force due to the hydrostatic head.

For a 0.05 inch diameter electron beam cavity in aluminum the required vapor pressure is about 25 Torr which corresponds to a surface temperature of about $1900^{\circ} \mathrm{C} .20$ During this welding process a highly focused electron beam or a beam with nonuniform energy distribution could produce a slightly higher metal temperature at the base of the cavity. If the cavity dynamics depend on the vapor pressure, then an increase in temperature of only a few hundred degrees could produce a high local vapor pressure that might also lead to momentarily deeper penetration (spiking phenomena). 
Analytical models of the electron beam weld process allow temperatures to be calculated in the vicinity of the weld region. A moving line source approximates the welding process as an infinitely small energy source generating heat along a line representing the location of the electron beam. A moving boundary condition assumes a cylindrical hole to be at a fixed temperature, usually, the melting temperature, and temperatures are calculated at positions away from the weld.

Temperatures can be measured in the vicinity of the weld using thermocouples. One technique is to place several of them near the weld joint and from the response during welding, extrapolate to a value representing the weld centerline temperature. An alternate method is to actually immerse a TC into the liquid metal surrounding the cavity and obtain a temperature response. ${ }^{5}$ However, none of the above analytical or experimental methods allow accurate calculation of temperatures at the surface of the molten metal which would allow one to determine the vapor pressure. Therefore, an experimental progam was initiated to determine the local molten metal temperature in the weld cavity. While obtaining this measurement may be very difficult, it still may be possible to detect perturbations in the cavity by measuring the molten pool temperature in the top area of the cavity surface. Answers to the following questions are of particular importance.

1. Can the measured temperature distribution in the molten pool and cavity during welding be related to the local liquid metal vapor pressure?

2. Do peak cavity temperatures depend on power setting and weld speeds? 
3. Do temperatures measured during welding incicate spiking?

4. Can cavity temperatures explain observed molten metal oscillations?

5. Will the knowledge obtained from this investigation either provide verification of existing analytical models or provide valuable guidelines for developing new models? 


\section{EXPERIMENTAL PROGRAM}

\section{EQUIPMENT}

To obtain an electron beam weld, the electrons must be generated and then focused into a concentrated beam by a device referred to as the EB gun. The work piece and the EB must be located in a vacuum environment. Appropriately designed equipment is available from several manufacturers. The studies described herein were conducted using a low voltage-high current we $7 \mathrm{der}^{\star}$ shown in Figure 1. The voltage-amperage limits were 32 kilovolts and 500 milliamps. The machine also has automatic control features. All materials welded were constructed of solid plates. Consequently, the weld studies do not represent joining of two separate plates. The vacuum pumping system maintained the work chamber at a typical nominal working pressure of about $10^{-5}$ to $10^{-6}$ Torr.

The method for making temperature measurements in the weld cavity was to use a small target infrared detector to sense the radiation given off by the molten weld pool. In order to obtain essentially local temperature measurements the infrared device must sense radiation from a small area, 5 mils to 30 mils in diameter. This was achieved with an optical fiber probe ${ }^{\star *}$ and a focusing lens, which sensed radiation from an area about $20 \mathrm{mils}$ in diameter. The horizontal location on the material surface plane where the detector was focused coutd be controlled

*Manufactured by Sciaky Bros., Inc., Model No. VX, ** Manufactured by Vanzetti Infrared Computer Systems, Inc., Model 1262. 


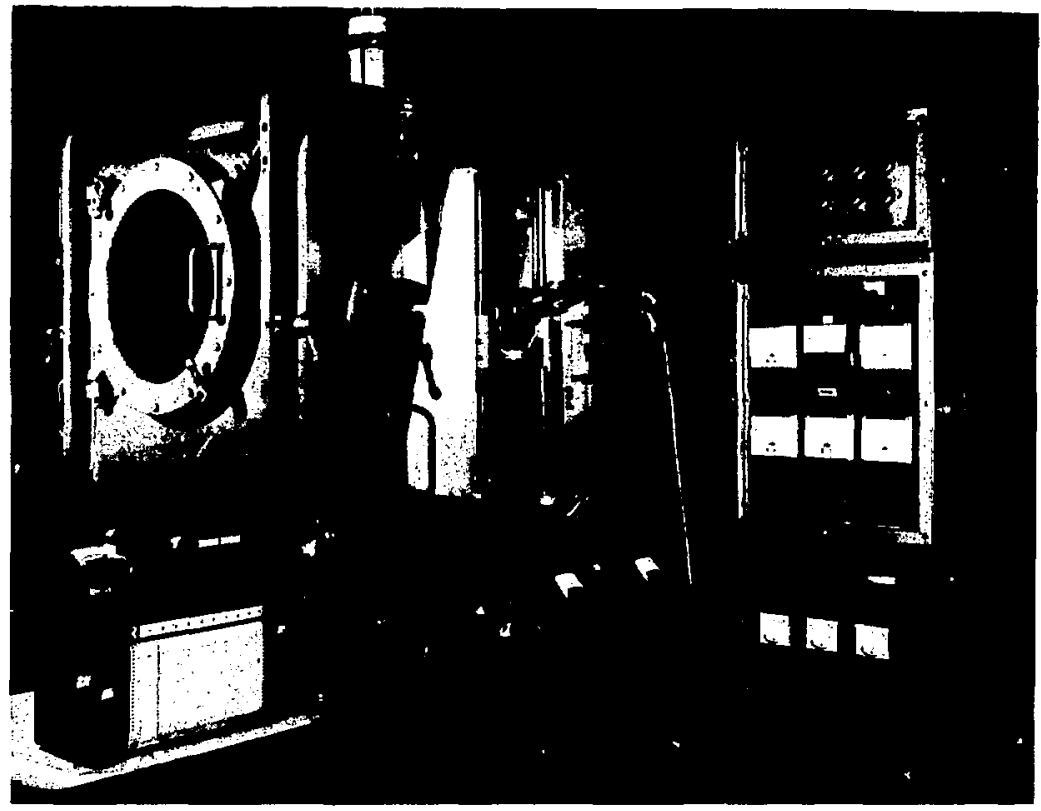

Figure 1. Electron beam welding research facility 
from outside the electron beam chamber during welding. Because of the EB gun geometry as shown in Figure 2, it was not possible to sight the detector directly into the weld cavity. To clear the focusing coil the viewing angle of the probe relative to the work piece surface had to be approximately $45^{\circ}$.

The radiation transmitted through the lens is focused at the end of a fiber optical cable shown in Figure 2. The focal length of this system was 13 inches. The radiation is then transmitted through the cable and through the walls of the electron beam chamber. Outside of the chamber the radiation is transmitted through a silicon filter and to a lead sulfide detector cell where it is converted into an electrical signal. The detector has a radiation wavelength response band of approximately 1 to 2.5 micrometers. The manufacturer recommends treating instrument measurements as monochromatic at an effective wavelength of 1.4 micrometers. Variation of this effective wavelength with temperature is indicated to be negligible.

The signal from the detector is then amplified and displayed as a direct current potential on the electronic digital console. The full scale response tilise is approxmately 50 milliseconds. The D.C. output potential was recorded on a strip chart recorder. The radiant temperature or brightness temperature was then determined from the calibration curve. If the spectral emittance of the specimen is known, the surface temperature can then be calculated. Subsequent to initial tests, adaption of this technique on a different welder resulted in cavity temperature measurements during welding. ${ }^{21}$ This was done because the sighting arrangement on this welder allowed a more direct observation of the cavity bottom. 
WELDING CHAMBER ATMOSPHERE

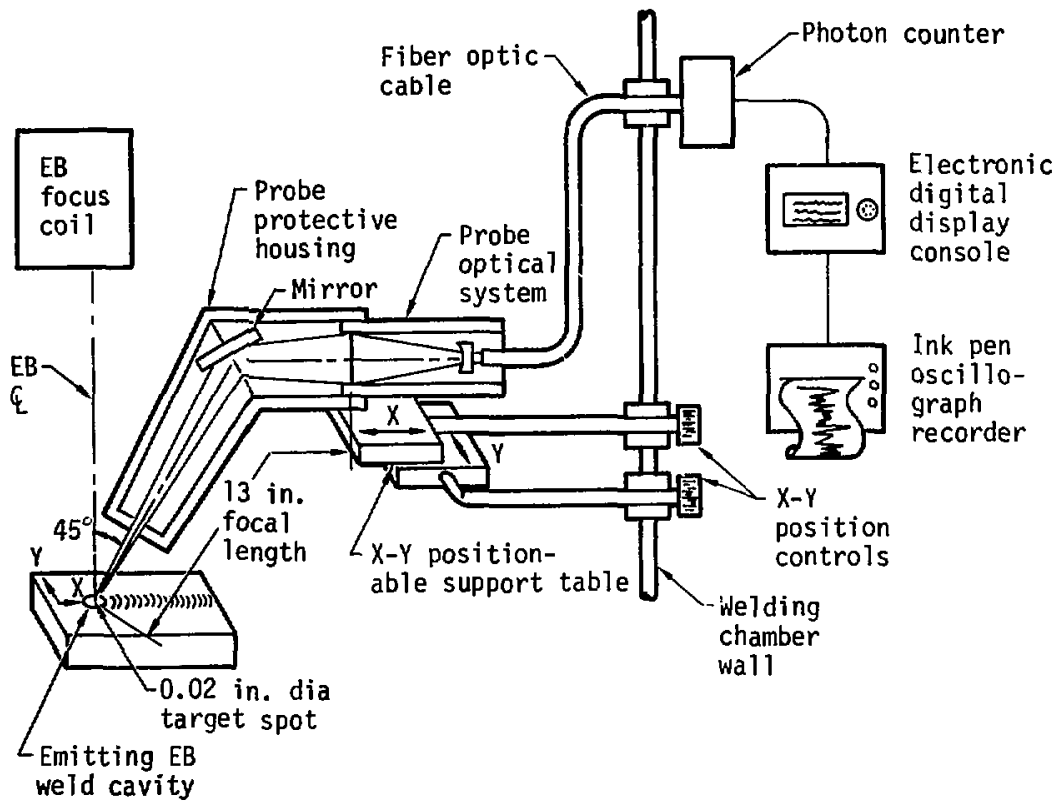

Figure 2. Schematic of temperature measuring system. 
During welding the vapor from the molten pool will deposit on any surface in the immediate surrounding. To prevent vapor from depositing on the focusing lens of the measurement probe a mirror was inserted in the optical path. The vapor then deposits on the mirror and not on the measurement probe lens. Experimental findings revealed that the mirror reflectivity changed appreciably during the first 3 - 6 seconds from the vapor deposits. After this initial change the vapor continually plates onto the mirror over the duration of the experimental measurement but does not change the reflectivity of the mirror appreciably for the next 60 - 100 seconds. Therefore, continuous temperature measurements can be obtained during welding.

An ads'itional concern was the fact that radiation could reflest off of the target area and reach the probe which would tend to increase the measured output above the actual value. To prevent this occurrence, a long cylindrical housing was used to incapsulate the optical path to a position very near the work piece surface (Figure 3 ). This allows very little reflected radiation to actually make its way to the probe. Several geometrical configurations were tried experimentally to see whether reflected radiation was a serious problem. However, no effect on the emittance could be detected. Also, Shintaku ${ }^{21}$ has estimated that the effect of absorption and emission of radiation by the metal vapor in a welding cavity was negligible.

The infrared radiation pyrometer was calibrated with available blackbody cavities. This involved the use of two electrically heated blackbody cavities, one operating up to a temperature of $1000^{\circ} \mathrm{C}$ and the other operating in a temperature range of 1100 to $3000^{\circ} \mathrm{C}$. The resulting cali- 


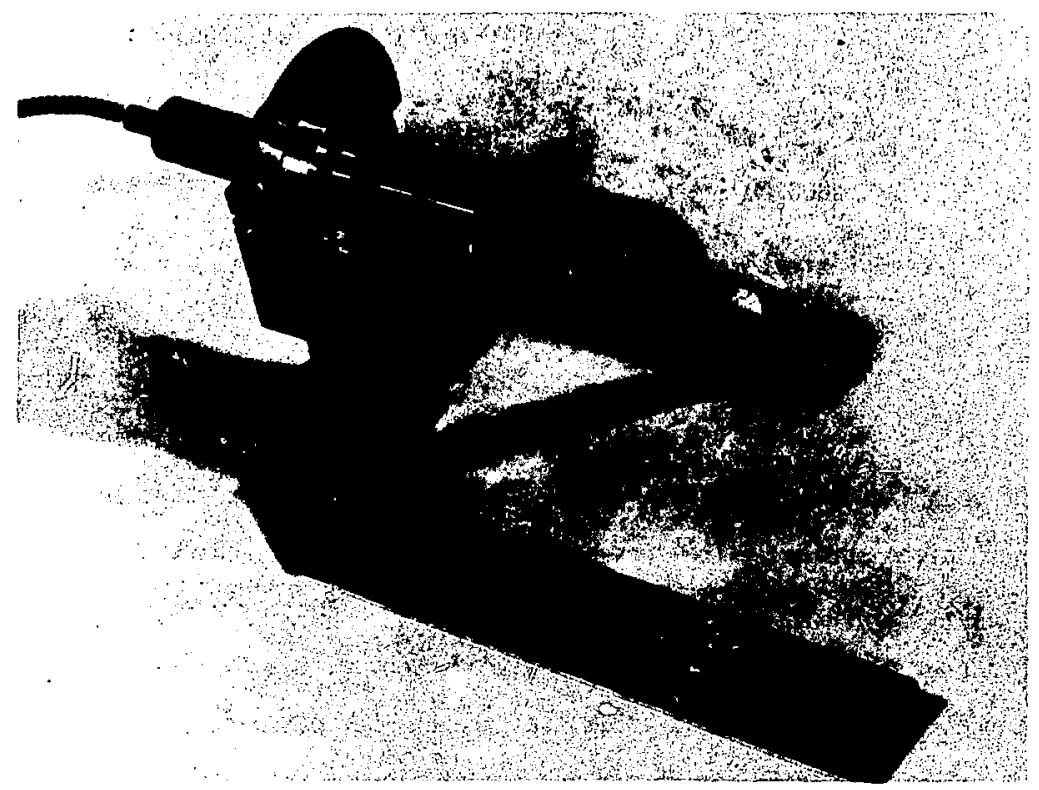

Figure 3. Focused probe optical system inserted into probe protective housing. 
bration curve, shown in Figure 4, was found to deviate from the curve supplied by the manufacturer at temperatures above $1000^{\circ} \mathrm{C}$. The accuracy of the calibration equipment was approximately \pm 1 percent. The radiation pyrometer has a temperature resolution of \pm 2 percent. Therefore, the accuracy of the obtained calibration data is considered to be approximately \pm 3 percent.

\section{EXPERIMENTAL PROCEDURE}

The approximate cavity location prior to welding was estimated using a metal pointer to simulate the $E B$ as shown in Figure 5. A high intensity light source located outside of the vacuum chamber was positioned at the end of the fiber optic bundle. This light was transmitted through the fibers and rest:ited in a brightly ililuminated spot on the viork piece surface. The spot was positioned to correspond with the tip of the pointer by turning the appropriate knobs outside of the chamber (Figure 6). The metal pointer was then removed, the IR detector attached to the fiber optic cable, and the chamber evacuated.

During welding the EB gun remains stationary while the metal test plate is rotated on an axis underneath resulting in a circular weld bead. Temperature measurements were obtained while welding the following materials: aluminum 1100, aluminum alloy, type 6061, type 5083, type 7075, steel alloys, type 20-6-9, type HY-180, stainless steel 304 , and finally pure tantalum. Each of these four aluminum materials were fabricated into $90^{\circ}$ pie sections. The sections were then supported and positioned to form a complete circular plate. The same weld parameters were used for each complete revolution of the plate. All of the other materials were welded separately. These particular alloys 


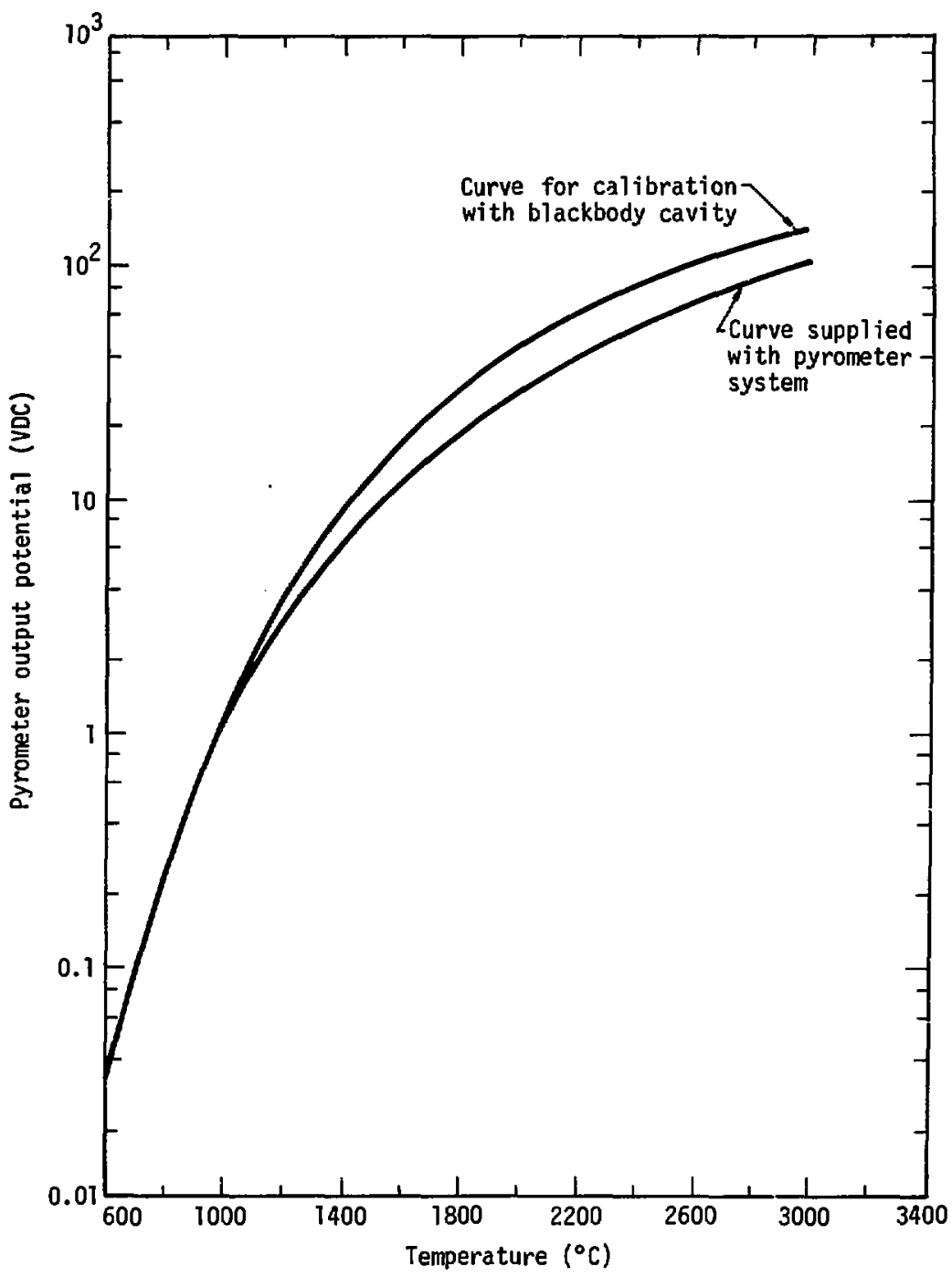

Figure 4. Pyrometer blackbody calibration curve. 


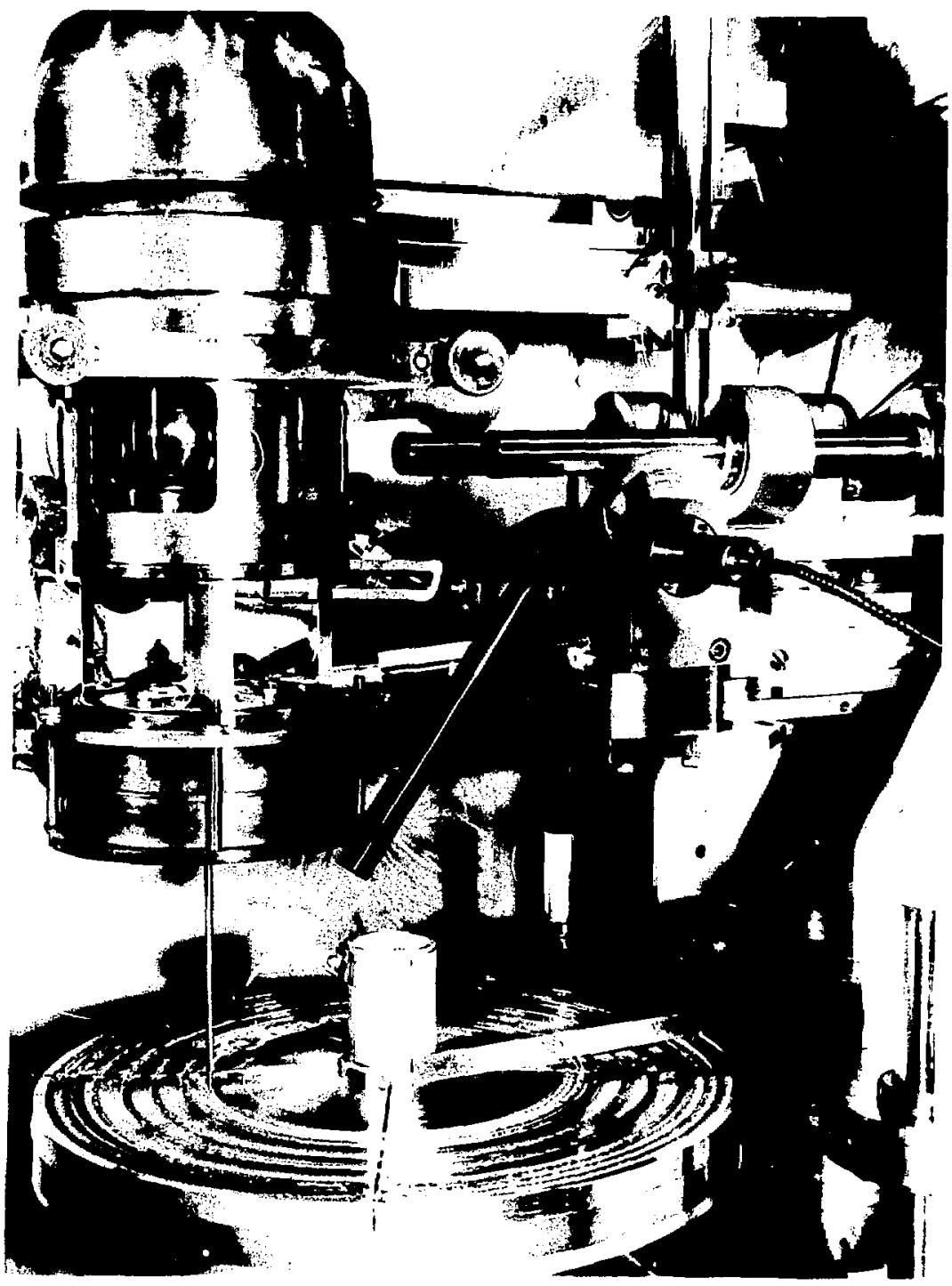

Figure 5. Focused probe optical system and protective housing mounted on $x-y$ positionable support table in welding chamber. 


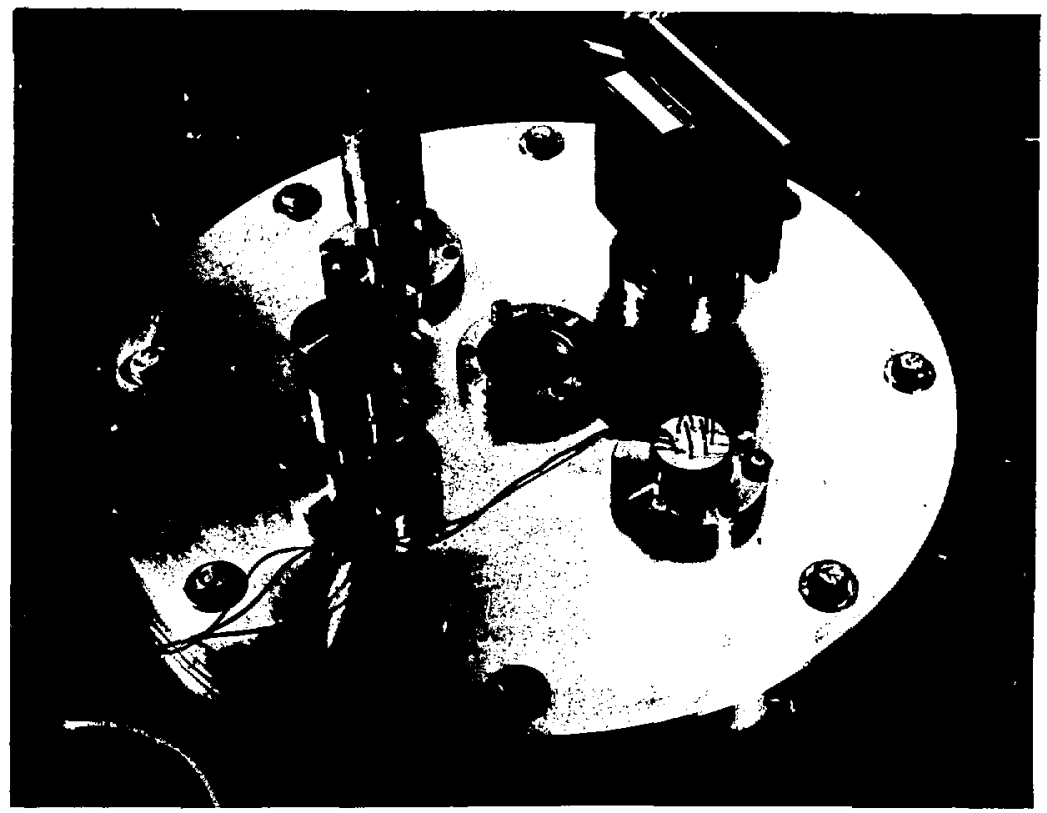

Figure 6. $X-y^{\prime}$ position controls and IR detector located on outside wall of welding chamber. 
were chosen because it was thought that the small amount of volatile materiais present might have some affect on the character of an electron beam welding cavity since the liquid metal vapor pressure is strongly dependent on the temperature.

Welding runs were performed at various weid speeds over the range of 10 to 60 inches per minute, and over power setting ranges of 13 to $20 \mathrm{kV}$ and 100 to $270 \mathrm{milt}$ famps. Temperature proftles perpendicular and parallel to the weld were obtained for several of the materials selected for welding. Sufficient temperature recordings were obtained for one aluminum weld, so that a contour temperature profile of the molten pool surrounding the cavity could be constructed.

Voltage and current parameters selected for many of the test welds resulted in a shallow weld cavity. This allowed the probe to be sighted on or near the cavity bottom even with a $45^{\circ}$ viewing angle. For a typical weld sequence the beam was turned on and the position of the temperature measuring spot was manual1y positioned by controls outside the electron beam chamber. To obtain the cavity temperature at the cavity bottom, the controls were adjusted to obtain peak output on the strip chart recorder. This was assumed to be the cavity temperature at the bottom. Once the maximum reading was obtained, the probe was not moved for the duration of the weld test. This allows continuous recording and observation of the temperature history in the region that represents the cavity bottom. Table 1 lists the materiais welded and the weld parameters used. 
Table 1. Materials and weld parameters

\begin{tabular}{|c|c|c|c|c|c|}
\hline & $\begin{array}{l}\text { Beam } \\
\text { Yolt } \\
\text { (kv) }\end{array}$ & $\begin{array}{l}\text { Beam } \\
\text { Current } \\
\text { (ma) }\end{array}$ & $\begin{array}{c}\text { Focus } \\
\text { Current } \\
\text { (amp) }\end{array}$ & $\begin{array}{c}\text { Weld } \\
\text { Speed } \\
\text { (in./min) }\end{array}$ & Comments \\
\hline $\begin{array}{l}1100 \mathrm{Al} \\
7 / 16 \text { in. Plate }\end{array}$ & $\begin{array}{l}15 \\
15 \\
15 \\
15 \\
17 \\
17 \\
13 \\
13\end{array}$ & $\begin{array}{c}125 \\
135 \\
215 \\
222 \\
150-270 \\
145-245 \\
98 \\
100\end{array}$ & $\begin{array}{l}3.4 \\
3.24 \\
3.24 \\
3.24 \\
3.2-3.5 \\
3.4 \\
3.0 \\
2.9\end{array}$ & $\begin{array}{l}60 \\
30 \\
34.3 \\
60 \\
20 \\
50 \\
30 \\
10\end{array}$ & \\
\hline $\begin{array}{l}\text { Pie Test } \\
1100-5083 \\
6061-7075 \\
\text { A1 } 7 / 16 \text { in. } \\
\text { Plate }\end{array}$ & $\begin{array}{l}15 \\
15 \\
15 \\
17 \\
17 \\
13 \\
13 \\
15\end{array}$ & $\begin{array}{c}130 \\
140 \\
135 \\
160 \\
155 \\
110 \\
115 \\
150-180\end{array}$ & $\begin{array}{l}3.4 \\
3.4 \\
3.2 \\
3.3 \\
3.3 \\
3.07 \\
3.04 \\
3 .-3.3\end{array}$ & $\begin{array}{l}29 \\
30 \\
60 \\
20 \\
50 \\
40 \\
10 \\
20\end{array}$ & $\begin{array}{l}\text { Full spiking thru } \\
\text { plate on } 5083,7075\end{array}$ \\
\hline $\begin{array}{l}H Y-180 \\
1 / 4 \text { in. Plate }\end{array}$ & $\begin{array}{l}15 \\
15 \\
16 \\
18 \\
15\end{array}$ & $\begin{array}{l}155 \\
155 \\
150 \\
174 \\
147\end{array}$ & $\begin{array}{l}3.25 \\
3.2 \\
3.43 \\
3.66 \\
3.32\end{array}$ & $\begin{array}{l}60 \\
60 \\
60 \\
60 \\
50\end{array}$ & \\
\hline $\begin{array}{l}\text { Stainless } \\
\text { Steel } 304 \\
1 / 4 \text { in. Plate }\end{array}$ & $\begin{array}{l}15 \\
16 \\
18 \\
15\end{array}$ & $\begin{array}{l}140 \\
145 \\
168 \\
140\end{array}$ & $\begin{array}{l}3.3 \\
3.3 \\
3.52 \\
3.2\end{array}$ & $\begin{array}{l}60 \\
60 \\
60 \\
50\end{array}$ & \\
\hline $\begin{array}{l}\text { Steel } 20-6-9 \\
1 / 2 \text { in. Plate }\end{array}$ & $\begin{array}{l}16 \\
16 \\
18 \\
19 \\
15\end{array}$ & $\begin{array}{c}152 \\
130 \\
175 \\
185-220 \\
135\end{array}$ & $\begin{array}{l}3.4 \\
3.4 \\
3.6 \\
3.72 \\
3.3\end{array}$ & $\begin{array}{l}31.2 \\
29.9 \\
28.6 \\
27.3 \\
26 .\end{array}$ & Small spiking region \\
\hline $\begin{array}{l}\text { Tantalum } \\
1 / 8 \text { in. Plate }\end{array}$ & $\begin{array}{l}18 \\
20 \\
19 \\
16 \\
18 \\
17 \\
16 \\
16.5 \\
16.5 \\
15 \\
15.5\end{array}$ & $\begin{array}{l}250 \\
245 \\
230 \\
210 \\
220 \\
220 \\
200 \\
230 \\
230 \\
130 \\
190\end{array}$ & $\begin{array}{l}3.7 \\
3.6 \\
3.5 \\
3.7 \\
3.4 \\
3.5 \\
3.45 \\
3.5 \\
3.5 \\
3.3 \\
3.4\end{array}$ & $\begin{array}{l}19.5 \\
18.7 \\
17.8 \\
17 \\
16.1 \\
21.1 \\
20.3 \\
19.4 \\
18.5 \\
17.6 \\
16.7\end{array}$ & $\begin{array}{l}\text { Full spiking } \\
\text { Full spiking } \\
\text { Partial spiking } \\
\text { Full spiking }\end{array}$ \\
\hline
\end{tabular}




\section{LIQUID METAL SPECTRAL EMITTANCE AS A FUNCTION OF PYROMETER TEMPERATURE}

Once the radiant temperature output recorded by the strip chart recorder was combined with the calibration data, the surface temperature of the molten metal in the weld cavity can be calculated if the apparent spectral emittance of the liquid surface is known. Although very little data exists on the spectral emittance of molten metals, some data are available for several liquid metals at the standard wavelength of 0.65 micrometers. $22,23,24$ However, no data was found in the literature for liquid metals at the effective wavelength of the pyrometer equal to 1.4 micrometers. Since the necessary data was lacking, values of spectral emissivity were determined experimentally using the pyrometer in the welding chamber vacuum environment. The material surface was heated at low power to create a pool of liquid metal in the target location of the probe. The electron beam power was then suddenly shut off and the pyrometer output was recorded as the molten pool solidifies. This solidification is indicated by the characteristic cooling curve pleateau obtained on the strip chart recorder output as shown in Figure 7 . This is caused by the latent heat released during solidification. A knowledge of the me?ting temperature then allows the emissivity to be determined at this temperature as described in the following. 


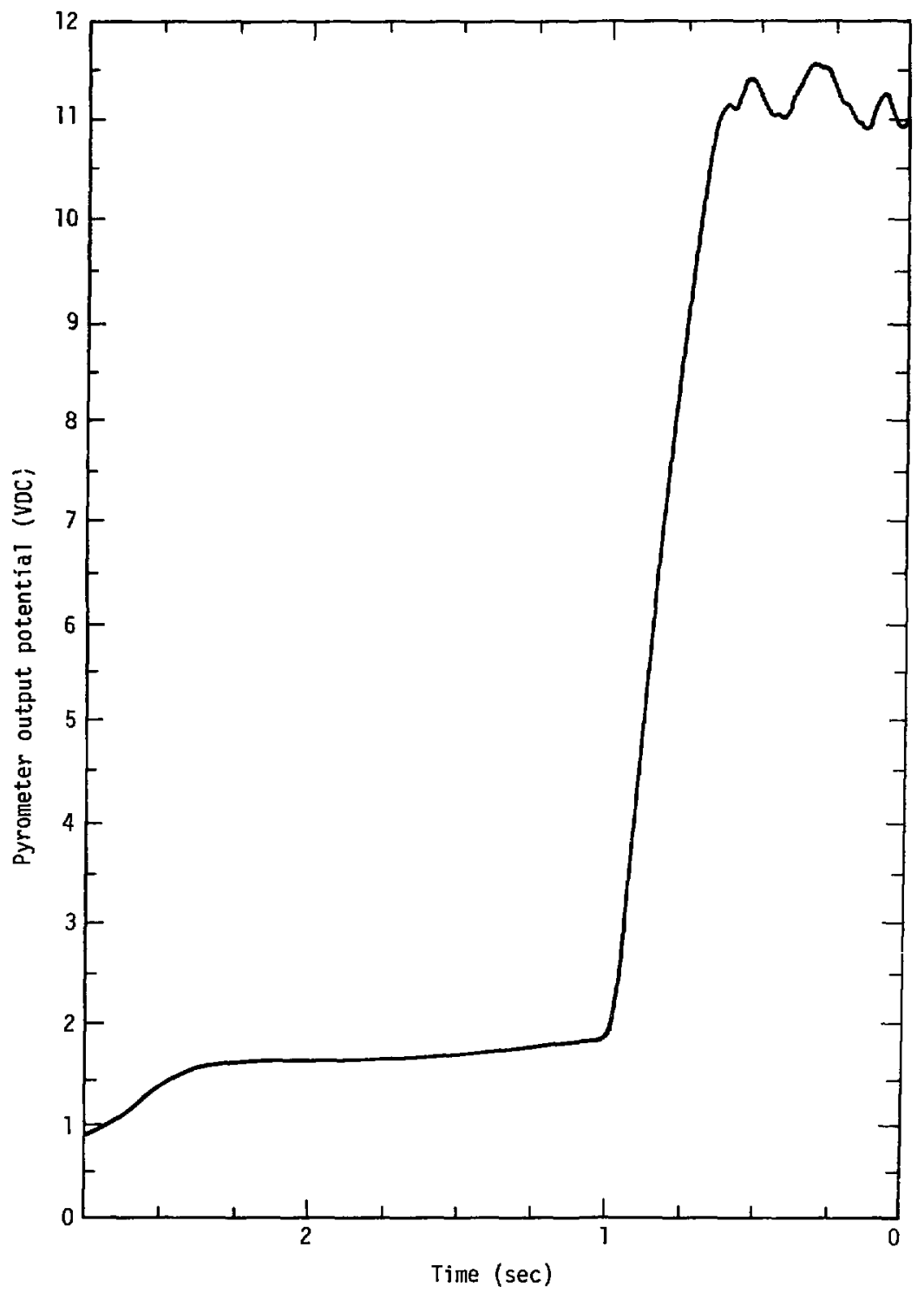

Figure 7. Oscillograph record of a typical stainless steel cooling experiment. 
The spectral emission from the liquid metal surface is a function of the emission angle, $\beta$. The viewing angle of the pyrometer with respect to the liquid metal surface varied from normal to $45^{\circ}$. Over this range, the directional spectral emissivity, $\varepsilon_{\lambda \beta}$, for a metal is approximately a constant. ${ }^{25}$ Therefore, an expression for the spectral intensity in terms of the spectral emittance can be written as,

$$
i_{\lambda}=\frac{e_{\lambda}}{\pi}=\frac{e_{\lambda b}}{\pi}
$$

where $e_{\lambda}, e_{\lambda b}$ are the hemispherical spectral emissive powers per unit area of the radiation emitted from a real surface and a blackbody surface, respectfully, at the same temperatures. Substitution of Planck's radiation law for $e_{\lambda b}$ yields the following expression for the spectral emittance,

$$
\varepsilon_{\lambda}=\frac{e^{c_{2} / \lambda T_{s}}-1}{e^{C_{2} / \lambda T_{r}}-1}
$$

where $C_{2}$ is the second $P 1$ anck constant and is equal to 1.4387 micrometer degree Keivin. Since 1 is small compared to the exponential terms with typical values for $T_{r}$ and $T_{s}$ for electron beam welding, Eq. (2) reduces to

$$
\varepsilon_{\lambda}=\exp \left[\frac{C_{2}}{\lambda}\left(\frac{1}{T_{s}}-\frac{1}{T_{r}}\right)\right]
$$

The spectral emittance can then be estimated by substituting a known melting temperature for $T_{s}$, and the effective wavelength 1.4 micrometers for $\lambda$. 


\section{EXPERIMENTAL DETERMINATION OF SPECTRAL EMITTANCE VALUES}

The method just described was used for determining a spectral emissivity for the steel alloys and tantalum. Unfortunately, the same technique could not be used for aluminum because the melting temperature was so low that the output of the pyrometer was not sufficient to obtain an accurate measurement.

Measurements on aluminum were obtained by using a similar but shorter focal length infrared radiation pyrometer and a tantalum specimen holder with a thermocouple attached to determine the spectral emittance from melting up to $1600^{\circ} \mathrm{C}$. This shorter focal length probe allowed emittance values to be determined experimentally over the temperature range of 600 to $1600^{\circ} \mathrm{C}$. Values of the spectral emissivity were obtained for high purity aluminum and 1100 alloy aluminum. The results for these two aluminum samples were nearly identical.

The above analysis assumes that the reflectivity, $\rho$, from the mirror used in the experimental apparatus was near?y 100 percent. Some materials such as the steel alloys evaporate elements which when plated onto the original mirror surface result in a reflectivity value which can be substantially less than 100 percent. Therefore, the above must be corrected for the reflectivity of the mirror surface. The radiation reaching the probe is given by,

$$
i=\rho_{\lambda} i_{\lambda}
$$

To determine the emissivity of molten metal from the above analysis reflectivity measurements of the mirrors used for taking measurements of each specific alloy must be made. Once the reflectivity is known the actual spectral emissivity $e_{\lambda a}$ can be determined from Eqs. (4) and (1). 
To determine the surface temperatures from the measured responses it is not necessary to actually determine the reflectivity of each mirror used during the temperature measurements. Nevertheless, reflectivity measurements were made for the mirrors used for each particular alloy, so that one could provide other researchers who may need spectral emissivity information in the future with representative values which are certainly lacking in the literature. Table 2 summarizes the emissivity values estimated for the test materials used in this research.

Table 2. Emissivity values of liquid metals measured at melting temperature and at an effective wavelength of 1.4 microns.

\begin{tabular}{lc}
\hline \multicolumn{1}{c}{ Material } & Emissivity \\
\hline Aluminum & 0.20 \\
304 Stainless Steel & 0.36 \\
20-6-9 Steel & 0.42 \\
HY-180 Stee? & 0.26 \\
Tantalum & 0.28 \\
\hline
\end{tabular}

There is theoretical support that the total spectral emissivity increases linearly with temperature. ${ }^{25,26,27}$ observation of experimentally observed total spectral emissivity values of metals over extended temperature ranges tend to verify the theory. ${ }^{24}$ However, the pyrometer used to make temperature measurements has an effective wavelength of $1.4 \mu \mathrm{m}$ over a wavelength response band of approximately ? to $2.5 \mu \mathrm{m}$. As temperature increases, the spectral emissivity decreases for wavelengths below $1 \mu \mathrm{m}$ and increases for wavelengths above $2 \mu \mathrm{m}$. For most metals the spectral emissivity dependence on temperature changes 
between 1 and $2 \mu m .27$ The effective wavelength of the pyrometer used is in this transition region. Since the temperature dependence of the spectral emissivity was unknown over the entire experimentally measured temperature range, a constant value was used.

\section{CAVITY EFFECT ON TEMPERATURE MEASUREMENTS}

Another problem in measuring temperatures of the molten metal in a cavity is that since the cavity is very deep and narrow it has the tendency to act like a blackbody source. This is because a significant portion of the radiation leaving the cavity is reflected from the cavity walls. To assume that all the radiation entering the probe was emitted from the target area having the spectral emittance of molten metal, may result ir an erroneously high calculated surface temperature. Actually the probe indicates that magnitude of the radiation coming from the target area in the cavity which includes both emitted and reflected radiation. This blackbody effect can be accounted for by using the following equation,

$$
T_{s}=\left[\frac{\lambda_{e}}{c_{2}} \ln \varepsilon_{\lambda a}+\frac{1}{T_{r}}\right]^{-l}
$$

where $\varepsilon_{\lambda a}$ is the apparent spectral emittance. Equation (5) states that all the radiation entering the probe should be treated as though it was being emitted from the target area, with the cavity effect being compensated for by the apparent spectral emittance.

A solution for the radiant interchange between the inner surface elements of a conical cavity with a uniform surface temperature by Lin and Sparrow ${ }^{28}$ allows an estimate to be made for the cavity effect. The 
apparent spectral emittance for use in Eq. (5) is approximated to be (see Appendix A),

$$
\varepsilon_{\lambda a}=\varepsilon_{\lambda}+\left(1-\varepsilon_{\lambda}\right) \varepsilon_{\lambda} E_{d A_{j}-A_{s}}
$$

where $\varepsilon_{\lambda}$ is the spectral emittance of the cavity surface and $E_{d A_{i}}-A_{S}$ is the excharige factor. The increase in $\varepsilon_{\lambda a}$ for temperature ineasurements made in shallow cavities can range from $10 \%$ at the top to $40 \%$ at the bottom. Therefore, Eq. (6) and Eq. (5) can be used to account for the cavity effect. However, the accuracy of these values are dependent on factors which are not precisely known. These include possible partial specular diffuse reflection variation in the cavity geometry as a function of time and variation in the surface spectral emittarce.

\section{EXPERIMENTAL MEASUREMENTS}

Electron Beam Welding Cavity Peak Temperatures. If the cavity pressure is indicative of the peak cavity temperature, then a temperature measurement of a pure metal cavity should enable an estimate to be made of the local vapor pressure from known vapor pressure data such as that shown in Figure $8 .^{29}$ Qualitatively, if approxima ely the same order of magnituce of vapor pressure is required to maintain an open weld cavity during welding, then based on the data shown in Figure 8 , a peak cavity temperature measurement of tantalum should ndicate a higher value than for aluminum. Also, aluminum alloys coitaining a highly volatile element such as zinc should result in a cavity temperature lower than that of a pure aluminum cavity. 


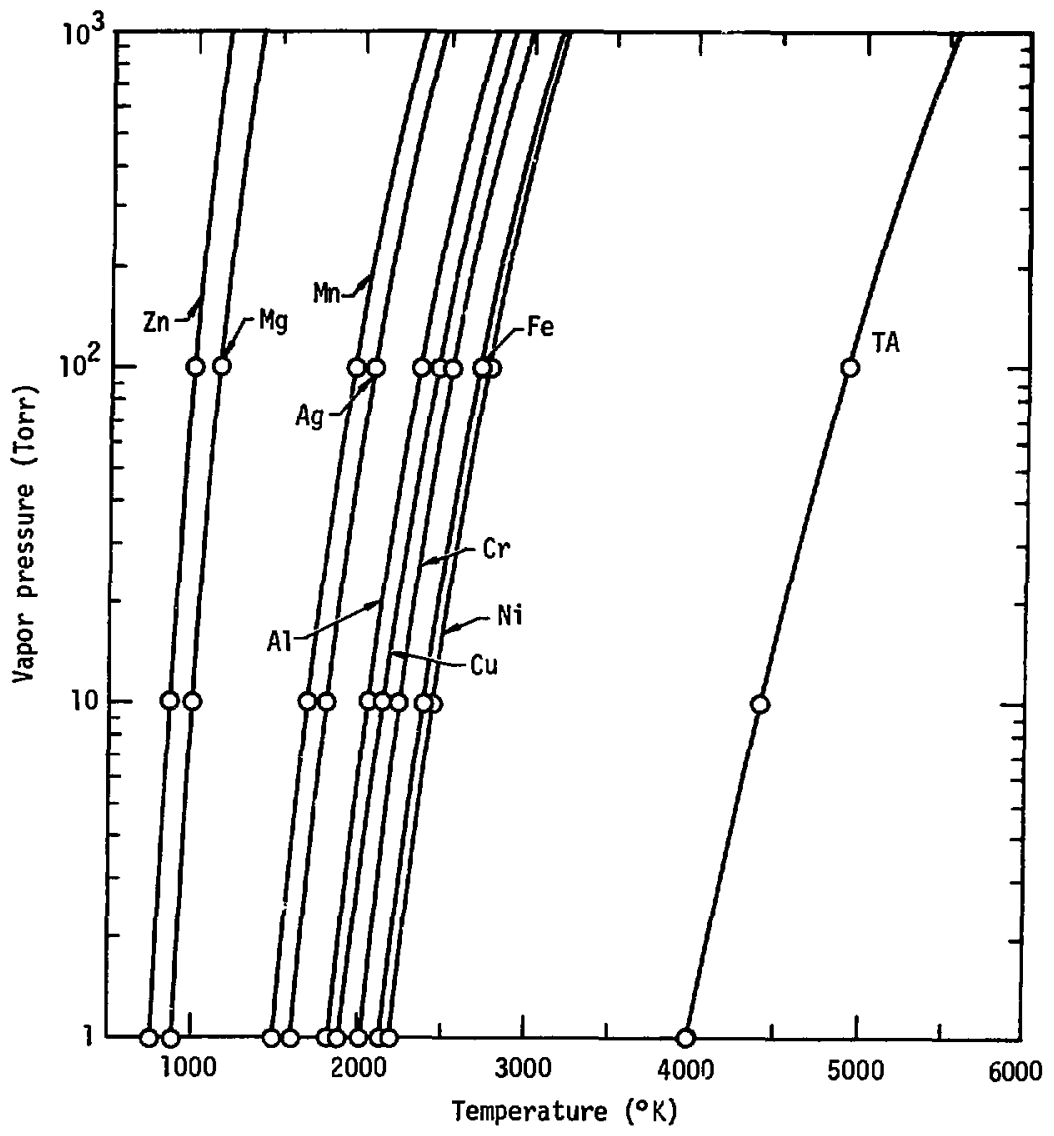

Figure 8. Metal vapor pressure curves 
To demonstrate the effect of volatile elements in an alloy on the measured cavity temperature and to provide direct comparison between several alloys the following test set-up was devised. Four $90^{\circ}$ pieshaped flat plate specimens of aluminum alloys $1100,5083,6061$, and 7075 were fabricated and assembled to form a circular plate as shown in Figure 9. During a test sequence, the machine power setting and elding speed were maintained constant for a weld pass through all four materials. Typical oscillograph records for a specific test weld are shown in Figures 10 and 11 . Peak temperature measurements, using the method previously described, indicace that the cavity temperature is highest for the 1100 aluminum and lowest for the 5083 and 7075 aluminum alloys. The 1100 alloy is $99+\%$ aluminum, while the 7075 alloy contains $5.5 \%$ zinc and $2.5 \%$ magnesium. An additional test weld in 1100 aluminum was performed with a sma 717075 aluminum alloy sample placed in the weld path as shown in Figure 12. A substantial decrease in temperature level, depicted in Figure 11 , occurred when the electron beam passed over the 7075 alloy sample.

The above test sequence illustrates the existence of a relationship between the peak cavity temperature and the vapor pressure in the welding cavity. As shown in Table 3, the peak temperature for the various alloys were $1080^{\circ} \mathrm{C}$ for the 7075 alloy $(5.5 \% \mathrm{Zn}, 2.5 \% \mathrm{Mg})$, $1250^{\circ} \mathrm{C}$ for the 5083 alloy $(5 \% \mathrm{Mg}), 1820^{\circ} \mathrm{C}$ for the 6061 alloy $(1 \% \mathrm{Mg})$, and $1900^{\circ} \mathrm{C}$ for the 3100 alloy $(99+\%$ pure $\mathrm{Al})$. In all cases, as the alloy content of the highly volatile elements $(\mathrm{Zn}, \mathrm{Mg})$ decreased, the measured peak temperature increased. Assuming that about the same 


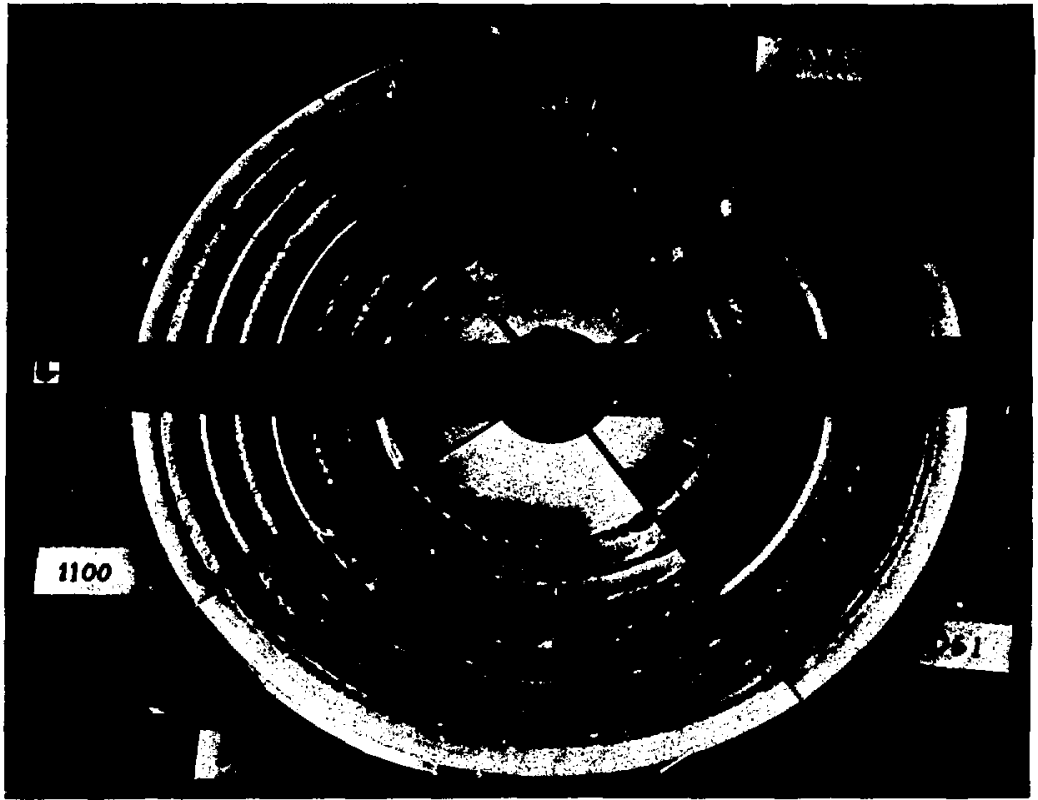

Figure 9. Welded pie test specimen consisting of $7 / 16$ inch thick plate alumi num a1loys $1100,5083,6061$, and 7075. 


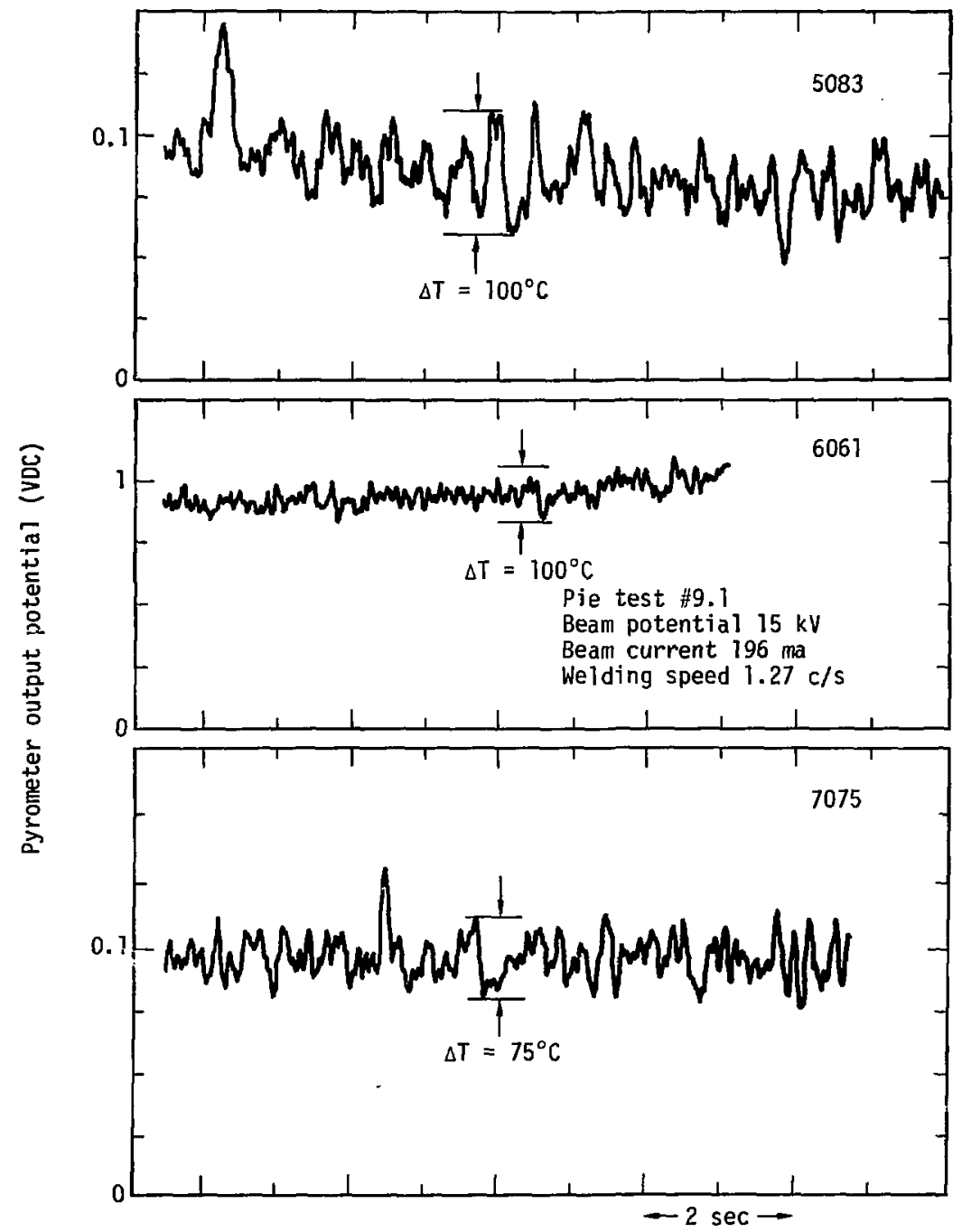

Figure 10. Uscillograph record of typical temperature histories at weld cavity base for aluminum alloys 5083, 6061, and 7075 . 


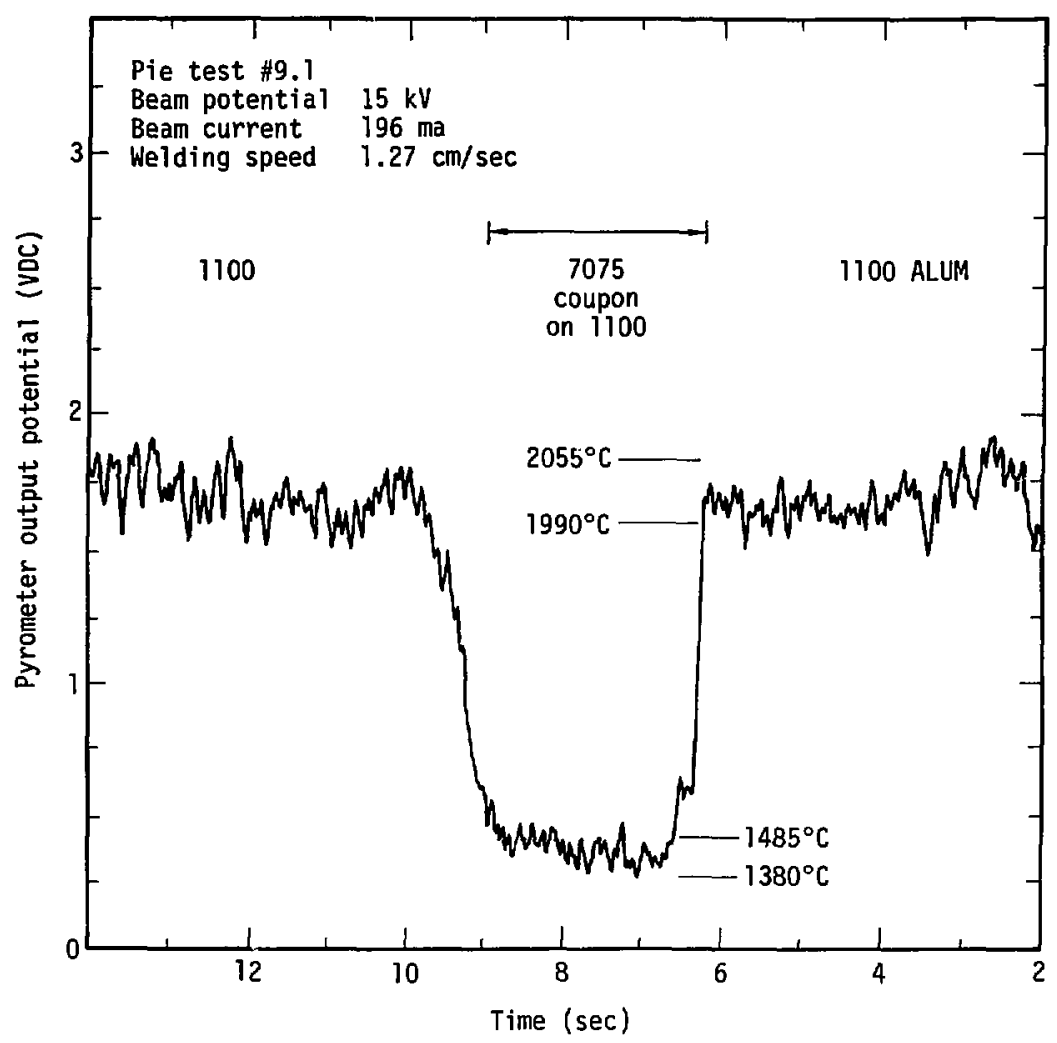

Figure 11. Oscillograph record of a typical temperature history of an aluminum $1100 \mathrm{~EB}$ weld cavity base with a 0.070 inch thick aluminum 7075 sample inserted in weld path on top of aluminum 1100 . 


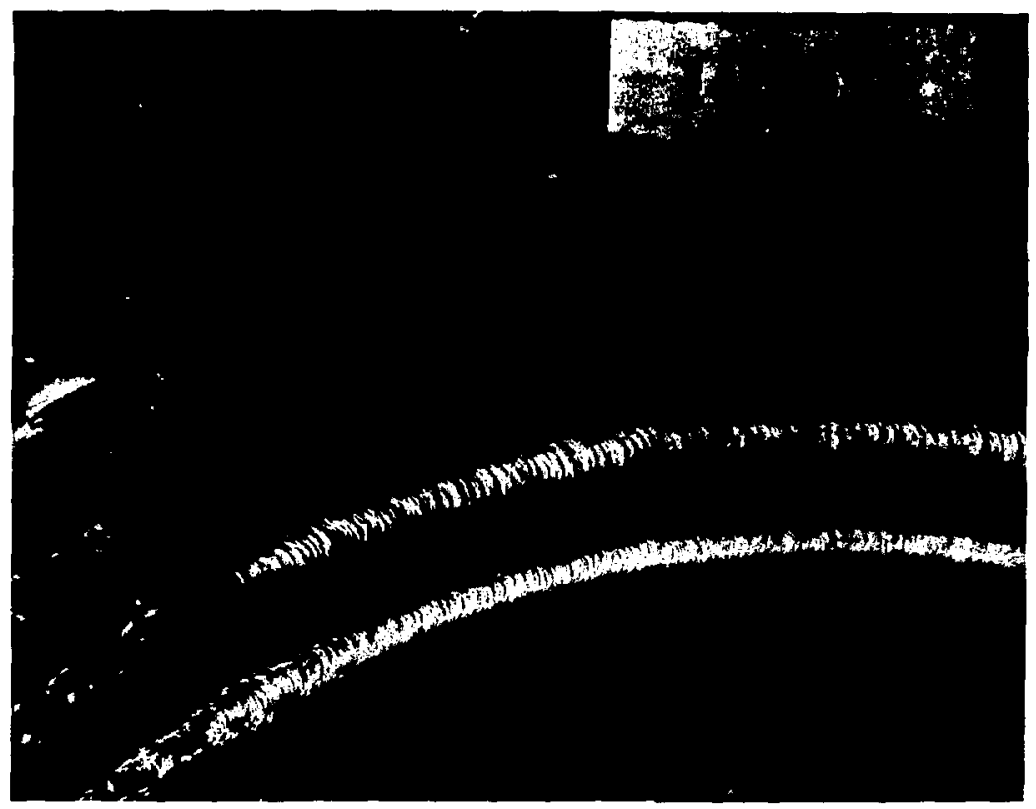

Figure 12. Weld bead over small test coupon of aluminum alloy 7075 (0.070 inch thick) placed on alloy 1100 . 
Table 3. Representative peak temperatures.

\begin{tabular}{lcc}
\hline Material & $\begin{array}{c}\text { Temperature } \\
\left({ }^{\circ} \mathrm{C}\right)\end{array}$ & $\begin{array}{c}\text { Temperature Vari- } \\
\text { ation }\end{array}$ \\
\hline $1100 \mathrm{C}$ $\mathrm{C})$
\end{tabular}

cavity vapor pressure is required to maintain the cavity in each aluminum alloy during welding indicates that the highly volatile elements must provide sufficient vapor pressure at a much lower temperature level. Since the thermal conductivity is lower for the aluminum alloys 7075 and 5083 analytical calculations indicate that the weld temperature in the joint region is generally higher than for pure aluminum (1100 alloy). This may be entirely correct as the molten material solidifies after the passage of the beam. However, the measured peak cavity temperatures are lower for these alloys when compared to pure aluminum. This suggests that the liquid surface temperature in the cavity is controlled more by the vapor pressure effect than by the themal conductivity effect. The fact that the alloy peak cavity temperature is lower combined with the thermal conductivity effect helps to explain why the weld cavity is deeper for a weld in the 6061,5083 , and 7075 alloys versus the 1100 alloy. Essentially the amount of energy to melt all four is the same. In the case of the alloys the EB energy vaporizes 
the volatile elements which exhibit significant vapor pressure and the vapor recoil force pushes the liquid metal aside to expose more fresh base metīl at a much lower temperature. The 1100 alloy having practically no volatile elements must be heated to a much higher temperature before sufficient vapor pressure is generated to push the molten liquid aside to allow deep penetration. Since more energy is required to heat the liquid surface of the 1100 alloy to a temperature that provides sufficient vapor pressure to maintain the cavity, then less energy is available for boring a hole deep into the material. Also, the lower thermal conductivity of the alloy compared to 1100 aluminum reduces the energy loss to the region surrounding the cavity and thus more energy is available for boring deeper into the alloy materials.

Temperature measurements were obtained for many different machine power settings and welding speeds but no observable trend of peak temperature was noted for a specific material. The peak temperatures for a specific material were relatively insensitive to any change in welding parameters. Vapor pressure is a very sensitive function of temperature. It is still possible that deeper welds in a specific material do have slightly higher temperatures. However, the instrument resolution was not sufficient to allow an absolutely accurate temperature to be determined. Table 3 presents a list of the peak temperatures that are representative of the cavity bottom temperature during welding.

Fusion Zone Weld Sections. Because there were a large number of test welds not all were sectioned. Figures 13 through 20 provide a portfolio of typical weld sections taken from various test welds. There 


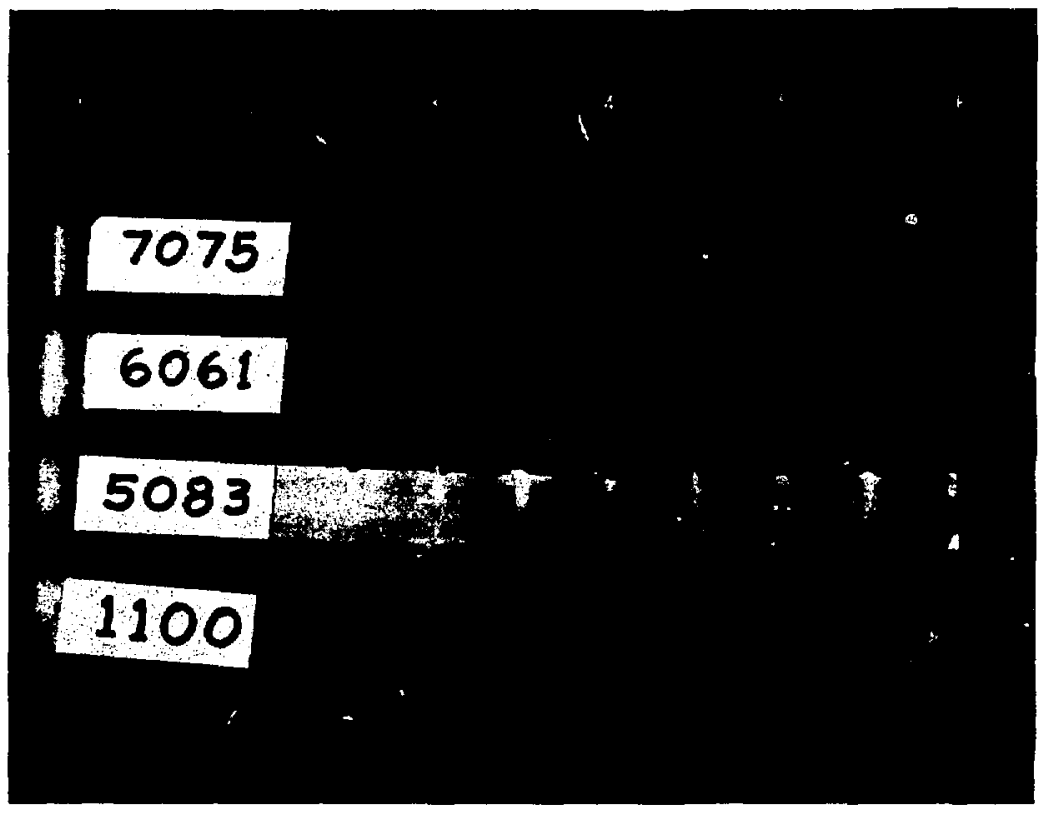

Figure 13. Weld sections taken from aluminum alloy pie test plate. 
$1100 \mathrm{Al}$

$15 \mathrm{kV}$
$130 \mathrm{ma}$
$29 \mathrm{in} . / \mathrm{min}$

Photo

Magnification

6. $6 X$

\section{$1100 \mathrm{~A} 7$}

$17 \mathrm{kV}$

$165 \mathrm{ma}$

20 in./min

Photo

Magnification 6. 6x

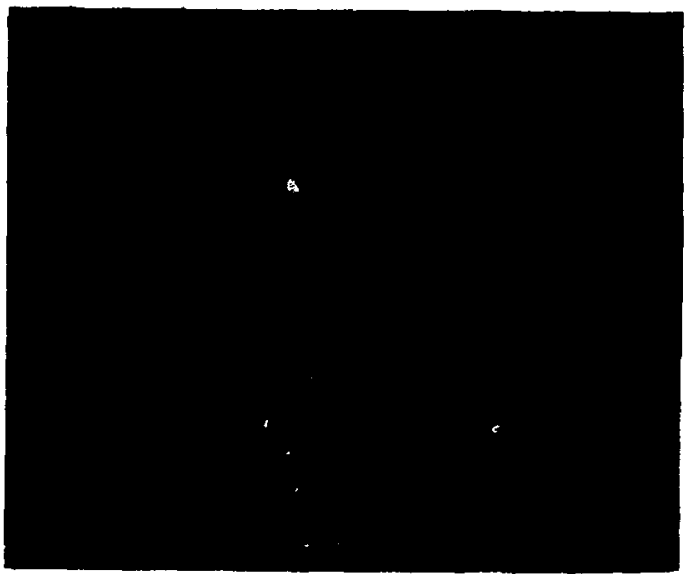

(a)

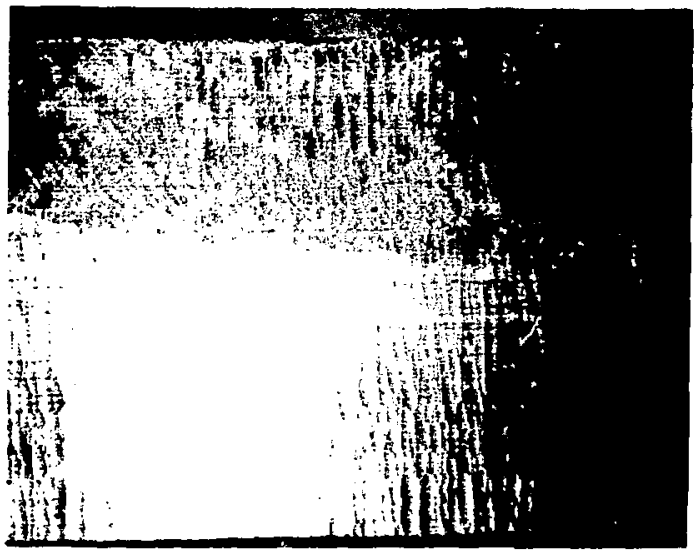

(b)

Figure 14. Aluminum alloy longitudinal weld sections of $7 / 16$ inch thick plate. 
5083 A1

$17 \mathrm{kV}$
$145 \mathrm{ma}$
$50 \mathrm{in.} / \mathrm{min}$

Photo

Magnification

$6.6 \mathrm{X}$

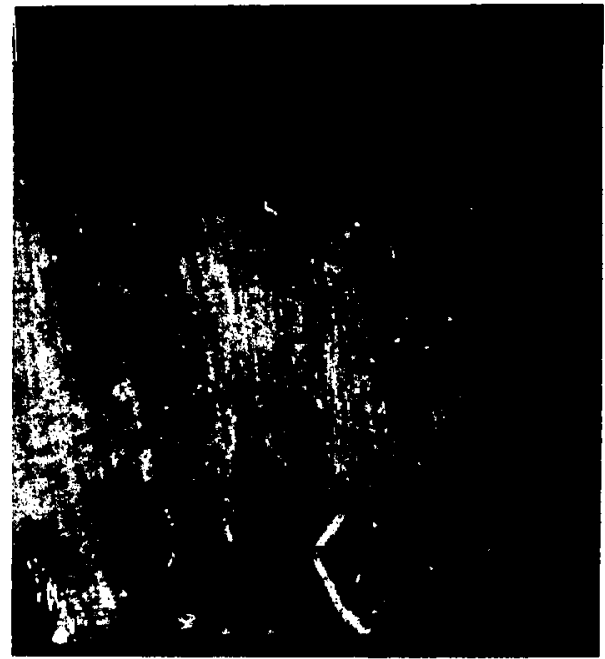

(a)

$5083 \mathrm{Al}$

$13 \mathrm{kV}$

$120 \mathrm{ma}$

$10 \mathrm{in.} / \mathrm{min}$

Photo

Magnification

6. $6 \mathrm{X}$

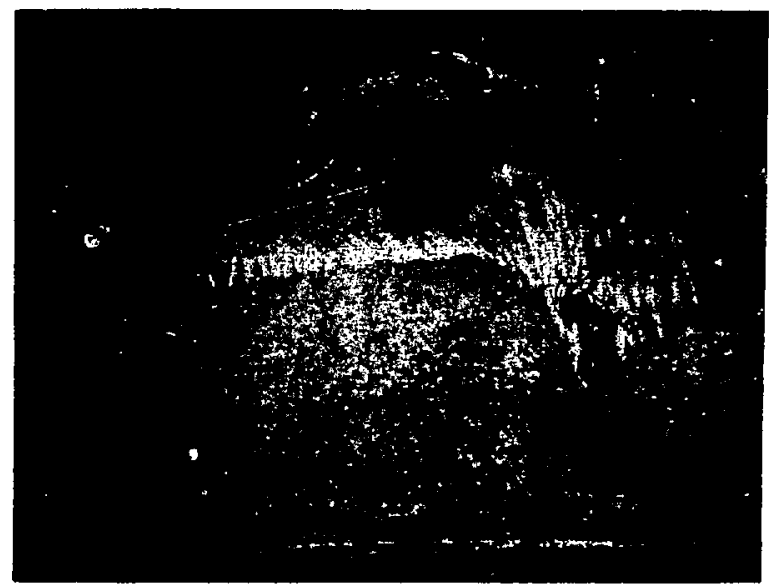

(b)

Figure 15. Aluminum alloy longitudinal weld sections of $7 / 16$ inch thick plate showing spiking (a) and void (b). 


\section{$6061 \mathrm{A1}$}

$15 \mathrm{kV}$

$130 \mathrm{ma}$

$29 \mathrm{in.} / \mathrm{min}$

Photo

Magnification

$6.6 x$

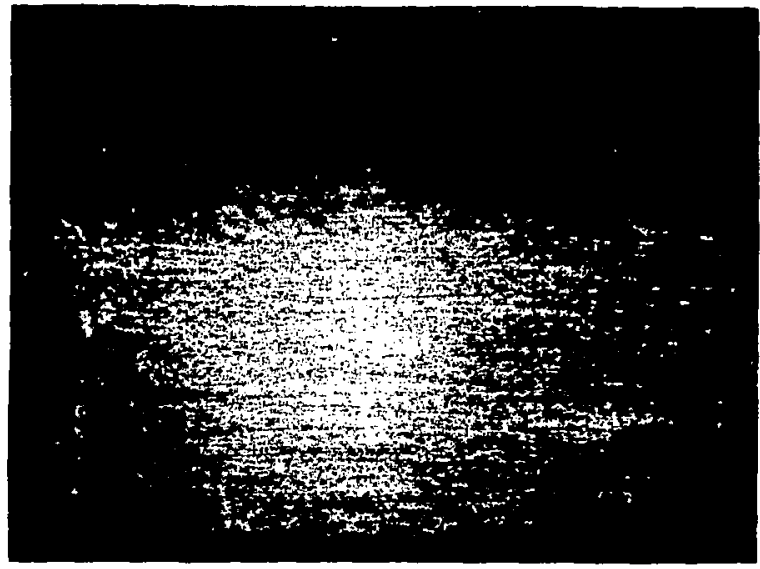

(a)

$5083 \mathrm{Al}$

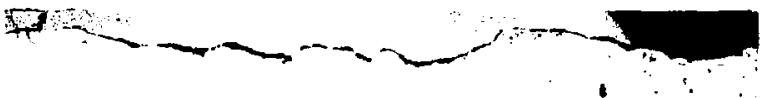

$15 \mathrm{kV}$

$135 \mathrm{ma}$

$60 \mathrm{in.} / \mathrm{min}$

Photo
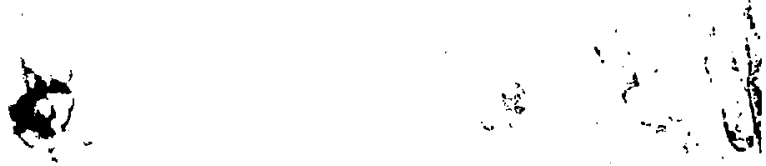

Magnification

$6.6 x$
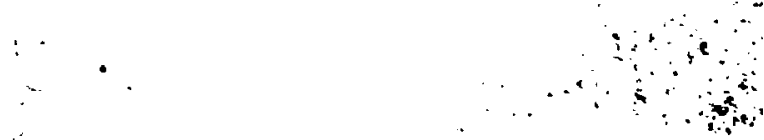

- $\because=$

(b)

Fìgure 16. Aluminum alloy longitudinal weld sections of $7 / 16$ inch thick plate. 
$7075 \mathrm{Al}$

$17 \mathrm{kV}$

155 ma

$50 \mathrm{in.} / \mathrm{min}$

Photo

Magnifiration

$6.6 \mathrm{X}$

7075 A1

$13 \mathrm{kV}$

$120 \mathrm{ma}$

$10 \mathrm{in.} / \mathrm{min}$

Photo

Magnification

6.6X

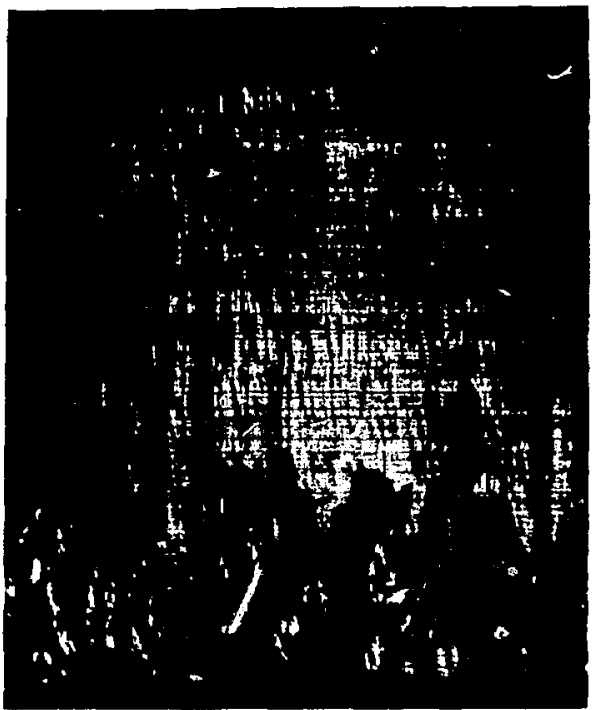

(a)

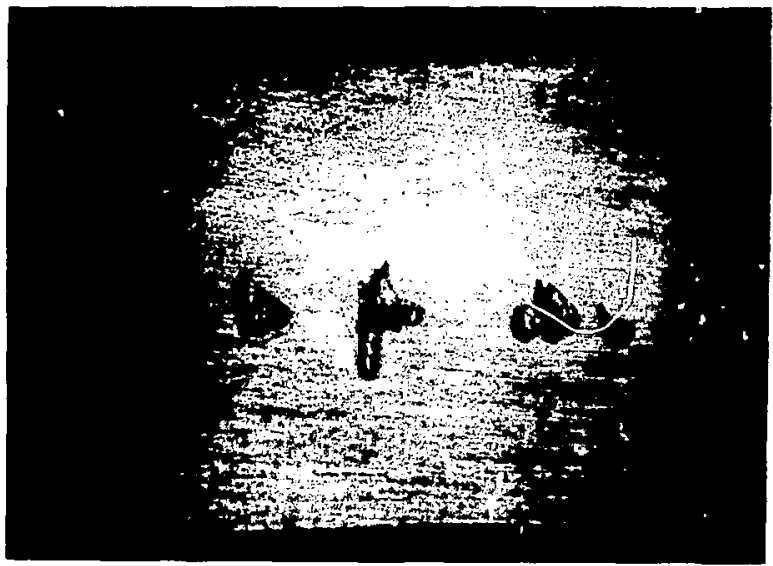

(b)

Figure 17. Aluminum alloy longitudina? weld sections of $7 / 16$ inch thick plate showing spiking (a) and voids (b). 


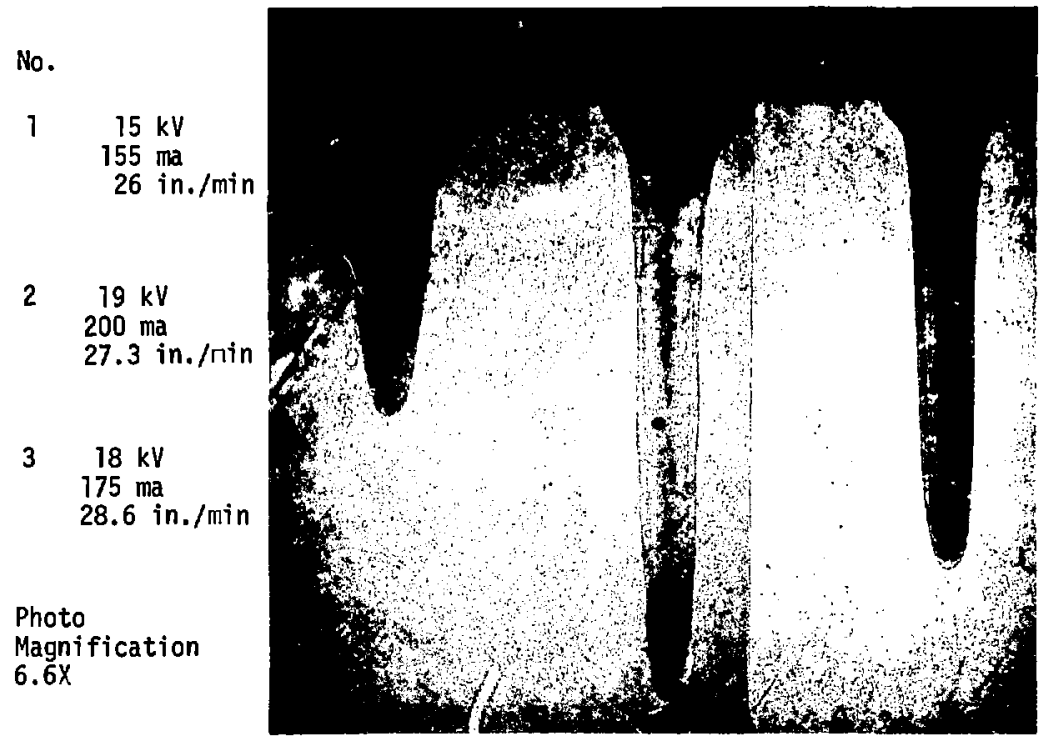

(a)

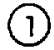

(2)

(3)

$15 \mathrm{kV}$

$155 \mathrm{ma}$

26 in./min

Photo

Magnification

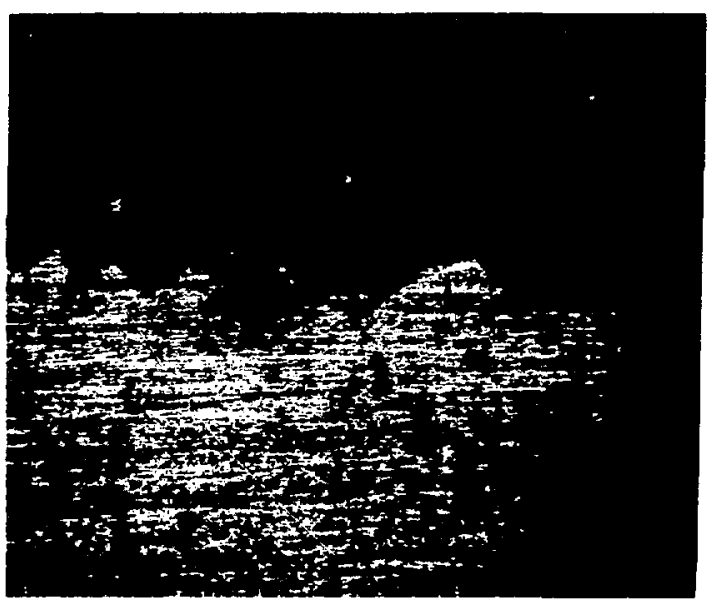

(b)

Figure 18. Steel alloy 20-6-9 transverse weld sections (a) and longitudinal weld section (b) of 0.5 inch thick plate. 
$18 \mathrm{kV}$

174 ina

$60 \mathrm{in.} / \mathrm{min}$

Photo

magnification

$75 x$

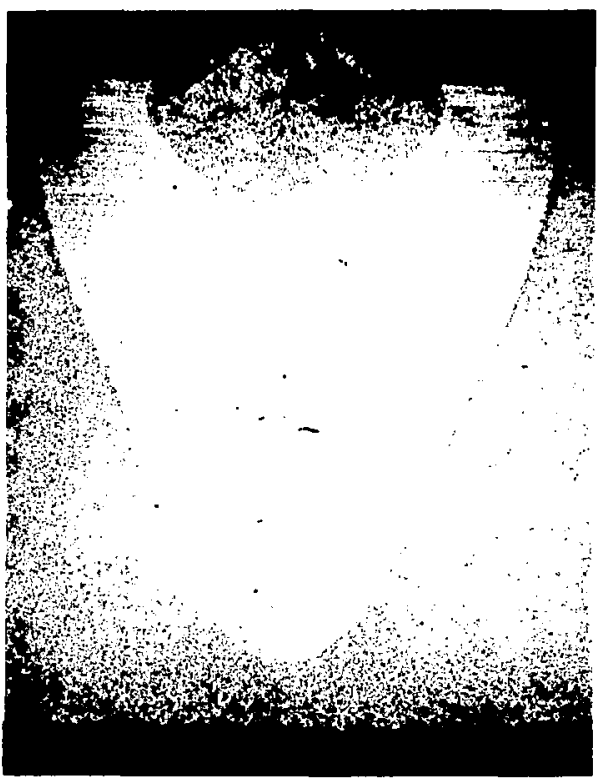

Figure 19. Steel alloy HY-180 transverse weld section of 0.25 inch thick plate. 
$18 \mathrm{kV}$

$168 \mathrm{ma}$

$60 \mathrm{in.} / \mathrm{min}$

Photo

magnification

$15 \mathrm{X}$

$18 \mathrm{kV}$

168 ma

$60 \mathrm{in.} / \mathrm{min}$

Photo

magnification

$6.6 X$

(b)

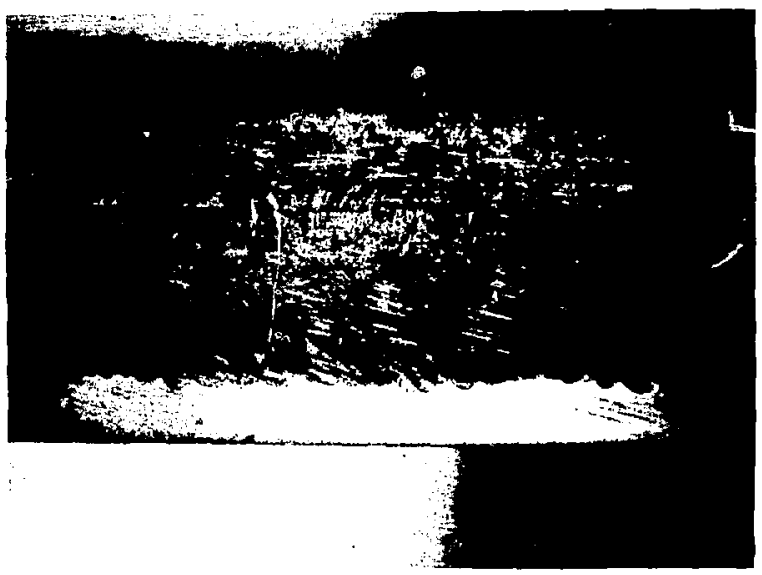

Figure 20. Stainless steel 304 transverse weld section (a) and longitudinal weld section (b) of 0.25 inch thick plate. 
are samples of weld cross sections as well as sections through the weld centerline. Photographic reproduction of weld sections that did not reveal what could be seen with the naked eye were purposely omitted. Detailed analysis along the centerline weld section of several test welds exhibiting spiking did not show any correlation with the measured temperature levels corresponding to the regions containing spiking.

Electron Beam Welding Cavity Temperature Distributions. To obtain the temperature distribution in the weld cavity, the measurement location was changed during a test weld resulting in a record such as is shown in Figure 21. This enables a temperature-position relationship to be determined for that particular weld. Combining the above with the estimated cavity shape based on a test weld section as shown in Figure 22, allows the cavity temperature to be determined as a function of position as shown in Figure 23.

To estimate the bottom cavity temperature for very deep and narrow welds, the following approach was used. During the beginning of the weld the depth of penetration is minimal. It was observed that the peak reading obtained during this initial period was essentially identical to that measured at the bottom of a shallow cavity. Then as the weld depth increased further, the measured response remained near this peak level for a short time and was followed by a decrease. This decrease corresponded to the weld bead position at which the detector was no longer able to sight on the cavity bottom. Therefore, the maximum temperature measured during the initial portion of the weld was selected to be the bottom cavity temperature at a later time when the cavity was very anp and narrow. 


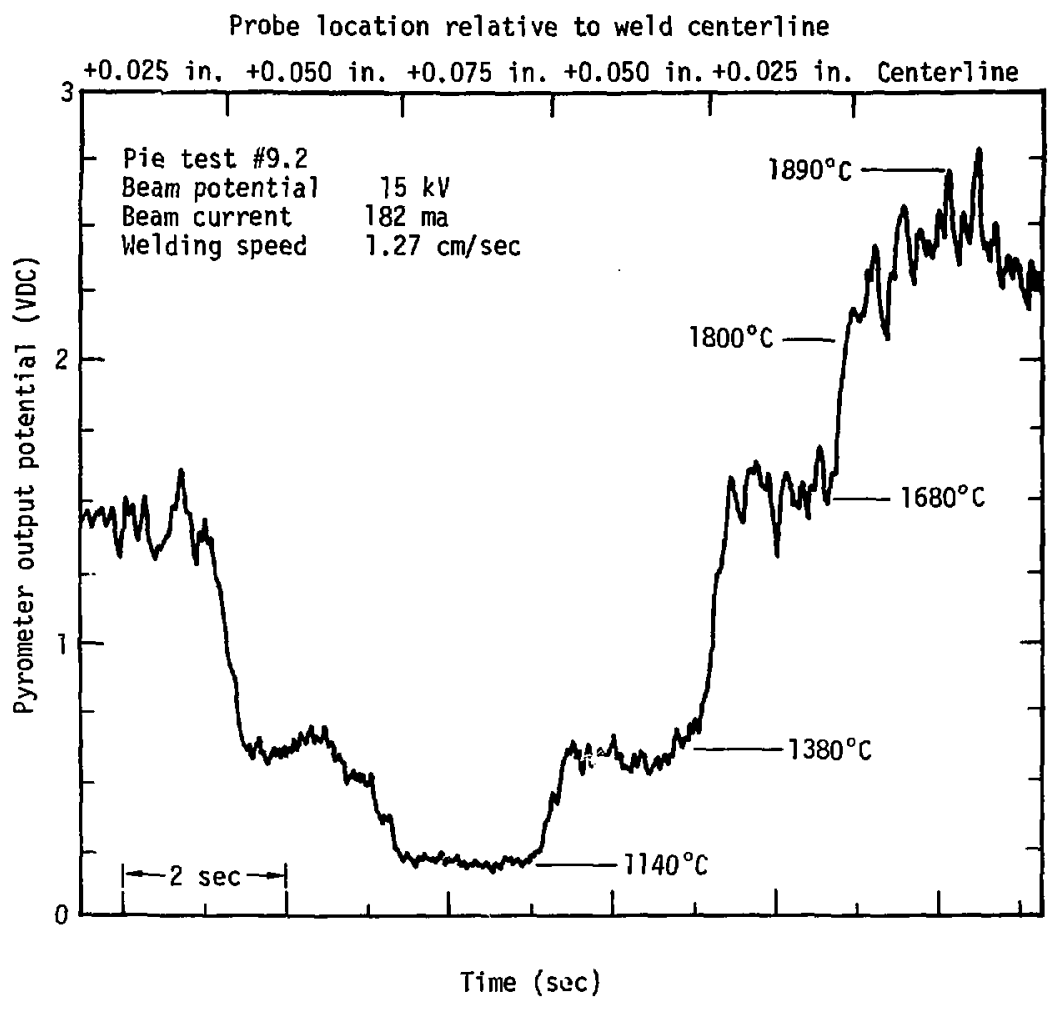

Figure 21. 0scillograph record of a typical temperature history of an aluminum $6600 \mathrm{~EB}$ weld cavity as the pyrometer measurement location was varied perpendicular to the weld direction. 

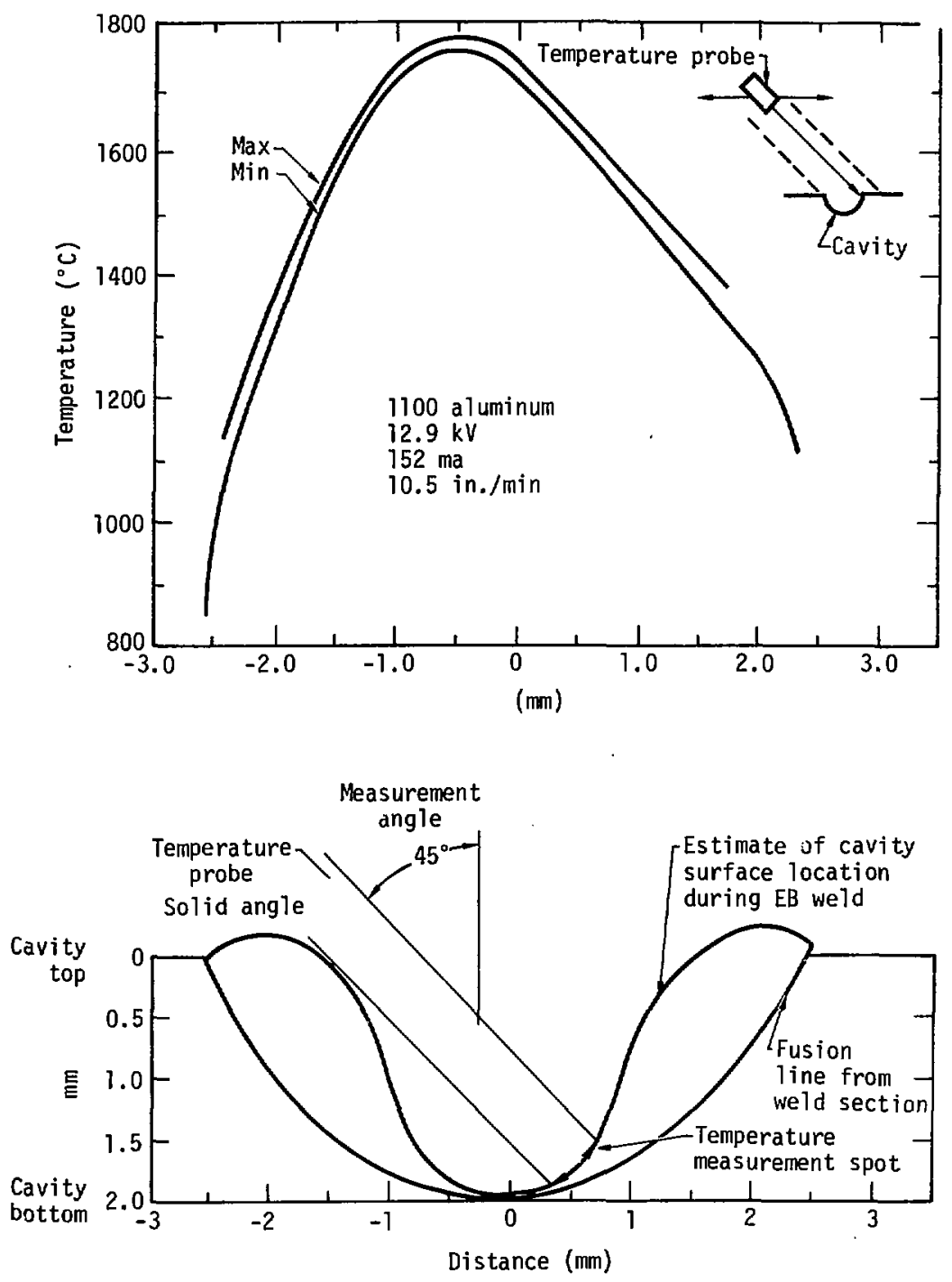

Figure 22. Measured temperatures across 1100 Aì weld cavity during one pass EB weld and approximated cavity shape based on weld section. Also shown is the geometrical relationship between the temperature probe and the liquid material surface. 


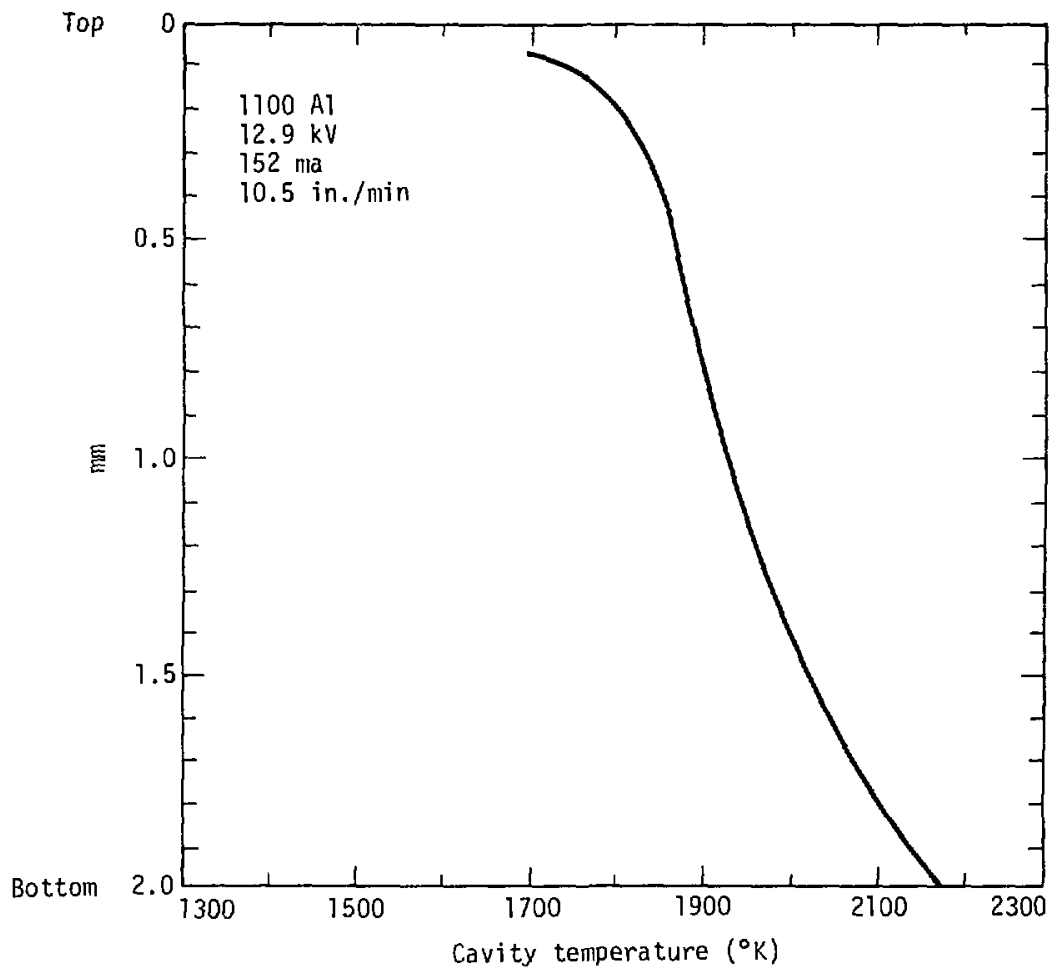

Figure 23. A typical measured cavity temperature distribution for 1100 aluminum. 
Representative cavity temperature distributions of the materials welded and the corresponding weld cavity shape are shown in the following figures. The temperature distribution in an aluminum alloy 7075 weld cavity (7 mm penetration depth) is shown in Figure 24. At the cavity bottom, the temperature remains at a level close to the peak temperature. This same characteristic can be observed in Figure 25 for a deeper weld cavity $(11 \mathrm{~mm})$ in 20-6-9 steel. Hote the rapid decrease in temperature for a shallow weld $(3.5 \mathrm{~mm})$ in 304 stainless steel, Figure 26. In contrast to the above temperature distributions, the temperature profile shown in Figure 27 for a tantalum weld $(2 \mathrm{~mm}$ penetration depth) displayed a nearly linear dependence on cavity location.

Material Composition Change of Alloy in Weld Region. A weld test series on the aluminum alloys $1100,5083,6061$, and 7075 , in which repetitive weld passes were made over the same weld bead region produced the results shown in Figure 28 . The increase in measured peak temperature with an increase in number of weld passes is directly related to the refining of the highly volatile elements. Due to rapid evaporation of the volatile elements, its concentration in the weld bead region is reduced with each weld pass. This reduced concentration requires that the liquid surface be heated to a slightly higher temperature to provide sufficient vapor pressure to maintain a weld cavity. A microanalysis of each weld section after 6 weld passes did indicate a decrease in the amount of the most volatile element as shown in Table 4. A chemical composition analysis of a deep penetration weld (115 mm) in a steel alloy produced similar results. ${ }^{30}$ Table 5 shows that only the concentration of the most volatile element, manganese, was reduced for a single pass EB weld. This test series on the aluminum alloys suggests 


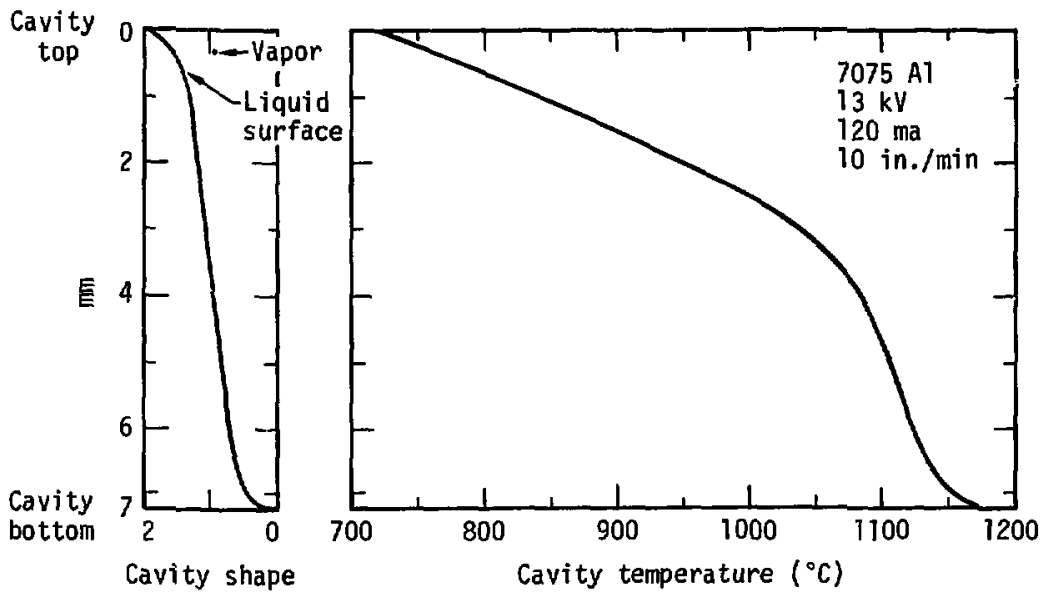

Figure 24. Approximated cavity shape during welding and typical measured cavity temperature profile for 7075 aluminum. 


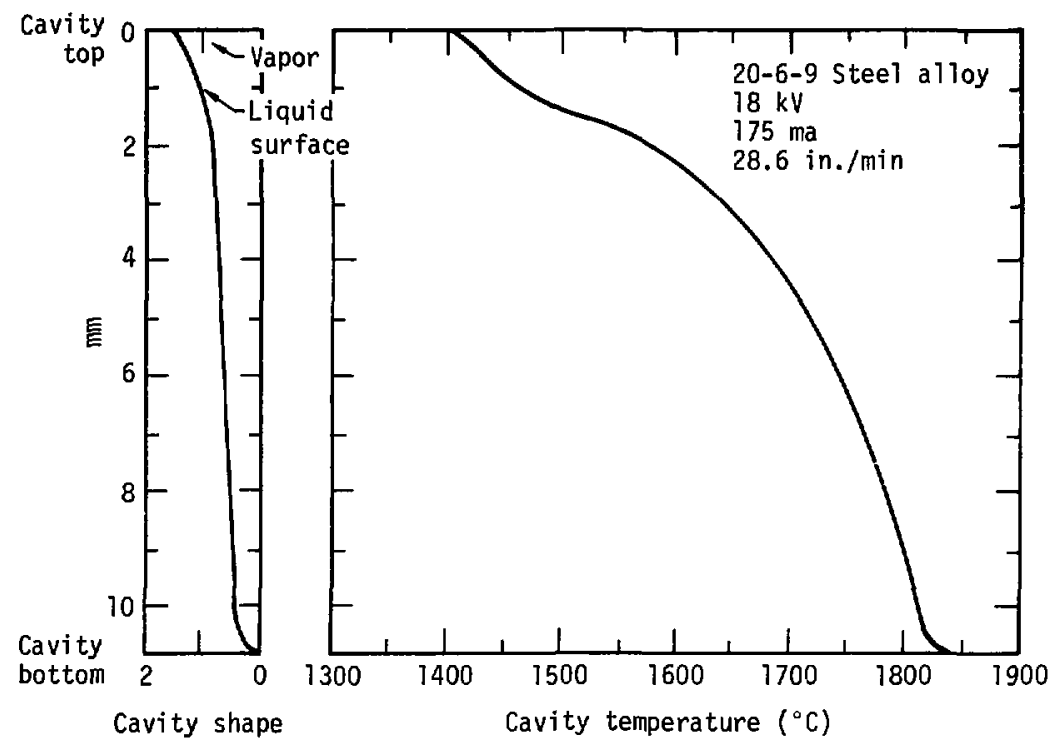

Figure 25. Approximated cavity shape during welding and typical measured cavity profile for 20-6-9 steel alloy. 


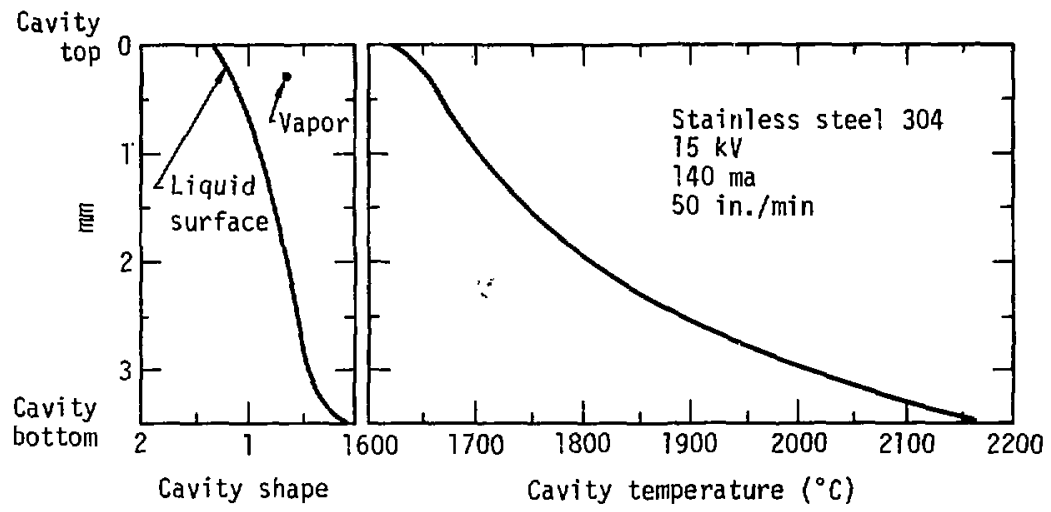

Figure 26. Approximated cavity shape during welding and typical measured cavity temperature profile for stainless steel 304 . 


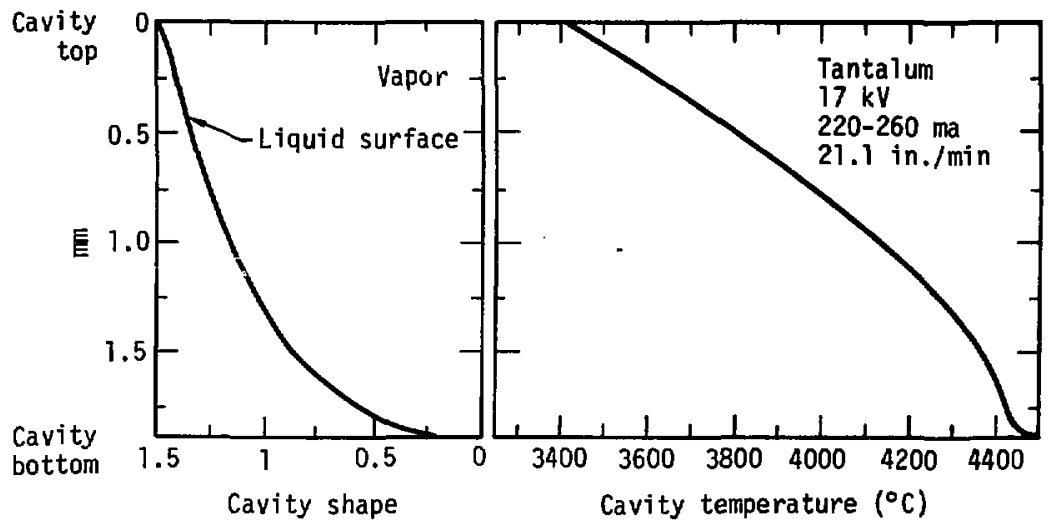

Figure 27. Approxinated cavity shape during welding and typical measured cavity temperature proftie for tantalum. 


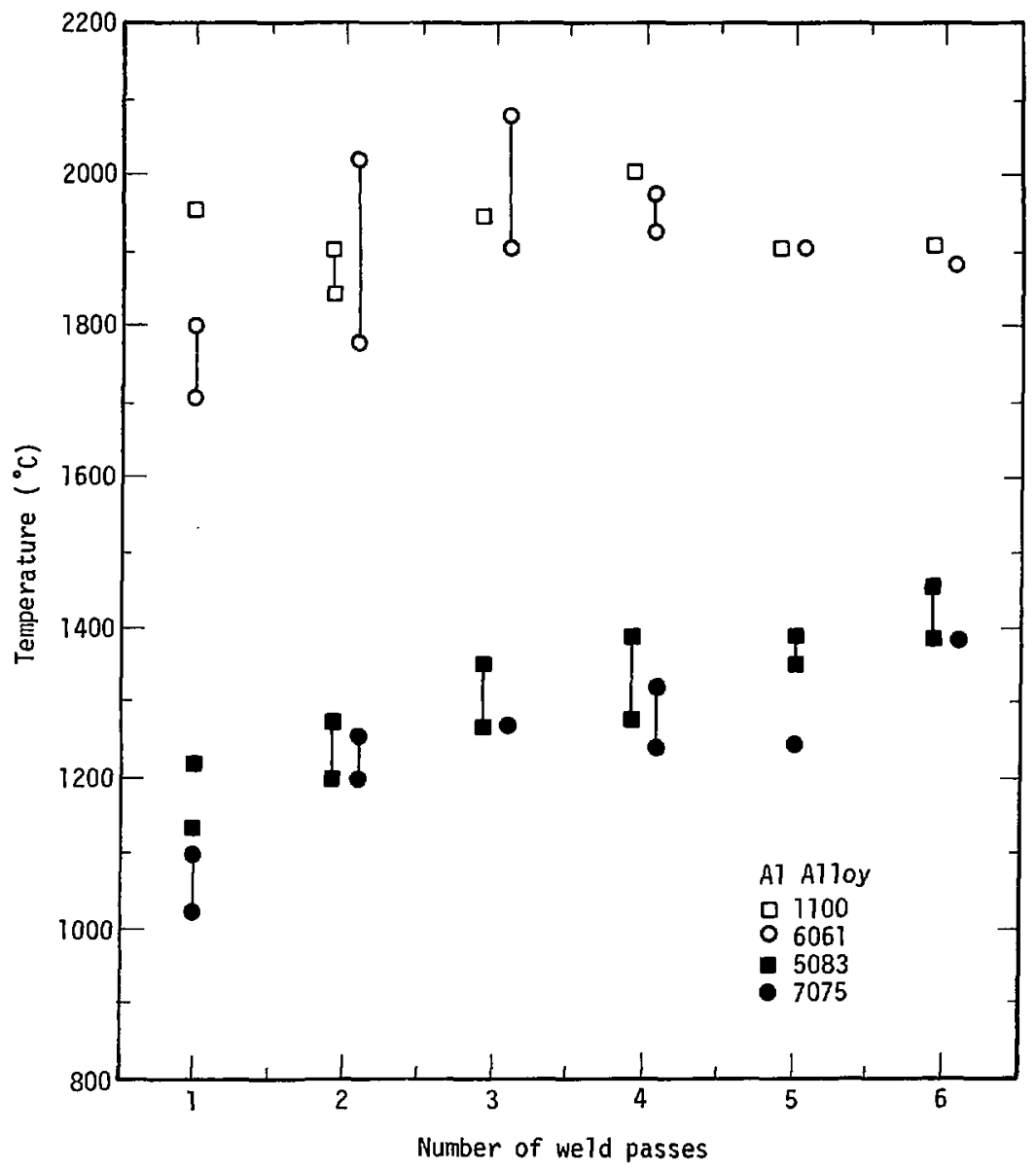

Figure 28. Variation of peak measured temperatures with number of weld passes. 
that a very small reduction in concentration of the volatile elements result in a significant and easily detectable change in the peak cavity temperature.

Table 4. Microanalysis* of aluminum alloys by wt\% after six weld passes.

\begin{tabular}{|c|c|c|c|c|c|c|c|c|c|}
\hline \multicolumn{4}{|c|}{ Alloy and Location } & $\mathrm{Zn}$ & & in & $\mathrm{Mg}$ & & $\mathrm{Cu}$ \\
\hline \multirow[t]{2}{*}{5083} & \multicolumn{3}{|c|}{ Parent Metal } & - & & 0.83 & 3.74 & & -- \\
\hline & \multicolumn{3}{|c|}{ Weld Region } & -- & & 0.63 & 3.47 & & -- \\
\hline \multirow[t]{2}{*}{6061} & \multicolumn{3}{|c|}{ Parent Metal } & 0.12 & & -- & 0.78 & & -- \\
\hline & \multicolumn{3}{|c|}{ Weld Region } & 0.02 & & -- & 0.65 & & - \\
\hline \multirow[t]{2}{*}{7075} & \multicolumn{3}{|c|}{ Parent Metal } & 6.1 & & -- & 2.1 & & 1.3 \\
\hline & \multicolumn{3}{|c|}{ Weld Region } & 4.9 & & - & 2.0 & & 1.3 \\
\hline \multicolumn{10}{|c|}{${ }^{*} 2$ to $4 \%$ relative error. } \\
\hline \multirow[t]{2}{*}{ Table } & \multicolumn{3}{|c|}{$\begin{array}{l}\text { Chemical compositio } \\
\text { EB weld. } 30\end{array}$} & by wt\% & f a s & steel a & oy for & ing & le pass \\
\hline & & C & S & $P$ & $S \mathbf{i}$ & MN & $\mathrm{Cr}$ & $\mathrm{Ni}$ & Mo \\
\hline Paren & letal & 0.16 & 0.034 & 0.010 & 0.29 & 0.87 & 0.19 & 1.13 & 0.41 \\
\hline Weld & & 0.16 & 0.014 & 0.008 & 0.31 & 0.17 & 0.16 & 1.13 & 0.41 \\
\hline
\end{tabular}


ANALYSIS AND INTERPRETATION OF WELDING PROCESS

\section{INTRODUCTION}

As anticipated at the outset of this investigation the cavity temperature measurements and post weld chemical and physical study results presented in the previous section did yield important new information about Electron Beam welding. In this section attention is now directed toward using this knowledge for developing an improved interpretation of how the various factors - in particular vapor pressure and surface tension - interact.

\section{CAVITY FORCE BALANCES}

It is generally agreed that vapor pressure plays a very important role in maintaining a cavity during Electron Beam welding. When vapor pressure is mentioned it is ustally used in a context that suggests its value need only be large enough to overcome the effects of the hydrostatic head. However, a very important additional force trying to close the cavity is due to the surface tension. During welding the cavity is assumed to resemble a deep and narrow depression with $i$ iquid walls. The surface tension action of the liquid walls tends to constrict the radiai size and depth of the cavity. Therefore the magnitude of the metal vapor pressure in the cavity must be sufficient to overcome both the constricting force due to surface tension and the filling force due to the hydrostatic head. The surface temperature of the liquid metal in the EB welding cavity will determine the magnitude of the metal vapor pressure. 
Investigations of the cavity shape during welding suggest that the shape of the cavity oscillates with time. $7,9,11$ It is thought that these oscillations are related to the forces acting in the cavity. Appropriate estimates can be made for the magnitudes for the various forces in the cavity during the EB welding process if a quasi-steadystate condition is assumed. This assumption is valid if time averaged values are assumed for surface temperatures in the welding cavity and consequently the vapor pressure.

Before making a force balance in the weld cavity, some assumptions must be made as to what the cavity shape might be during welding. It is reasonable to assume that the cavity shape during welding will look very similar to that defined by the fusion line observed in a weld crosssection. For very deep welds the shape is similar to that of a triangle with a circular radius at the bottom of the cavity. Rotating this shape about the vertical axis results in a cone with a spherical radius at the apex. With this assumed shape an appropriate force balance can be made in the welding cavity.

Figure 29 illustrates the proposed cavity shape and pictorially demonstrates the various forces acting. A force balance at the cavity bottom involving the surface tension, vapor pressure, and liquid hydrostatic head on a very thin liquid surface layer can be arrived at by considering the geometry and the forces in Figure 30. The magnitude of each of these three forces during welding can be estimated from the following relationships. Assuming the base to be at a uniform temperature, and thus having a uniform vapor pressure, the resulting vapor pressure force in the vertical direction can be defined as, 


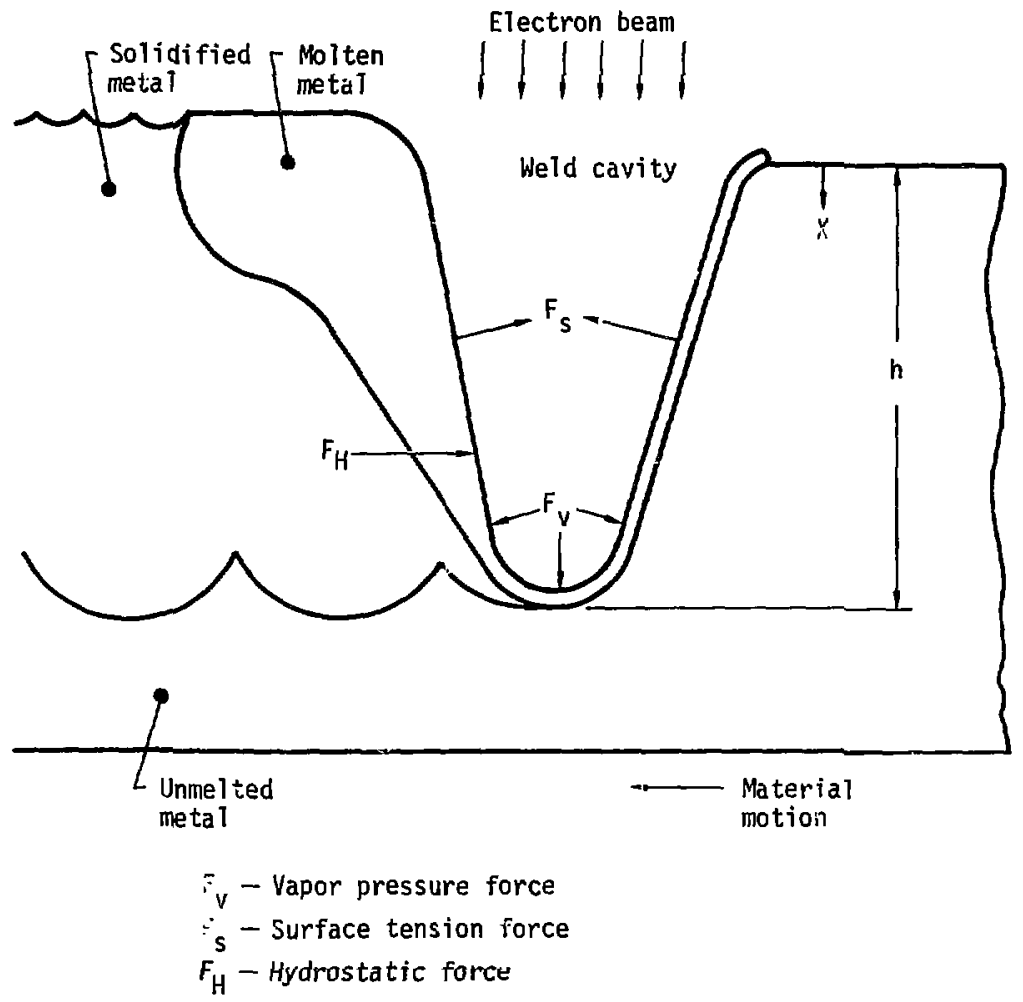

Figure 29. Representative cavity cross-section parallel to weld showing forces acting during welding. 


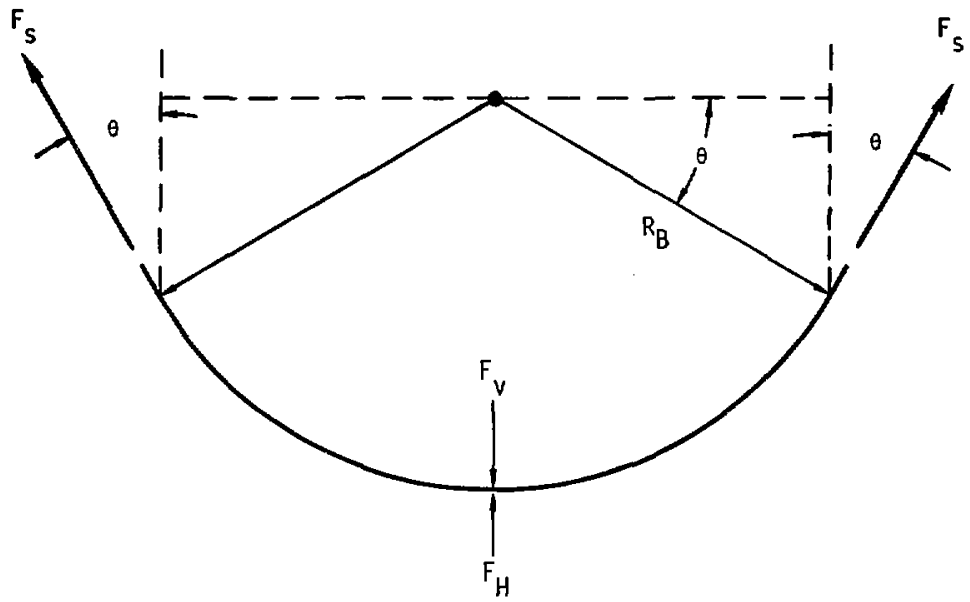

Figure 30 . Forces acting on the liquid surface at the spherical cavity bottom. 


$$
F_{V}=2 \pi\left(R_{B} \cos \theta\right)^{2} P_{V}
$$

where $R_{B}$ is the base radius which is assumed to be spherical, and $P_{V}$ is the vapor pressure. Here, $\theta$ is the angle between vertical and the side of the cavity at the plane of the vertical force balance.

The vertical force due to the hydrostatic head, $F_{H}$, acting on a circular area, where $\rho$ is the liquid density, $g$ is the gravitation constant and $x$ is the liquid depth is,

$$
F_{H}=2 \pi\left(R_{B} \cos \theta\right)^{2} \rho g x
$$

To obtain the vertical component due to surface tension, the force acting on the circular line length at the force balance plane must be multiplied by $\cos \theta$. This results in the vertical component due to surface tension as,

$$
F_{S}=2 \pi\left(R_{B} \cos \theta\right) \gamma(\cos \theta)
$$

The above three forces define the vertical force balance to be,

$$
F_{v}-F_{H}-2 F_{S}=0
$$

Substituting expressions for the three forces from Eqs. (7-9) into Eq. (10) results in,

$$
2 \pi\left(R_{B} \cos \theta\right)^{2}\left(P_{V}-\rho g X\right)-4 \pi R_{B} \cos ^{2} \partial_{Y}=0
$$

At the bottom of the cavity, the depth of the liquid, $x$, is usually very close to being equal to the depth of penetration, $h$. For this situation, the above expression for the force balance at the bottom of the cavity can be solved for the vapor pressure in terms of the other variables yielding

$$
P_{V}=\frac{2 Y}{R_{B}}+p g h
$$


Along the sides of the conical cavity the following expression defines the forces. Considering a short vertical segment of the surface as shown in Figure 31, a horizontal force balance will produce the following expressions. The vapor pressure force acting on a small ring of height $\mathrm{dx}$ is defined by,

$$
F_{v}=2 R_{x} d x P_{v} \cos \theta
$$

where $\cos \theta$ is the cone angle. The force due to the hydrostatic head of liquid is given by,

$$
F_{H}=2 R_{X} d x \rho g x \cos \theta
$$

The constricting force from the surface tension is

$$
F_{S}=\gamma d x
$$

The following force balance then relates the three forces at the side wall of a conizal cavity,

$$
F_{v}-F_{H}-2 F_{s}=0
$$

Substituting the expression for the three forces defined by Eqs. (13-15) Eq. (16) results in

$$
2 R_{x} d x \cos \theta\left(P_{v}-\rho g x\right)-2 \gamma d x=0
$$

This reduces to the following relation for the vapor pressure in terms of the hydrostatic head and the surface tension as shown by

$$
P_{v}=\rho g x+\frac{\gamma}{R_{x} \cos \theta}
$$

For very deep and narrow welds, $\cos \theta$ is nearly unity so that Eq. (18) reduces to the following,

$$
P_{v}=\rho g x+\frac{Y}{R_{x}}
$$



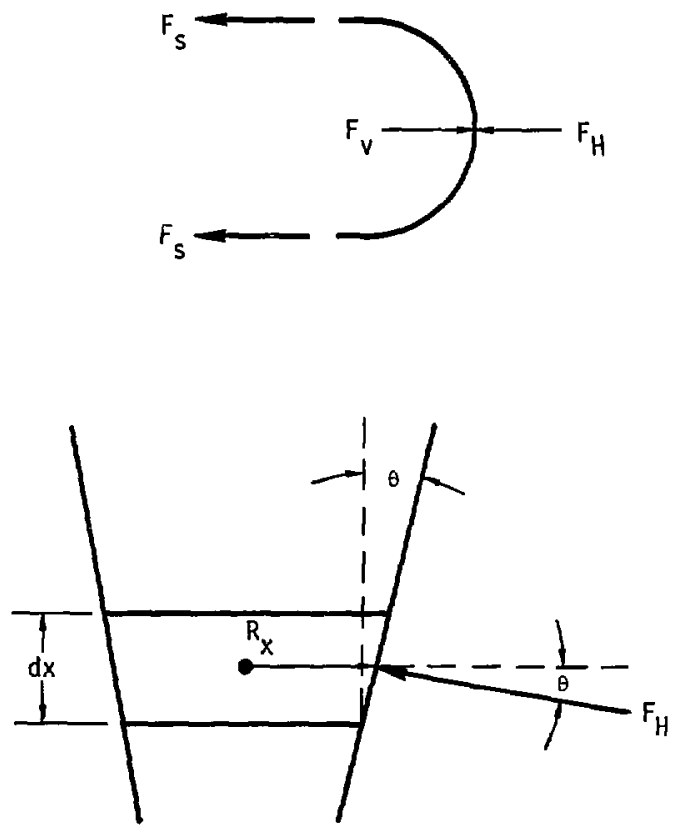

Figure 31 . Forces acting on the liquid surface at the sides of the conical cavity. 
Comparing Eqs. (12) and (19) shows that the force component due to surface tension at the cavity bottom is twice that at the cavity side walls. Therefore, a greater vapor pressure at the cavity bottom is required to maintain equilibrium.

\section{CALCULATIONS OF FORCES IN CAVITIES}

The experimental measurements indicated that a temperature variation exists in the cavity. Because of this variation, it can be expected that the vapor pressure of the liquid will also vary along the cavity wa11. At the cavity base the vapor pressure should be in equilibrium with the liquid at its maximum temperature. If the pressure was less than the corresponding liquid partial pressure the depth of penetration would decrease since not as much liquid could be pushed aside to expose fresh base metal. The vapor pressure from near the cavity base to the top opening may not be exactly in equilibrium with the liquid surface because of mass flow out of the cavity. Mass addition from vaporization along the cavity walls supports the concept of subsonic flow in an increasing channel with a negative pressure gradient. It is reasonable to assume that the liquid surface conditions are close to equilibrium at any location in the cavity. Therefore, the temperature distribution in the cavity is indicitive of the local pressure.

From the peak temperatures measured at the cavity base during welding one can determine the corresponding vapor pressure from available data such as that shown in Figure $8 .^{29}$ For 1100 aluminum, the maximum temperature measured at the cavity base was about $1900^{\circ} \mathrm{C}$. From Figure 8 the corresponding vapor pressure is 27 Torr. For a shallow aluminum weld with a depth of penetration equal to $0.2 \mathrm{~cm}$, a cavity base radius of 
$0.05 \mathrm{~cm}$, the measured cavity temperature distribution was plotted in Figure 23. Substituting values into Eq. (16) and using an appropriate value for liquid surface tension it can be determined that at the base of the cavity the vapor pressure is slightly larger than the pressures due to the surface tension constriction and the liquid hydrostatic head tending to fill the cavi.y. Along the cavit $f^{\prime}$ walls Eq. (19) must be used.

Assuming the cavity shape during welding to be similar to that defined hy the fusion $l$ ine in a transverse weld section taken after welding, allows the temperature measurements to be related to locations in the cavity. Then values were calculated for the surface tension and the local metal vapor pressure in the cavity as a function of temperature and thus position. These values are only approximate, since the actual cavity dimensions during welding are not known. This implies that there is some uncertainty associated with the exact location in the cavity to which the measured temperature is assigned. Finaily, the term associated with the liquid hydrostatic head which is a function of the depth of position in the cavity can be calculated. It is immediately recognized that the magnitude of liquid hydrostatic head force is small when compared to the magnitudes of the surface tension or the vapor pressure forces.

The magnitude of the force due to the liquid hydrostatic head is sufficiently small such that it can be neglected. Then Eq. (19) reduces to a comparison between the vapor pressure and the surface tension pressure, defined as $\gamma / R$. 
Using the temperatures measured in the cavity as a function of position, values can be estimated for the vapor pressure and the surface tension pressure as a function of cavity depth. This was done for the shallow aluminum weld and the results are presented in figure 32.

A deeper penetration weld, also in 1100 aluminum was obtained by Shintaku, ${ }^{21}$ who aiso measured the cavity temperature during welding. * The cavity shape and the temperature variation in the cavity, figure 33, were used to determine values for the vapor pressure and surface tension force, $\gamma / R$, as a function of cavity depth. The results for this deeper aluminum weld are presented in Figure 34.

Comparing the results for the shallow weld against those from the deeper weld indicate the following. The temperature, and consequently the vapor pressure at the cavity bottom for these aluminum welds are the same. However, the surface tension pressure at the bottom is greater for the deeper weld. There is a cross-over point between the two pressure distributions, and it occurs near the bottom of the shallow weld.

\section{CAVITY DYNAMICS}

For the cavity forces caiculated for the previous welds, a position exists in the cavity at which the vapor pressure is greater than

* The measurements presented in Ref. 21 were undertaken subsequent to the initiation of this study and were made with sensing equipment similar to that used herein. Data were obtained with a different EB welder which permitted more direct observation of the weld cavity and deeper welds. 


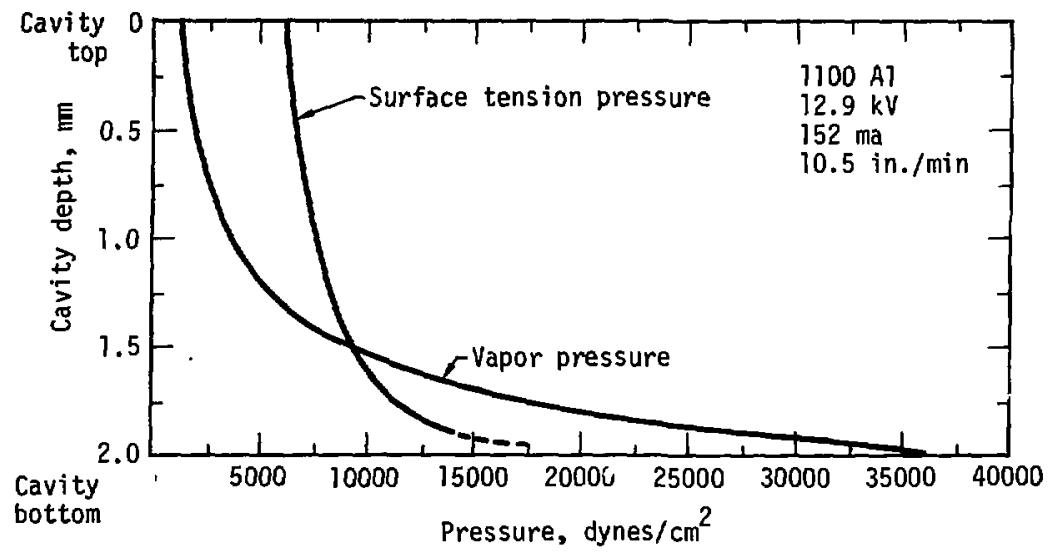

Figure 32. Calculated values of surface tension pressure and vapor pressure in an 1100 aluminum EB welding cavity as a function of cavity depth. 


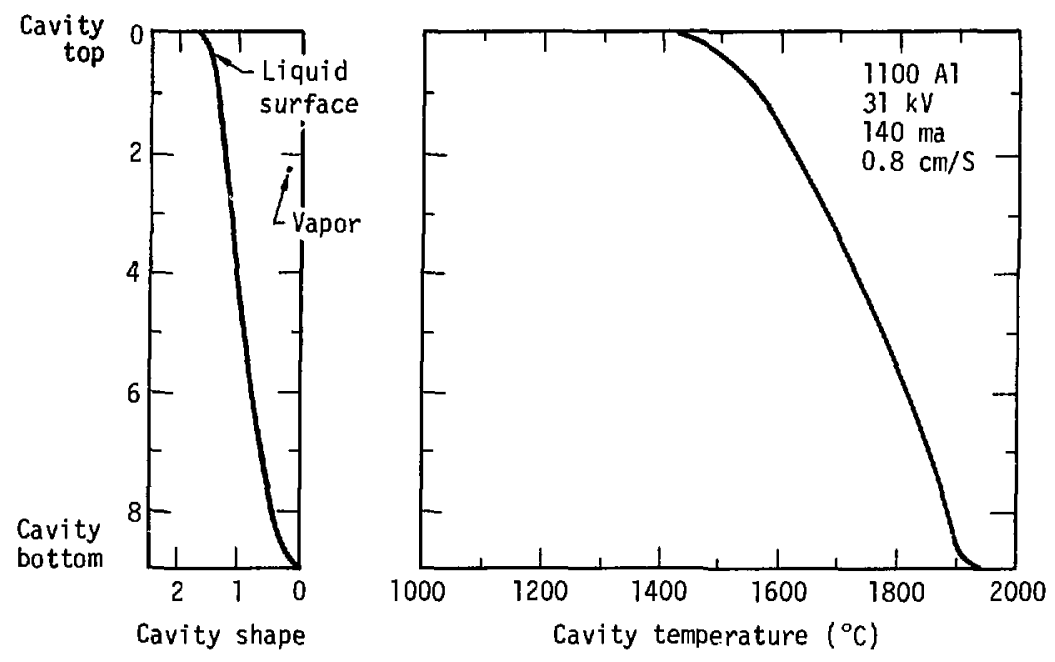

Figure 33. Approximated cavity shape during welding and typical measured cavity temperature profile21 for 1100 aluminum. 
the surface tension pressure (Figures 32 and 34 ). This is certainly the case from the cavity bottom up to the cross-over point or force imbalance location. Above, the forces are comparable but the surface tension pressure is sufficiently greater than the vapor pressure to cause liquid metal to move inwards slightly. As a result, the liquid tends to flow downwards until it reaches the region of the force imbalance. Since the vapor pressure force is overpowering below this location, the liquid is forced to move towards the cavity center thus forming a liquid projection as demonstrated in Figure 35(a).

This concept is not entirely new. Leskov, et al. ${ }^{15}$ suggests that the action of the beam along the leading edge of the liquid wall could cause small liquid projections to move into the EB path. Once the projection is in the path of the EB the upper liquid surface will be heated to a very high temperature and the recoil from the vapor generated associated with this high temperature will drive the projecting liquid towards the bottom of the cavity as shown in Figure 35(b). This action will partially fill the cavity, Figure 35(c). The EB then acts on a thicker molten pool and bores a hole through the liquid metal (Figure $35(d)$ ) to reestablish the force imbalance which caused the material to enter the path of the EB. Filling the bottom of the hole will then occur again as this action repeats neriodically.

When the cavity bottom is partially filled, i: $:$ liquid metal has already been heated to a high temperature. The EB should be able to bore througn this "super-heated" liquid very' easily and encounter unmelted base metal that has been heated by conduction from the pool of 


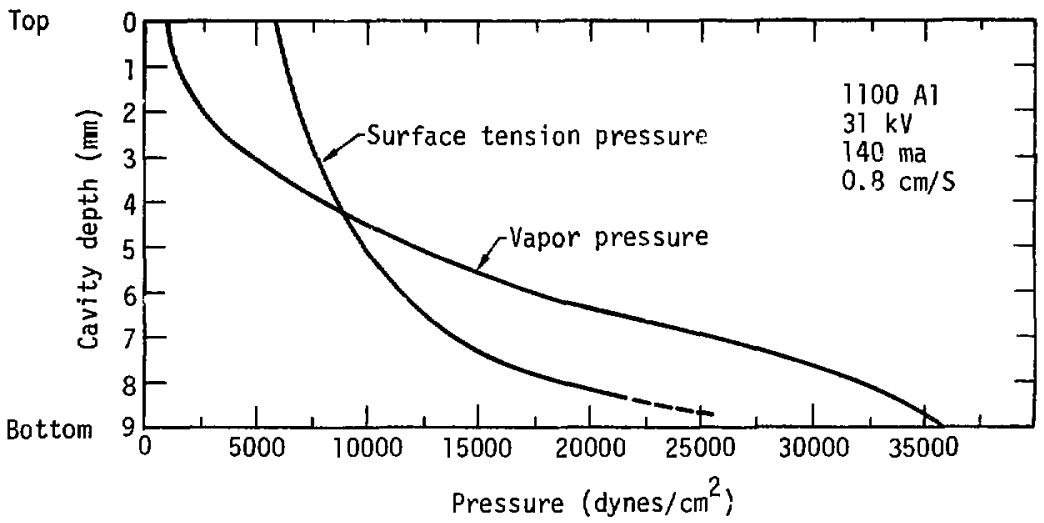

Figure 34. Calculated values of surface tension pressure and vapor pressure in a 1100 aluminum EB welding cavity as a function of cavity depth. 


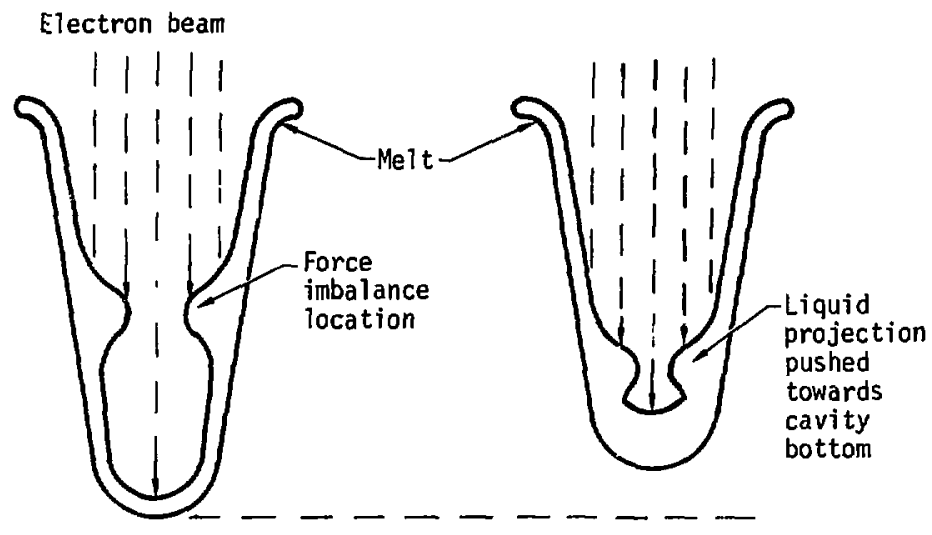

(a)

(b)

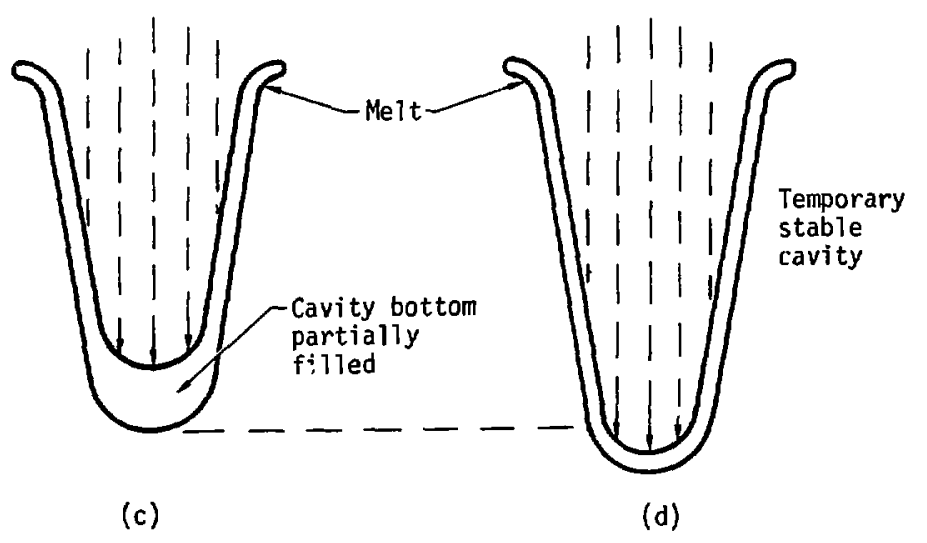

Figure 35. Cavity oscillation sequence. 
hot molten liquid. When the EB impinges upon this base metal, it is possible that the beam could bore to a slightly greater depth than normal, because the metal has been preheated, more than usual, and thus cause a spike. Instability of penetration or the spiking phenomena could be associated with the formation of these liquid projections, iheir movement toward the weld root by the vapor reaction, and the consequent reopening of the cavity bottom.

\section{SIZE ESTIMATION OF LIQUID PROJECTION}

An estimate of the size of the liquid projection in the region of the force imbalance can be obtained by considering the geometry arid forces at the point of the imbalance. Before any movemerit can occur the constricting force due to the surface tension combined with the hydrostatic head must be substantially greater than the local vapor pressure force, as indicated in Figure 36 . The net inward force is described by

$$
\begin{aligned}
2 \gamma d x+\imath R_{2} d x\left(\rho g x-P_{v}\right) & =P_{i n} 2 R_{2} d x \\
\frac{Y}{R_{2}}+\rho g x-P_{v} & =P_{\text {in }}>0
\end{aligned}
$$

where $P_{\text {in }}$ is the equivalent inward pressure. Next it is assumed that some equilibrium shape exists as defined by

$$
\gamma\left(-\frac{1}{R_{1}}+\frac{1}{R_{2}^{\prime}}\right)+P_{\text {in }}=0
$$

where $R_{1}$ and $R_{2}^{\prime}$ are the two radi $i$ of curvature of the liquid surface under the action of surface tension forces. Next substitute the expression for the net inward pressure, from Eq. (20) into Eq. (21) and solve for the radius of curvature $R_{T}$ in terms of the other variables. 

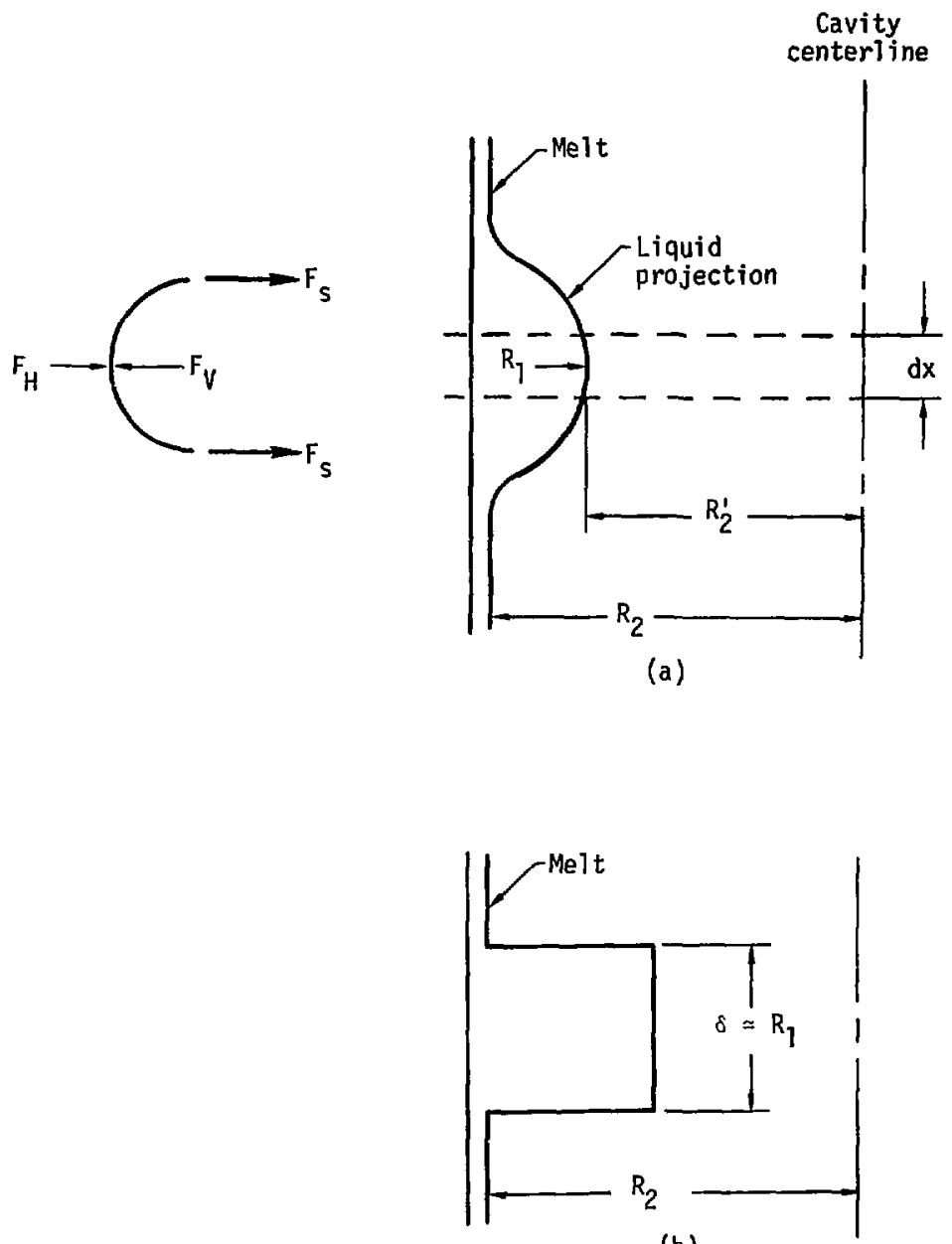

(b)

Figure 36. (a) Geometry and forces acting on a small dx element in the cavity at the force imbalanre location.

(b) Approximated geometry of liquid projection at the force imbalance location. 


$$
r\left(\frac{1}{R_{1}}-\frac{1}{R_{2}}\right)=P_{\text {in }}=\frac{Y}{R_{2}}+\rho g x-P_{v}
$$

for

$$
\begin{aligned}
& R_{2}^{\prime}=R_{2} \\
& \frac{\gamma}{R_{1}}=\frac{2 \gamma}{R_{2}}-P_{v}+\rho g x \\
& R_{1}=\frac{\gamma R_{2}}{2 \gamma+\left(\rho g x-P_{v}\right) R_{2}}
\end{aligned}
$$

When the vapor pressure is about equal to $\rho g x$, the radius of curvature of the material projection is approximately equal to half the cavity radius at the vertical position. It is then hypothesized that the thickness of the liquid projection should be on the order of the radius $R_{1}$ as shown in Figure $36(b)$.

\section{ESTIMATE OF TIME TO FILL CAVITY BOTTOM}

At the point of the force imbalance as shown in Figure 37 , the liquid will move into the path of the EB. This will cause a local increase in the concentration of beam power on the projecting liquid surface causing evaporation of some of the metal and creating a force that will tend to drive the liquid metal to the bottom of the cavity. This force is directly related to the evaporation rate of the liquid metal. Langmuir ${ }^{19}$ related the rate of evaporation of an element or pure substance into a vacuum to the temperature of the condensed phase. This relationship based on kinetic theory and the concept of dynamic equilibrium has been proven accurate by countless investigators for many simple evaporating species including elemental iiquid and solid 


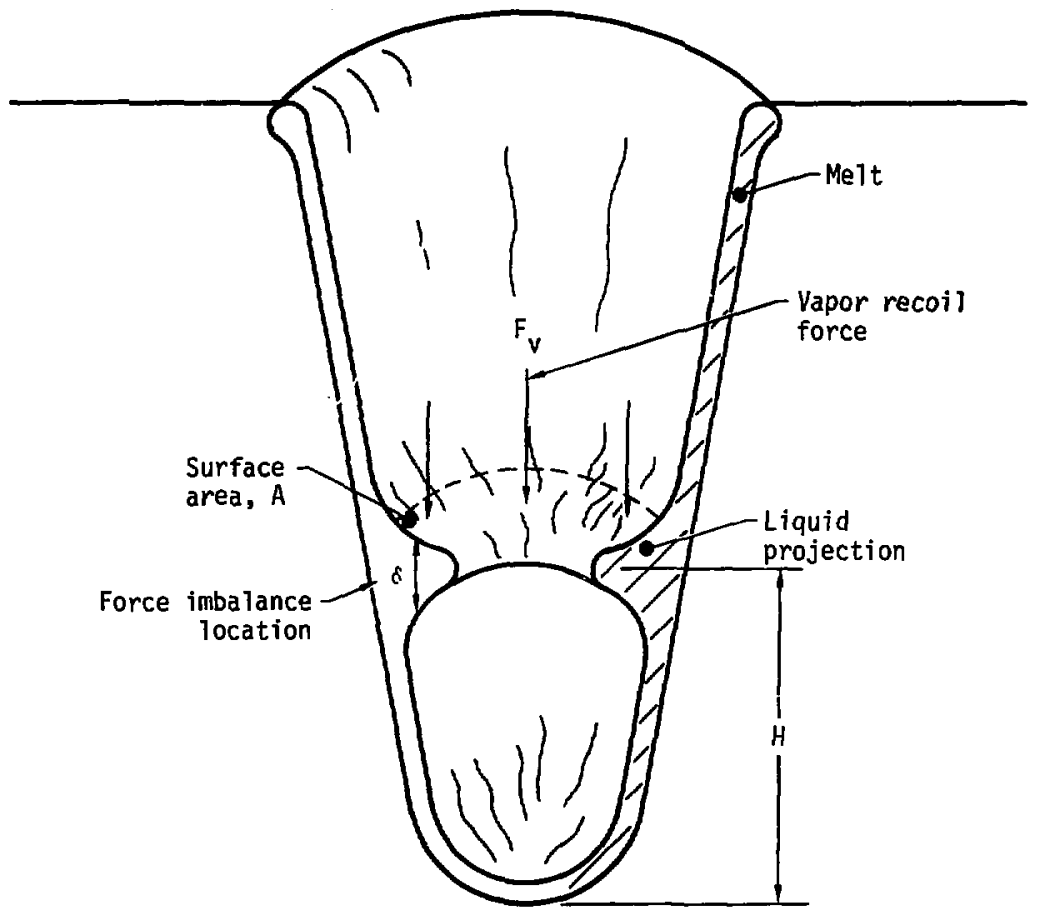

Figure 37. Weld cavity cross-section showing the vapor recoil force acting on the upper surface of the liquid projection at the force imbalance location. 
metals. Recently, the equation has been shown to applay to alloy evaporation. $31,32,33$ Here the assumption is that each species in the solution will evaporate at a rate consistent with its partial pressure over the solution. Applied in this manner, the Langmuir equation written for a single component is as follows,

$$
J=0.0583 \alpha \gamma N P^{0}\left(\frac{M}{T}\right)^{1 / 2}
$$

Here, $\alpha$ is the evaporation coefficient, unitless, $\gamma$ is the activity coefficient of species in alloy, unitless, $N$ is the atomic fraction of species in alloy, unitless, $\cdot \mathrm{P}^{0}$ is the vapor pressure of pure species, Torr, $M$ is the atomic weight, $\mathrm{gm}, T$ is the absolute temperature, ${ }^{\circ} \mathrm{K}$ and $J$ is the evaporative flux per unit area, $\mathrm{g} / \mathrm{cm}^{2}-\mathrm{sec}$.

The liquid metal projection at the point of the force imbalance will be accelerated towards the bottom of the cavity according to Newton's second law where the force is that due to the surface evaporation on the liquid projection as shown in Figure 37.

As the liquid projection forms and is pushed towards the cavity bottom, surface tension forces continually act on this distorted surface. The actual liquid surface contour during this reaction would be extremely difficult to define. Because of the complexity, the surface tension was not treated in the present analysis.

The evaporation force is defined using the evaporation rate from the Langmuir equation, the area of the projection, and the time of evaporation $\tau_{1}$ which is also the time required to push the liquid projection to the cavity bottom.

$$
F_{v}=J A \tau_{1}
$$


The mass of the liquid projection is estimated to be equal to the product of the liquid density, $\rho$, the projected area, $A$, and the thickness of the projection, $\delta$ or $\rho A \delta$. Substituting into Newton's law, $F=$ ma, results in

$$
\begin{aligned}
& J A \tau=\frac{\rho A \delta}{g} \frac{d^{2} x}{d t^{2}} \\
& \frac{d^{2} x}{d t^{2}}=\frac{J \tau g}{\rho \delta}=B
\end{aligned}
$$

The solution to this equation is well known, and is,

$$
x(t)=B \frac{t^{2}}{2}+C t+D
$$

Two boundary conditions are needed to evaluate the constants $C$ and $D$. The first B. C. is defined by zero velocity at time zero. This requires that $C$ be zero. The second $B$. C. states that at time $\tau_{1}$ the liquid projection has moved a distance $H$, representing the cavity bottom. This defines the constant $D$ as;

$$
D=H-\frac{B \tau_{1}^{2}}{2}
$$

The solution is therefore given by substituting Eq. (28) into Eq. (27),

$$
x(t)=\frac{B}{2}\left(t^{2}-\tau_{1}^{2}\right)+H
$$

Then at time zero, $x$ is zero, and one can solve Eq. (29) for $\tau_{1}$, the time required to push the liquid projection to the bottom of the cavity. The result is

$$
\tau_{1}=\left[\frac{2 \rho \delta H}{J g}\right]^{1 / 3}
$$




\section{ESTIMATE OF TIME REQUIRED TO REOPEN CAVITY}

After the liquid projection has been driven to the bottom of the cavity it is assumed that the bottom is filled with liquid metal. Now the EB must bore through the molten metal to recipen the cavity to approximately the same depth as at the time of the force imbalance.

Tong and Giedt ${ }^{7,8}$ presented an analytical model for the penetration time of the cavity as a function of the vapor pressure, surface tension, and the hydrostatic head. Their analysis allows the time it takes the EB to penetrate into a cavity that has been completely filled with molten metal to be calculated. In the present situation, it is argued that the cavity is only partially filled. However, the dynamics of boring a hole in a partially or completely filled cavity will remain the same. Therefore, their analytical expression was used to determine the time it takes the EB to bore a hole through the liquid of a partially filled cavity. Their analysis assumed that the cavity could be represented as solid body of zero mass forced to move through the liquid metal by the net force due to vapor pressure, surface tension, and the hydrostatic head. The following expression

$$
\tau_{2}=\frac{2\left[\left(\frac{\mathrm{P}}{\mathrm{ex}}\right)^{1 / 2}-\left(\frac{\mathrm{P}_{\mathrm{ex}}}{\mathrm{\rho gh}}-1\right)^{1 / 2}\right]}{\left(\frac{\mathrm{g}}{\mathrm{h}}\right)^{1 / 2}}
$$

defines $\tau_{2}$, the time required for the massless solid body to penetrate a distance equal to the depth of penetration osserved from weld sections. Equation (31) shows the relationship between the external pressure, $P_{\text {ex }}$, the fluid density, $\rho$, and the penetration depth, $h$. 
The external pressure, which is forcing the massless body to the bottom of the cavity, was suggested to be the difference between the local surface vapor pressure and the surface tension constriction force from a spherical depression in the liquid surface as shown by,

$$
P_{\text {ex }}=P_{v}-\frac{2 y}{R}
$$

- where $P_{V}$ is the local surface pressure, $\gamma$ the surface tension, and $R$ the radius of the spherical depression. It is further noted that the external pressure must be greater than the hydrostatic head in order to achieve any penetration at all,

$$
P_{\text {ex }} \geq \rho g x
$$

\section{CAVITY OSCILLATION FREQUENCY}

It is now argued that this oscillatory behavior of filling the cavity bottom followed by a displacement of the liquid metal from the cavity is reflected by the wavy patterns observed from weld sections at the weld root and sometimes referred to as spiking. The total time for one complete cycle is the sum of the time to push the metal projection to the cavity bottom and the time required to bore a hole in the partially filled cavity to achieve maximum penetration. This can be represented by,

$$
\tau=\tau_{1}+\tau_{2}
$$

where $\tau_{1}$ is defined by Eq. (30), and $\tau_{2}$ is defined by Eq. (31). The frequency can be defined by the reciprocal of the cycle time,

$$
f=\frac{l}{T}
$$

If this description of the cavity dynamics during welding is valid a 
correlation should exist between a frequency calculated by the above method and the actual oscillation frequency measured from a weld section after the weld has been completed.

CAVITY OSCILLATION FREQUENCY CALCULATION FOR WELD IN PURE ALUMINUM

The methods outlined above were used to calculate a cavity uscillation frequency for a material whose temperature was measured during welding. ${ }^{21}$ This material was aluminum alloy 1100 . The welding conditions for this particular weld were $31 \mathrm{kv}, 140 \mathrm{Ma}$ with a welding speed of 0.8 cenitmeters per second. The weld depth varied from 6 to $9 \mathrm{milli-}$ meters.

The assumed cavity shape during welding based on the cavity shape for a weld section along with the measured temperature distribution are reproduced and shown in Figure 33 . Using the assumed cavity shape and the measured temperature distribution as a function of depth from Figure 33 the surface tension constriction pressure can be calculated from Eq. (19) for the cavity wall and Eq. (12) for the cavity bottom, Surface tension data for aluminum by Wilson ${ }^{34}$ was used to determine the surface tension temperature dependence. The temperature vapor pressure data of Figure 4 for pure aluminum and the temperature distribution as a function of depth allowed the vapor pressure to be calculated as a function of depth.

In Figure 34, the vapor pressure and the surface tension pressure as a function of cavity depth are plotted. The force imbalance location occurs approximately $4 \mathrm{~mm}$ from the top of the cavity, where the 
cavity radius is about $0.09 \mathrm{~cm}$. The value used for the thickness of the liquid projection was equal to $1 / 2$ of the cavity radius at the $i m-$ balance location according to Eq. (22), or $0.045 \mathrm{~cm}$. Since the total cavity depth is $9 \mathrm{~mm}$ the distance that the liquid projection must move to reach the bottom of the cavity, $H$, is $5 \mathrm{~mm}$.

When the liquid projection moyes into the path of the electron beam it is assumed that the maximum temperature attained on its upper surface is the same as the maximum temperature measured at the cavity bottom. From Figure 33, the temperature at the bottom of the cavity was $2173^{\circ} \mathrm{K}$. The corresponding vapor press!!re for pure aluminum from Figure 8 is 27 Torr. For pure aluminum, the value of the constants in Eq. (23) $\alpha, \gamma$, and $N$ are all equal to 1 since this is a pure species. When the above values are substituted into 5. . (23), the evaporation rate is $0.176 \mathrm{gm} / \mathrm{cm}^{2}-\mathrm{sec}$. The time required to push the liquid projection to the cavity bottom is computed to be equal to 0.089 second using Eq. (30).

The momentary greater value of the vapor pressure compared to the surface tension force, $P_{\text {ex }}$ (as defined by Eq. (32)) can be determined by using the vapor pressure corresponding to the temperature at the bottom of the cavity, $2173^{\circ} \mathrm{K}$, the corresponding surface tension, 747 dynes $/ \mathrm{cm}$, and a radius equal to 0.05 centimeter. Since the electron bealn is trying to push it's way wo the bottom of the cavity through this volume of liquid, a radius was chosen that is typical of the radius of the electron beam. Evaluation of Eq. (32) results in approximately 6000 dyns $s / \mathrm{cm}^{2}$ for $P_{e x}$.

In Eq. (31), the value used for $H$ which is to represent the thickness of molten metal which the electron beam must bore through was set 
equal to the magnitude of the distance between the point of the force inbalance and the bottom of the cavity. Since it is assumed that the cavity will only be partially filled when the liquid projection is drives to the iottom of the cavity, the actual depth of liyuid in the cavity will be assumed to be equal to $3 \mathrm{~mm}$. This is a value that is somewhat less than the distance from the point of the force imbalance to the cavity bottom which is $5 \mathrm{~mm}$. Estimating the time to bore a hole in this thickness of material from Eq. (31) yields 0.006 second. The oscillation frequency can then be calculated by taking the reciprocal of the sum of these two times which leads to a value of 10.5 cycles per second.

Most satisfactory EB welds when sectioned along the weld bead centerline will exhibit a wavy pattern at the wela root. The periodic occurrence of these waves are argued to be related to the cavity oscillation frequency. As the EB bores deeper during one portion of a cavity oscillation cycle, its penetration is reflected by a depression in the weld root fusion line. However, for a shallow weld the waves caused by the cavity oscillation are sometimes not evident. This could be due to a very small ampitude of oscillation.

For the above weld the number of waves per unit length were determined from a weld section. Then multiplying this number by the welding speed yielded an experimental oscillation frequency of 10 cycles per second. This compares very favorably with the calculated oscillation frequency of 10.5 cycles per second. 


\section{VAPOR PRESSURE-TEMPERATURE RELATIONSHIP FOR ALLOY CAVITY}

For alloys a slightly different approach is required to determine the vapor pressure-temperatura relationship. A theoretical determination of the vapor pressure is not possible because of the complexity of the phenomena involved. The activity coefficient and the evaporation coefficient for each species, and the effect of the elements having greatiy differing vapor pressures as a function of temperature are generally unknown. Also, the interaction of several elements in the welding cavity during welding is generally unknown.

The kinetics of evaporation utilizing the Langmuir equations have shown that evaporation rates can be caiculated during electron beam evaporation for selected steel alloys and certain binary alloys. $31,32,33$ Experimental results indicate that these methods can be used when the alloy components have vapor pressure differences of a factor 5000 or less. ${ }^{35}$ Generally, prediction of evaporation rates, which are directly dependent on the vapor pressure, has been considered impractical when constitutents of the alloy to be evaporated have more than a factor of $10^{3}$ difference in vapor pressure. ${ }^{36}$ This is due to the evaporation rate being dependent on the transport processes in either or both the liquid or the vapor phase.

To obtain an estimate of the vapor pressure in an alloy cavity the following approach was used. During welding, a glass slide was inserted into the electron beam chanEer and positioned such that the vapor jetting out of the cavity would plate onto this slide. After welding, the glass slides were removed and the composition of the deposited layers determined using fiuoroscopic and chemical analyses methods. Assuming 
that the percentage of each element on the glass slide would be equal to the percentage of that particular element in the vapor phase in the cavity during weiring, Dalten's law can then be used to estimate the total cavity vapor pressure of the alloy as a function of temperature based on the sum of partial pressures of each element at a particular temperature. Table 6 lists al of the alloys welded with the percentage of each element in the unwelded material and the percentage measured in the vapor phase during welding.

An examination of the vapor pressure-temperature data for the steel alloy constituents show the maximum difference in vapor pressure to be less than 1000 . The aluminum alloys reveal very large vapor pressure d:fferences in excess of 15,000 - 50,000 for the alloy constituents. Based on the results of many other investigators 35,36 this sug. gests that the vapor pressure dependence on temperature cannot be reliably determined for any of the aluminum alloys. However, it is possible that the vapor pressure of the steel alloys can be determined experimentally.

The above approach is still an approximation since it assumed that the vapor composition remins constant for any temperature. The compcsition of the deposited elements represents material evaporated not onily from the cavity bottom, but also from the cavity side walls and the molten pool at the material surface. However, the compositional data show that the volatile elements must evaporate at rates substantially greater than those of the base metal for the alloys investigated. This suggests that nearly all of the temperature dependence of the alloy pressure will be directly related to the particular volatile element. Therefore, the constant composition assumption as a function of temperature 
Table 6. Alloys welded comparing specified wt\% alloying elements with wt\% alloying element vapor plated onto glass slide during a test weld.

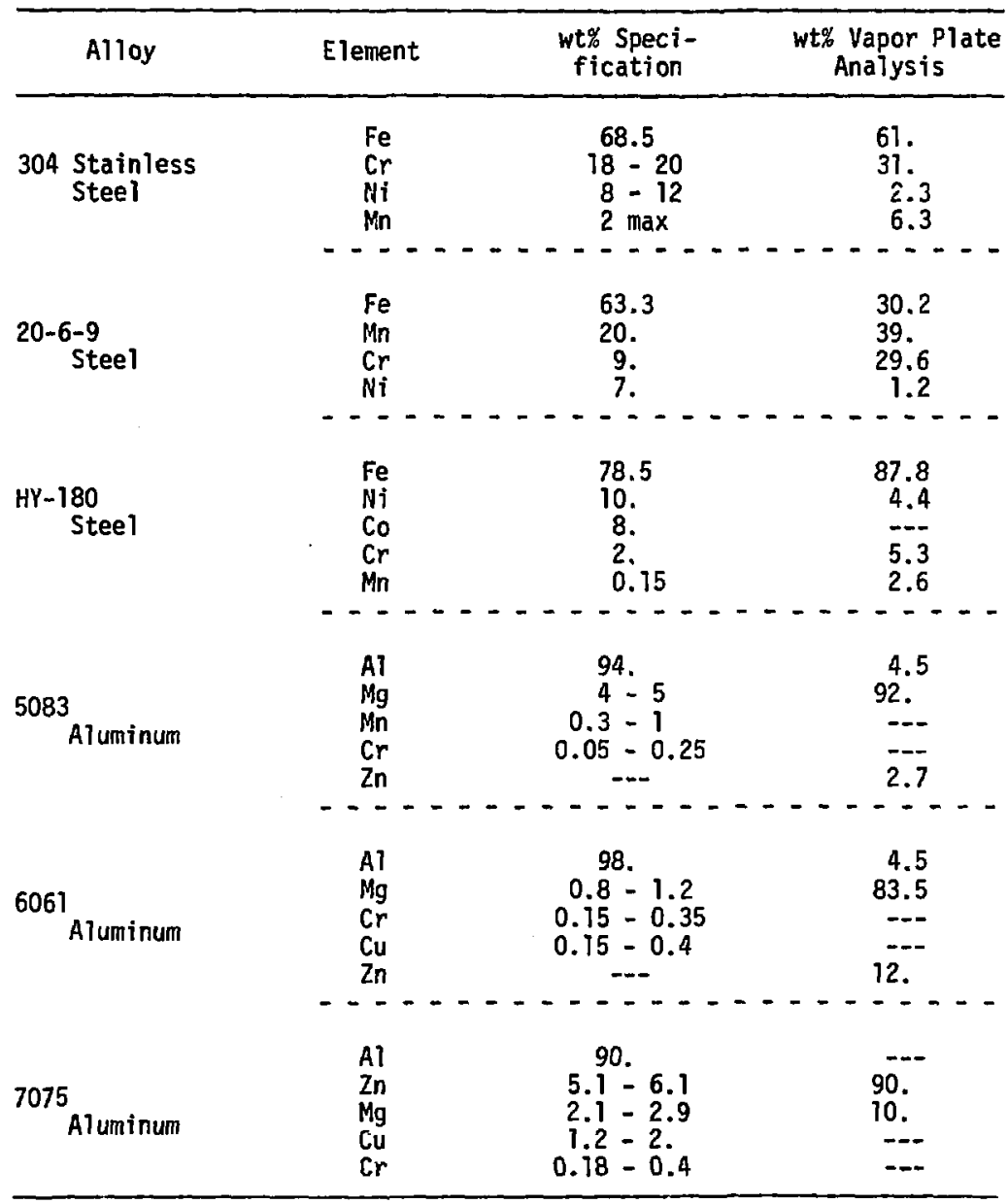


should allow a reasonable estimate to be made for the alloy vapor pressure over a limited temperature range for those alloys composed of elements having similar vapor pressures. Figure 38 displays vapor pressure versus temperature calculated by the above approach for each of the steel alloys welded during this investigation.

Because of the large vapor pressure differences between the constituents of the aluminum alloys no similar attempt was made to determine the aluminum alloy vapor pressure based on the analysis of the evaporated material. A calculation for comparative purposes only was made for these alloys based on the specifications of each alloy and plotted in Figure 38. These are to be used only as a means of showing that the alloys with larger wt\% of the highly volatile elements such as zinc and magnesium can have substantially greater vapor pressure.

Similar calculations were done for other test welds in pure aluminum and pure tantalum. Table 7 summarizes the comparison between the experimental oscillation frequency determined from weld sections and the calculated oscillation frequency using the analytical procedure described above. Figure 39 shows a representative plot of the two major cavity forces as a function of depth for a test weld in tantalum. 


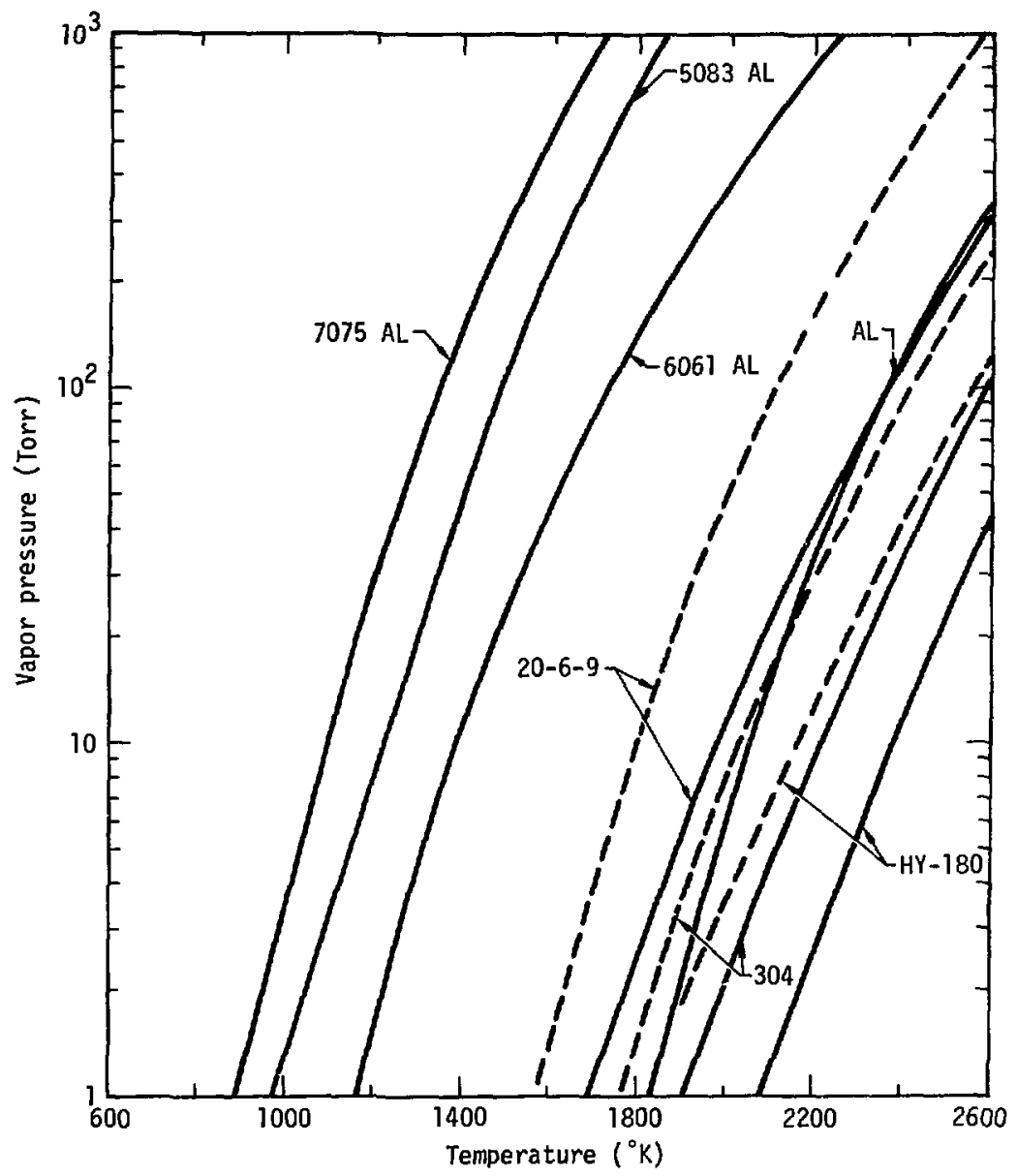

Figure 38. Vapor pressure dependence on temperature for several alloys. Solid lines are based on specified elemental wt\% in alloy material. Dashed lines are based on element wt\% as determined by analysis of vapor plating. 


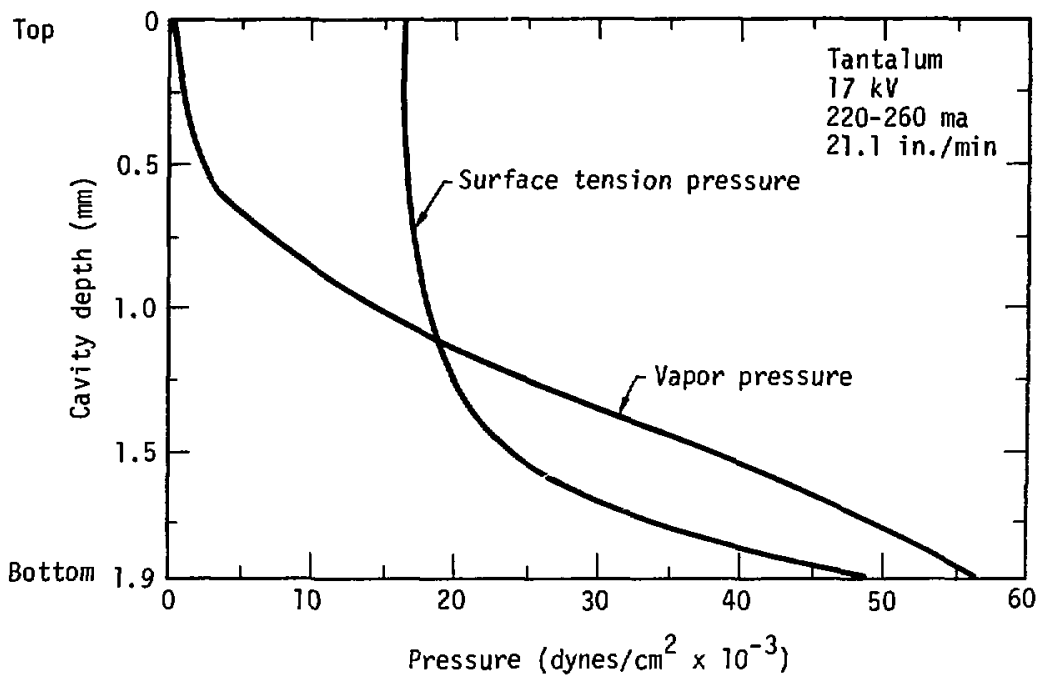

Figure 39. Calculated values of surface tension pressure and vapor pressure in a tantalum EB welding cavity as a function of cavity depth. 
Table 7. Cavity oscillation frequencies for pure metals.

\begin{tabular}{|c|c|c|c|c|c|c|}
\hline Material & $\begin{array}{l}\text { Beam } \\
\text { voltage } \\
\text { (kv) }\end{array}$ & $\begin{array}{c}\text { Beam } \\
\text { Current } \\
\text { (ma) }\end{array}$ & $\begin{array}{c}\text { Weld } \\
\text { Speed } \\
\text { (in./min) }\end{array}$ & $\begin{array}{l}\text { Weld } \\
\text { Depth } \\
(\mathrm{mm})\end{array}$ & $\begin{array}{c}\text { Oscillation } \\
\text { (cycles } \\
\text { Experimental }\end{array}$ & $\begin{array}{l}\text { Frequencies } \\
\text { s/sec) } \\
\text { Calculated }\end{array}$ \\
\hline $1100 \mathrm{Al}$ & 17. & 165 & 20 & 5.5 & 13. & 10.6 \\
\hline $1100 \mathrm{A1}$ & 12.9 & 152 & 10.5 & 2 & $20-40$ & 24 \\
\hline $1100 \mathrm{Al}^{21}$ & 31 & 140 & 19 & $6-9$ & 10 & 10.5 \\
\hline Tantalum & 17 & 240 & 21.1 & 1.9 & 20 & 14 \\
\hline
\end{tabular}

SURFACE TENSION OF LIQUID IN ALLOY CAVITY

The other unknown factor for alloys is the actual value of the surface tension. Surface tension values of alloys are generally not available. No data was found for the materials investigated in this study. Therefore, it was assumed that the temperature dependence was that of the major element. Also, it was assumed that the actual value of surface tension was that of the major element although it is recognized that the value could be much lower for particular alloys.

The uncertainty of the surface tension value will not be so great for those elements which contain elements whose surface tellsion values are similar, however; some uncertainties still exist for alloys having elements with greatly different surface tension values. For these particular alloys it is not possible to predict accurately the location of the force imbalance in the welding cavity.

\section{ALLOY EFFECTS ON CAVITY OSCILLATION FREQUENCY}

The presence of a highly volatile element in an alloy can influence cavity oscillation. This highly volatile element may evaporate from the 
surface at a rate that is greater than the rate at which it can diffuse to the surface. This is referred to as a diffusion limited process. 32 For an alloy that is diffusion limited, as the highly volatile element is completely vaporized from the surface the vapor pressure will experience a decrease. This will cause the force imbalance location in the cavity to move rapidly towards the cavity bottom. Consequently, the liquid on the walls of the cavity will flow towards the cavity bottom and mix to some degree. When the liquid has mixed it is very likely that the element that is highly volatile will now be present in the liquid surface region. The electron beam will then evaporate this highly volatile element creating a very high vapor pressure which will quickly force the liquid from the cavity resulting in a cavity of maximum penetration. This process could repeat itself and might even exhibit some periodicity. It is not clear at the present time what the physiral relationship might be.

An additional mechanism which may influence the cavity oscillation frequency is due to the fluctuation of the liquid surface tension value. For an alloy that contains elements with greatly differing surface tension values, as the composition of the surface changes due to unequal elemental evaporation rates, the surface tension could vary. For an alloy that contains a highly volatile element whose concentration substantially decreases as a function of time, the surface tension value may change considerably. 


\section{CAVITY OSCILLATION FREQUENCY CALCULATION FOR ALLOY}

The same methods used for calculating a cavity oscillation frequency for a pure material will now be used for an alloy. The material was stainless steel type 304. For the particular test weld chosen, the welding conditions were $15 \mathrm{Kv}, 140$ ma with a welding speed of $50 \mathrm{in./min}$. The weld depth averaged about $3.5 \mathrm{~mm}$.

The measured temperature distribution in this cavity during welding was presented in the Experimental Program Section, Figure 26. This allows the surface tension pressure that is constricting the cavity to be calculated using Eqs. (12) and (19). Surface tension data for iron 34 was used to determine the surface tension temperature dependence for all the steel alloys. The vapor pressure data for stainless steel 304 presented in Figure 38 combined with the cavity temperature distribution allowed the vapor pressure to be estimated as a function of depth.

The vapor pressure and the surface tension pressure as a function of cavity depth are plotted in Figure 40 . The force imbalance occurs $0.095 \mathrm{~cm}$ from the cavity bottom where the cavity radius is about 0.051 $\mathrm{cm}$. The thickness of the liquid projection according to Eq. (22) is $0.0255 \mathrm{~cm}$. When the Tiquid projection moves into the path of the electron beam it is assumed that the maximum temperature attained on its. upper surface is identical to the maximum temperature measured at the cavity bottom. From Figure 26 , the cavity bottom temperature was $2448^{\circ} \mathrm{K}$. The estimated vapor pressure (Figure 38 ) at that temperature is 110 Torr. To determine the evaporation rate for an alloy using Eq. (23), it is estimated that the product of the constants is equal to unity. Then using an average molecular weight of stainless steel for 


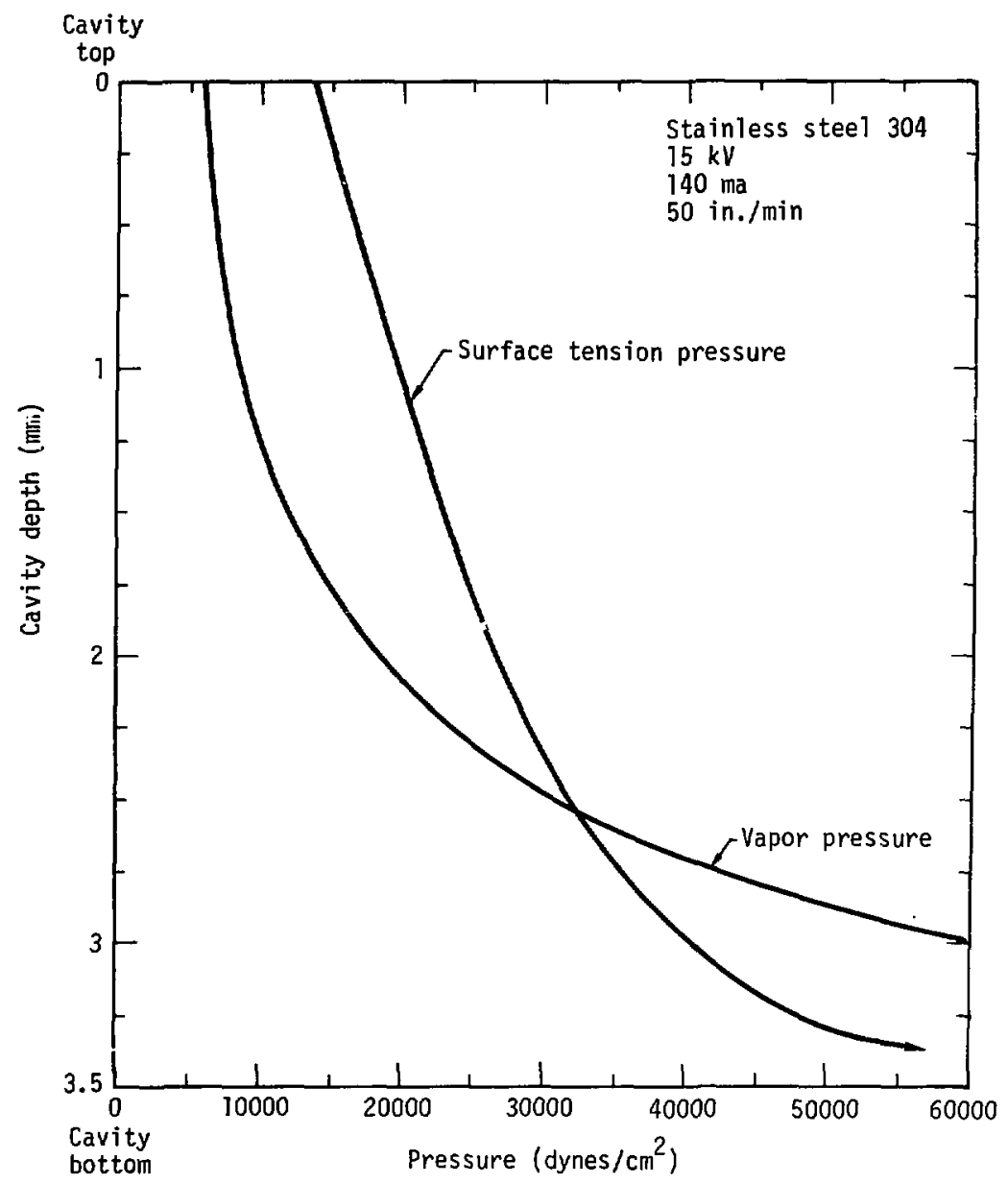

Figure 40. Calculated values of surface tension pressure and vapor pressure in a stainless steel $304 \mathrm{~EB}$ welding cavity as a function of cavity depth. 
this alloy the evaporation rate is calculated to be $0.965 \mathrm{~g} / \mathrm{cm}^{2}-\mathrm{sec}$. The time required to push the liquid projection to the cavity bottom is determined to be $0.0345 \mathrm{sec}$ using Eq. (30).

The momentary greater value of the vapor pressure compared to the surface tension force, $P_{\text {ex }}$, defined by Eq. (32) can be computed by using the vapor pressure corresponding to the temperature at the bottom of the cavity, $2448^{\circ} \mathrm{K}$, the corresponding surface tension, 1538 dynes $/ \mathrm{cm}$, and a radius equal to $0.027 \mathrm{~cm}$. This radius is typical of the electron beam radius as the beam pushes it's way toward the cavity bottom through the superheated molten liquid. Evaporation of Eq. (32) results in $P_{\text {ex }}=3300$ dynes $/ \mathrm{cm}$.

The thickness of the molten metal through which the EB must bore was set equal to $0.09 \mathrm{~cm}$, just slightly less than the value of $H$ $(0.095 \mathrm{~cm})$. Equation (31) allows the time to be estimated to bore a hole in this thickness of liquid metal. This time, $0.0014 \mathrm{sec}$ combined with the time to push the liquid material projection to the cavity bottom yields a cycle time of $0.0359 \mathrm{sec}$. By taking the reciprocal the oscillation frequency is determined to be $28 \mathrm{cycles} / \mathrm{sec}$. This compares very favorably with the experimentally determined value of $32 \mathrm{cycles} / \mathrm{sec}$.

Calculations done for other alloy test welds are summarized in Table 8. Comparison of the experimental and calculated oscillation frequencies show good agreement. The oscillation analys is presented by Tong and Giedt ${ }^{18}$ also allows the oscillation frequency to be calcuiated. The frequencies determined for 1100 aluminum and type 304 stainless steel with penetration depths of 10 to $20 \mathrm{~mm}$ ranged between 9 and 13 cps for weld conditions similar to some of those listed in 
Tables 7 and 8 . The frequencies calculated by the present analysis; agree favorably with those of Tong and Giedt for welds having comparable weld depths.

Table 8. Cavity oscillation frequencies for alloy materials.

\begin{tabular}{|c|c|c|c|c|c|c|}
\hline Material V & $\begin{array}{l}\text { Beam } \\
\text { Voltage } \\
\text { (kv) }\end{array}$ & $\begin{array}{c}\text { Beam } \\
\text { Current } \\
\text { (ma) }\end{array}$ & $\begin{array}{c}\text { Weld } \\
\text { Speed } \\
\text { (in./min) }\end{array}$ & $\begin{array}{l}\text { Weld } \\
\text { Depth } \\
(\mathrm{mm})\end{array}$ & $\begin{array}{r}\text { Oscillation F } \\
\text { (cycles } \\
\text { Experimental }\end{array}$ & $\begin{array}{l}\text { Erequencies } \\
\text { s/sec) } \\
\text { Calculated }\end{array}$ \\
\hline $6061 \mathrm{Ai}$ & 15 & 130 & 29 & 4.4 & 16 & --- \\
\hline $7075 \mathrm{Al}$ & 13 & 120 & 10 & 7.2 & $4-5$ &.- \\
\hline $5083 \mathrm{Al}$ & 15 & 135 & 60 & 6.7 & $30-40$ & --- \\
\hline $\begin{array}{l}\text { HY- } 180 \\
\text { Steel }\end{array}$ & 18 & 174 & 60 & 5.5 & $23-30$ & 18 \\
\hline $\begin{array}{c}20-6-9 \\
\text { Steel }\end{array}$ & 15 & 135 & 26 & 7. & $11-17$ & 11.2 \\
\hline $\begin{array}{c}20-6-9 \\
\text { Steel }\end{array}$ & 18 & 175 & 28.6 & 10.8 & 10 & 10.5 \\
\hline $\begin{array}{l}\text { Stainless } \\
\text { Steel } 304\end{array}$ & $4^{18}$ & 154 & 60 & 5.4 & $42-40$ & 42 \\
\hline $\begin{array}{l}\text { Stainless } \\
\text { Steel } 304\end{array}$ & $4^{15}$ & 140 & 50 & 3.5 & 32 & 28 \\
\hline $\begin{array}{r}\text { Stainless } 21 \\
\text { Steel } 304\end{array}$ & 32 & 155 & 12 & 20 & $6-9$ & 6 \\
\hline
\end{tabular}

No calculations were attempted for the aluminum alloys since it was not possible to make a reasonable estimate for the temperaturevapor pressure relationship. Figures 41 and 42 show typical calculated vapor and surface tension pressures in the weld cavities for HY-180 and 20-6-9 steel alloys. 


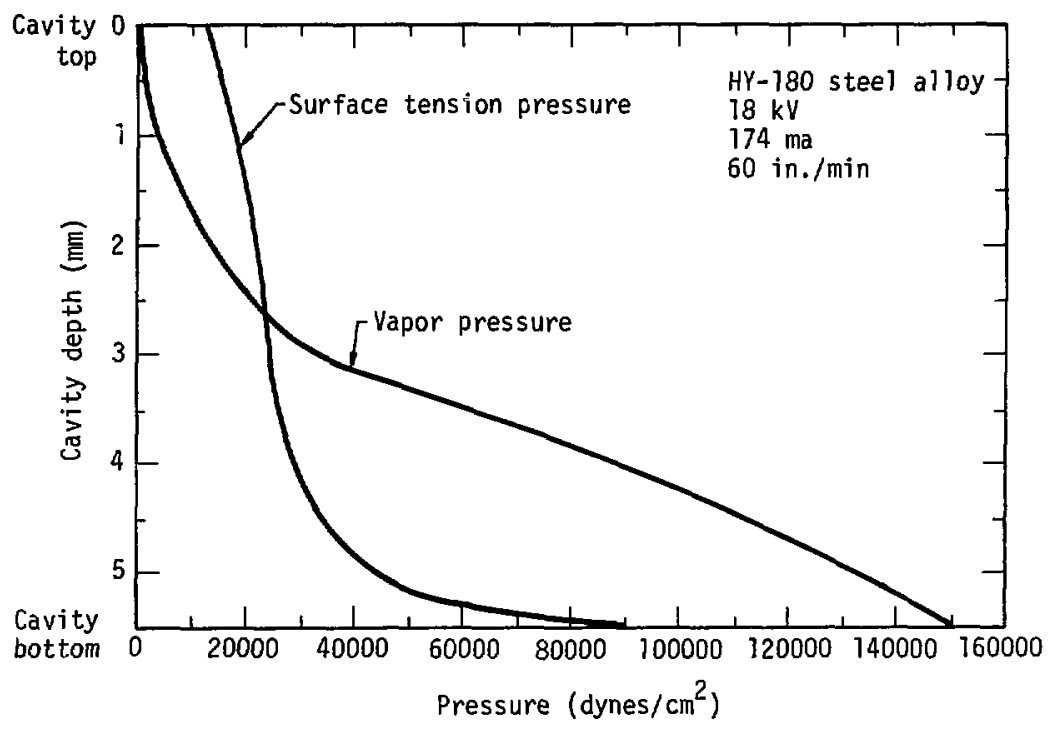

Figure 41. Calculated values of surface tension pressure and vapor pressure in a HY-180 steel alloy EB welding cavity as a function of cavity depth. 


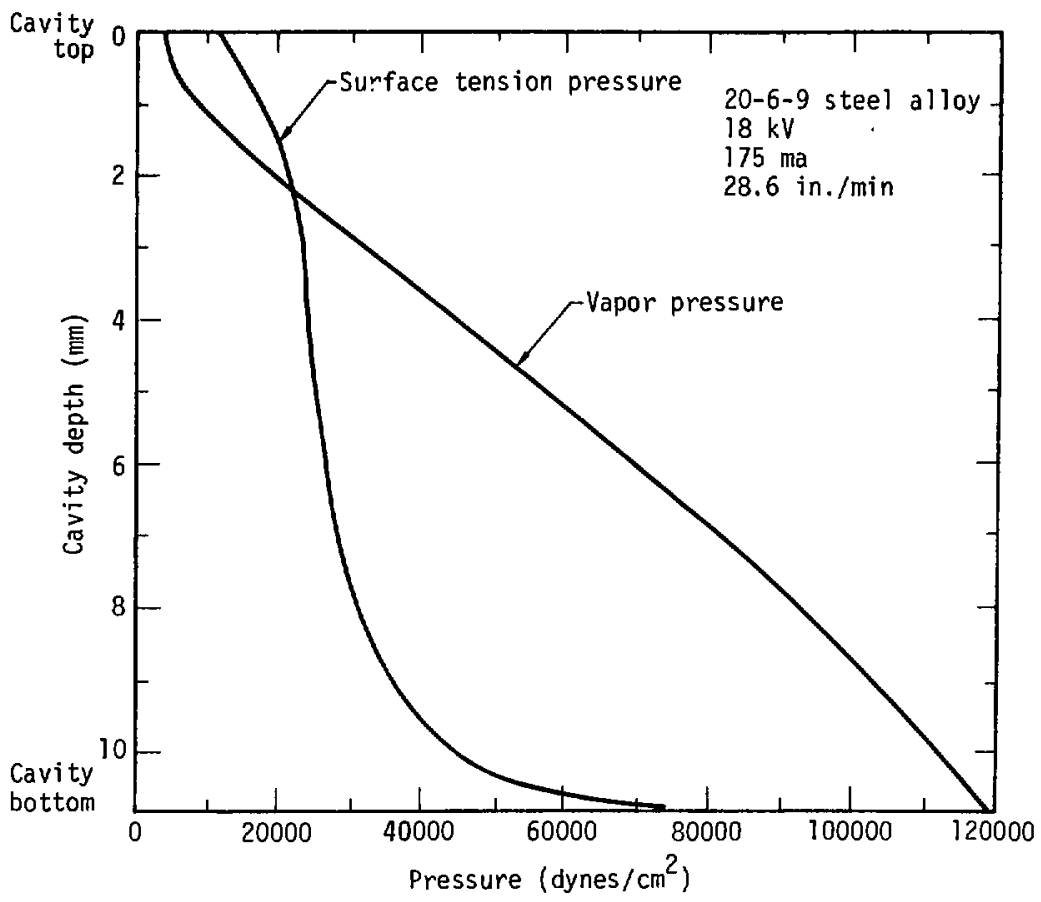

Figure 42. Calculated values of surface tension pressure and vapor pressure in a 20-6-9 steel alloy EB welding cavity as a function of cavity depth. 
FORMATION OF FREEZE RING PATTERN ON WELD BEAD SURFACE

Examination of the weld bead after completing a satisfactory weld reveals many small ripples on the weld surface. The frequency of these ripples can be determined by multiplying the number of ripples in $1 \mathrm{~cm}$ of weld length by the welding speed in $\mathrm{cm} / \mathrm{sec}$. The cavity osciliation frequency obtained from a calculation based on the dynamics at the cavity bottom, or from an examination of a center weld section along the length of the weld quite of ten does not agree with the ripple frequency. This suggests that the formation of the bead pattern is caused by an oscillation of the molten metal at the cavity top and is not necessarily identical to the root pattern.

The cause of the freeze ring patterns in the weld bead may be the result of an imbalance between the surface tension force acting at the cavity top and the vapor pressure. As the opening increases in diameter, the surface tension dominates and causes the hole size to decrease. Then the pressure buildup of the metal vapor in the cavity pushes the liquid back and causes a liquid wave to travel away from the cavity. This wave washes onto solidified metal, but as it travels outward over the solid area the surface tension acts to decelerate the liquid. As it is decelerated, it solidifies onto the solid material forming an overlapping bead pattern. These patterns are sometimes called freeze rings, ridges, or ripples.

The interaction between the surface tension and the vapor pressure at the cavity top was analyzed (see Appendix B). For a particular aluminum 1100 weld, if the cavity top opening is reduced from a diameter of 
$0.07 \mathrm{~cm}$ to $0.03 \mathrm{~cm}$ for $10 \mathrm{microseconds}$, the pressure buildup is twice as great as the existing cavity pressure. This is certainly great enough to quickly enlarge the opening. Since this pressure buildup will be rapid, it will probably act like an impulse on the liquid at the top of the cavity and drive it back towards the solidified weld bead region. As this happens, the mater zal ; ill wash onto the already solidified metal and a portion will freeze as the surface tension force acts to reverse it's flow direction. This repetative action could explail the freeze ring patterns. Approximating the cycle time to be twice the estimated time to close the cavity, or about $0.072 \mathrm{sec}$, the frequency is about 68 cycles per second compared to the experimentally determined frequency value of 71 . Calculated values of the frequency at the weld bead surface for several weld conditions are listed in Table 9 and show favorable agreement with the experimental vaics. Therefore, the freeze

Table 9. Comparison of estimated top we1d bead frequency with experimental value for several specified test welds.

\begin{tabular}{lccccc}
\hline Material & $\begin{array}{c}\text { Beam } \\
\text { Voltage } \\
\text { (kv) }\end{array}$ & $\begin{array}{c}\text { Beam } \\
\text { Current } \\
\text { (ma) }\end{array}$ & $\begin{array}{c}\text { We1d } \\
\text { Speed } \\
(\mathrm{cm} / \mathrm{sec})\end{array}$ & $\begin{array}{c}\text { Top We1d Bead Frequency } \\
\text { Experimental }\end{array}$ \\
\hline $1100 \mathrm{~A} 1$ & 15 & 140 & 2.54 & 71 & 68 \\
$1100 \mathrm{~A} 1$ & 17 & 210 & 0.61 & 21 & 14 \\
Tantalum & 17 & 240 & 0.89 & $45-62$ & 48 \\
304 Stainless & 18 & 154 & 2.54 & $127-178$ & 142 \\
$\quad$ Steel & & & & & \\
\hline
\end{tabular}


ring pattern could be associated with the cavity dynamics at the cavity top. It is also possible that natural wave motion is responsible for the freeze ring patterns. But it is not clear at this time what the actual mechanism might be. 


\section{DISCUSSION}

\section{INTERPRETATION OF THE ELECTRON BEAM WELDING PROCESS}

The temperature measurements and the analys is presented support the general concept of vapor pressure and surface tension interaction in the cavity for both pure metals and alloys. Now that the temperature has been measured, postulations as to what might be happening in the cavity can be better determined. Vapor pressure values can actually be estimated in the cavity as well as the magnitude of the surface tension constricting force based on the temperature measurements. For the first time a reasonably accurate assessment can be made of the forces acting on the cavity as a function of depth.

This work focused primarily on combining observations with physical descriptions to further the understanding of the process. Temperatures measured in the cavity and on the surrounding molten pool support the concept that the metal vapor pressure maintains an open cavity. The temperature on the molten pool surface at the top of the cavity is much lower than at the cavity bottom. The vapor pressure corresponding to the temperature at the top is very small and would result in no substantial metal movement caused by the vapor recoil force. However, at the cavity bottom, the corresponding vapor pressure at the liquid surface is quite sufficient to result in a significant vapor recoil force. The existence of this force has been verified experimentally. ${ }^{5}$ The action of this force can explain how the liquid gets pushed aside to expose fresh base metal and thus enable deep penetration. 
The measured temperature distributions in the cavity did not indicate the existence of a substantial temperature gradient from the front region to the rear. This tends to discount the importance of metal movement from the front to the rear of the cavity as a result of thermocapillary forces. ${ }^{14}$ Homogeneous mixing of the material can still be caused by material transfer from the cavity bottom to the top caused by the temperature gradient induced thermocapillary force.

Based on oscillations detected in the cavity with a piezoelectric sensing element it is believed that intensive vaporization takes place only at the weld root. ${ }^{15}$ The peak temperature measured at the cavity bottom of a pure aluminum weld and the corresponding high vapor pressure support this concept. Leskov et al. ${ }^{15}$ argued qualitatively that as the vapor jet moves upward it could interact with the molten metal in the pool to cause surface waves. The tops of the waves could be projected into the path of the beam, be intensely evaporated, and the resulting vapor recoil force could push the liquid towards the cavity bottom. Examination of $x$-ray photography revealed the EB electrons collide with the material in regions along the cavity wal1.9,10,11,12 The beam is observed to strike material at various locations suggesting that some liquid material has been forced into the EB path. The above arguments are very similar to the oscillation analysis presented in this research.

Arata et a1. 11 observed that spiking could be suppressed by inserting an alloy foil containing a highly volatile element into the upper portions of the weld joint. Placing the foil at the bottom of the joint had no effect on the spiking. The analysis presented herein can 
explain the above results. Locating the volatile element in the upper cavity portion maintains a very high vapor pressure in the region where nomally a cavity force imbalance would develop. The excessive vapor pressure released upon welding maintains an excess over the surface tension constriction force and prevents the formation of a periodic cavity oscillation since there is no tendency for material to be inserted into the path of the beam. However, placing the foil near the cavity bottom does not prevent the force imbalance from forming in the upper cavity region. The surface tension pressure excess over the local vapor pressure causes liquid metal to be projected into the beam, its surface to be intensely evaporated, and then be driven towards the bottom. This action results in development of a periodic oscillation and does nothing to suppress spiking.

The cavity force imbalance presented and the subsequent proposed metal movement in the cavity also provide an explanation for the-development of weld defects such as voids, porosity or cold shuts. As the liquid metal projection at the force imbalance location is driven towards the cavity bottom, it is possible that molten metal on the underside of the projection may solidify before partially filling the bottom resulting in a void. It is also possible that a larger chunk of solidified metal does not fuse to the sides of the hole and causes a cold shut.

The magnitude of the hydrostatic head force when compared to either the force due to vapor pressure or surface tension has little influence as far as closure of the cavity is concerned. Paton ${ }^{37}$ demonstrated this by performing welds in which the gravitational force acted in a direction perpendicular, parallel, and opposite the penetration direction. Very little difference wäs observed between the resulting 
Welds except when the penetration depth was very large. For this situation, there was a tendency for some of the liquid to flow out of the cavity when performing a deep penetration upside down weld.

PROPOSED DYNAMIC EB WELDING MODEL

On the bisis of the foregoing discussion, the following model has been developed to describe the electron beam weld process. The temperature measurements support the concept that at the bottom of the cavity the temperature is higher than at the top. The resulting high temperatures at the cavity bottom allow sufficient vapor pressure to develop such that the cavicy cannot completely collapse. Proceeding up the cavity wall the temperature decrease causes a pressure drop and a decrease in the surface tension force. However, the decrease of the vapor pressure is much more rapid because of its strong dependence on temperature. At a position located on the cavity wall somewhere between the top and bottom of the cavity, the surface tension constricting force becomes larger than the force due to the local vapor pressure from the evaporation of liquid metal. Above this position, the surface tension force is greater than the vapor pressure force and causes some molten liquid to move inwards slightly. Because of the lower vapor pressure force, this liquid tends to flow downwards along the cavity wall until it reaches the region of the force imbalance. At this location the vapor pressure force is overpowering and the liquid is forced to move toward the cavity center resulting in the formation of a liquid projection. This liquid projection moves directly into the path of the EB. The EB then heats the surface of the liquid projection to a very high tempera- 
ture. This results in intense evaporation of the surface and causes the liquid projection to be pushed towards the cavity bottom by the vapor recoil force. Also, the projection will fall since the surface tension will be reduced on the upper surface of the projection due to the higher temperature compared to the underside. This action partially fills the cavity bottom with liquid metal. Next the EB penetrates through this layer of very hot liquid metal to achieve maximum penetration. It has been proposed that this repetitive behavior is related to the oscillation frequency observed in EB weld sections. Oscillation frequencies calculated based on a model of the above behavior agree well with measured values.

Additional analyses based on the observation of photographic movies of the EB weld process and dynamic considerations from the force imbalance at the cavity top, suggest that the freezing rings associated with the EB welding are a result of a periodic semiclosing of the cavity at the upper portion of the cavity. This periodic behavior at the top of the cavity is one in which the surface tension imbalance force tries to close the cavity. This pulls metal in the upper regions of the cavity towards the cavity center and decreases the size of the opening through which both the EB enters and the evaporated metal vapors escape. If the top diameter gets reduced to a value approximately one-half of that which is associated with intense evaporation at the cavity bottom, then there is an almost instantaneous pressure buildup which forces the liquid at the cavity top to move away from the center towards the solidified weld bead region. This action pushes a liquid wave orto the solidified metal behind the cavity. As this mate- 
rial. is moving away from the cavity, a deceleration force due to surface tension tends to decrease the liquid velocity. As the liquid is slowed down and then accelerated towards the cavity again, some of the metal solidifies on the weld bead. This action forms a weld bead that has a series of ridges referred to as weld rings. It has been shown that from the dynamics of this type of behavior one can calculate a frequency that agrees with the actual measured freeze ring frequency.

\section{PREDICTION OF SPIKING TENDENCY}

Gne of the major problems associated with EB welding is the tendency for spiking to occur. A correct model should be capabile of indicating whether this will happen. In this section, the application of the information obtained in this study for the development of a procedure for predicting spiking tendency will be presented. A stability parameiter is defined that provides a means of evaluating whether a specified set of weld parameters will produce spiking and provides a qualitative measure of the spiking magnitude. This is based on an important characteristic of the measured temperature distribution, which will be described first.

Dimensionless Temperature Profile. Many cavity temperature measurements were obtained during the course of this investigation. After preparing plots of these temperatures versus cavity position, the following observation was noted. The temperatures at the bottom of a shallow cavity decreased more rapidly than those at the bottom of a deep cavity. In other worc's, the temperature along the walls of a deep cavity remained at a level cluser to the peak temperature than those in 
a shallow cavity of the same material. An attempt was made to generalize this information in the form of dimensionless temperature and cavity location. The following two relations were defined to represent these dimensionless values. The dimensionless cavity location parameter is

$$
\alpha=\left(1-\frac{x}{h}\right)
$$

where $x$ is measured from the cavity top towards tha bottom, and $h$ is the penetration depth. The dimensionless cavity temperature variable is,

$$
\theta=\frac{T_{B}-T(x)}{T_{B}-T_{T}}
$$

where $T_{T}$ and $T_{B}$ are the temperatures at the cavity top and bottom respectively, and $T(x)$ is the temperature at location $x$. Some representative temperature profiles are shown in Figure 43 in terms of these parameters.

Observation of the dimensionless data suggest that, as the penetration depth increases, there is a definite change in the shape of the temperature profile. Looking at the profiles for the steels in particular, the shape changes from concave upwards to concave downwards with increasing weld penetration. Although not as dramatic, the aluminum group displays the same behavior as penetration depth increases. Because of the consistency of this observed trend, an attempt was made to fit a simple functional form to the data. This would allow temperature profiles to be estimated for any test material. The following points were considered during the development of this function: 


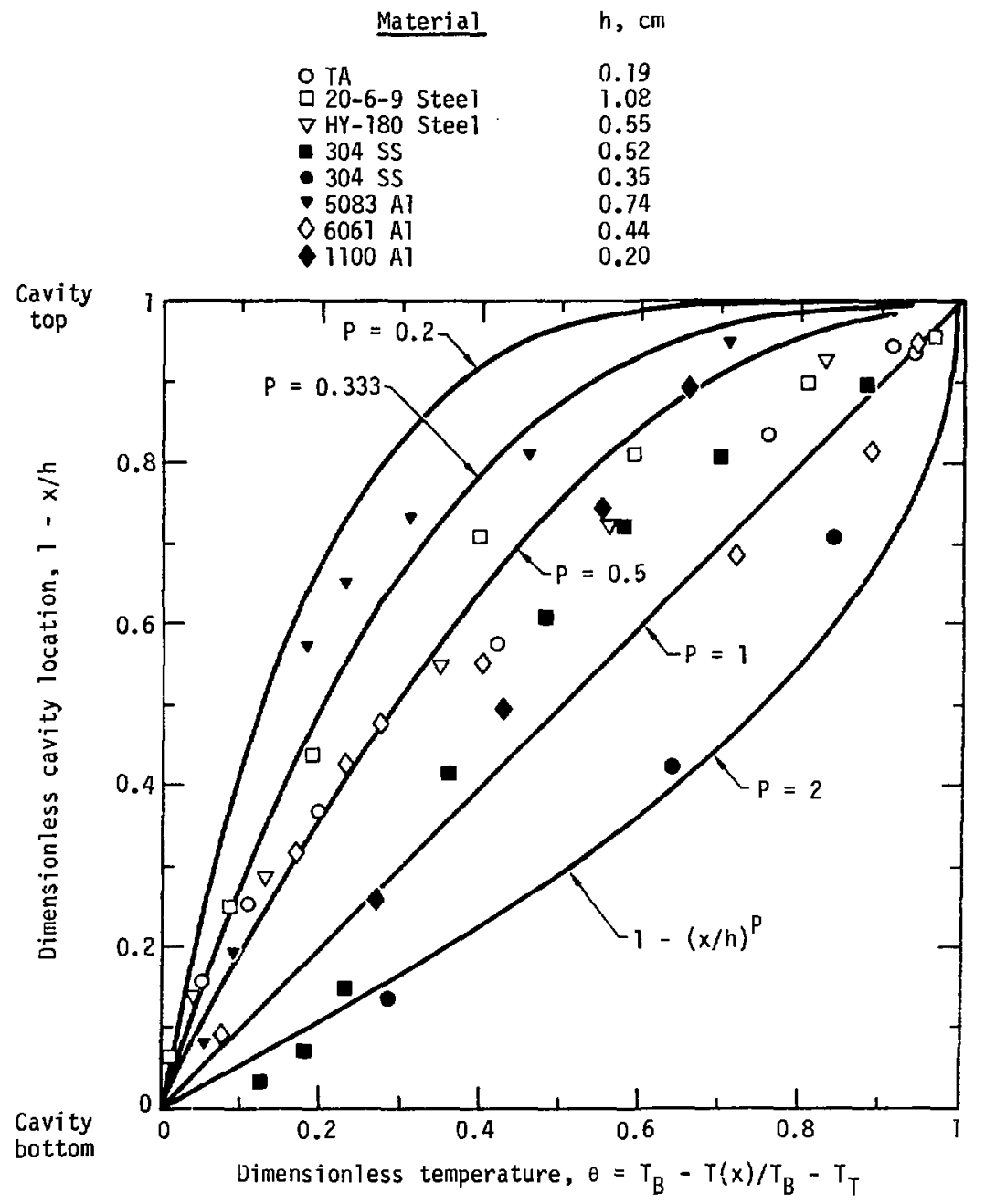

Figure 43. Experimental dimensionless temperature profiles and proposed dimensionless temperature function. 
1. The function should be dependent on penetration depth.

2. The function may be material dependent.

3. The function may be dependent on the particular EB welder used.

of the many functions that could be selected to represent the experimental data, the following expression was chosen:

$$
\theta=1-\left(\frac{x}{h}\right)^{p}
$$

where $P$ is the power to which the dimensionless cavity location, $x / h$, is raised. In the process of determining which value of the exponent, $P$, best represented the experimental data, it was discovered that $P$ could be represented as the following ratio:

$$
P=\frac{c}{h}
$$

In this simple form, $c$ represents the penetration depth at which the weld root area starts to change from a relatively smooth 1 ine to a more wavy line. This interpretation has physical significance and allows the function, Eq. (38), to be both material and machine dependent, as well as dependent on penetration depth. The final form that was used to represent the experimental dimensionless temperature profiles was therefore

$$
\theta=1-\left(\frac{x}{h}\right)^{[c / h]}
$$

Table 10 lists recommended values to use for the materials considered in this study. Using Eq. (40), it is possible to generate representative temperature profiles in aluminum, steel, or tantalum weld cavities for a variety of weld penetration depths. 
Table 10. Value of $c$ to use in Eq. (40)

for materials investigated.

\begin{tabular}{ll}
\hline Material & $\mathrm{c}, \mathrm{cm}$ \\
\hline Aluminum & 0.35 \\
Steels & 0.50 \\
Tantal. & 0.15 \\
\hline
\end{tabular}

The two dominating forces in the weld cavity result from the local liquid metal vapor pressure and the surface tension pressure. For all of the materials investigated (except the aluminum alloys) it was possible to calculate representative values for these pressures at the cavity bottom using the approach presented in the Analysis Section. A comparison between the two pressures over an extensive range of weld parameters indicated that the vapor pressure is slightly in excess of the surface tension pressure (Appendix C). This observation allows a procedure whereby the vapor pressure-temperature relationship can be approximated for an alloy containing a highly volatile element. Appendix $C$ demonstrates the procedure for 7075 aluminum which contains the volatile element zinc. The definjtion of the alloy vapor pressure-temperature data allows the vapor pressure dependence to be estimated in the cavity.

Stability Parameter. Some investigators ${ }^{9,10}$ have suggested that spiking is associated with the near closure (at the cavity top) of a stable cavity. The spike occurs when the cavity remains in a stable configuration for an extended period such that the beam continues to penetrate deeper with no interruptions. Normally, the beam is thought 
to be interrupted at regular intervals by the liquid material in the cavity region. It is logical to assume that these interruptions may occur at the location of the force imbalance between the vapor pressure and surface tension (Analysis Section). If this happens, it could be argued that when the imbalance location is near the cavity bottom, the magnitude of a potential spike is very small since the cavity shape with the projected liquid is essentially identical to the "stable" cavity shape. In other words, the imbalance height is small relative to the depth of penetration, $h$. However, if the imbalance is iocated near the top of the cavity, the shape of the cavity containing the liquid material projection will be greatly different than the stable cavity shape (i.e., the projection will fill more of the cavity crosssection). It is possible that a spike of large magnitude could develop under these conditions.

The above reasoning suggests that the ratio of the imbalance location height to the penetration depth may be an important parameter. When this ratio is small, the magnitude of spiking is also small and a stable weld should result. However, when the ratio is extremely large, say near 1.0, then large spikes or an unstable weld may be the result. Hence it is proposed to call this ratio, $S$, the stability parameter.

$$
S=\frac{H}{h}
$$

The experimental data shown in Table 11 covers a large range of weld conditions. The procedure indicated in the Analysis Section was used to determine the value of $\mathrm{H}$, the force imbalance location, for at least one weld condition for each material welded except for the aluminum alloys. Concentrating only on the last two columns, when $S$ is 0.3 or 
Table 11. Experimentally determined stability parameter, $\mathrm{S}$.

\begin{tabular}{|c|c|c|c|c|c|c|c|}
\hline Material & $E, k v$ & 1, ma & $\mathrm{U}, \mathrm{cm} / \mathrm{sec}$ & $\mathrm{H}, \mathrm{cm}$ & $h, c m$ & $S=\frac{H}{h}$ & $\begin{array}{l}\text { Comments } \\
\text { on weld } \\
\text { root area }\end{array}$ \\
\hline $1100 \mathrm{Al}$ & 12.9 & 152 & 0.44 & 0.05 & 0.20 & 0.25 & $\begin{array}{l}\text { Smooth-no } \\
\text { spiking }\end{array}$ \\
\hline $1100 \mathrm{~A} 7^{21}$ & 31 & 140 & 0.80 & 0.50 & 2.00 & 0.25 & No spiking \\
\hline Tantalum & 17 & 240 & 0.89 & 0.08 & 0.19 & 0.27 & No spiking \\
\hline 55304 & 15 & 140 & 2.11 & 0.095 & 0.35 & 0.27 & No spiking \\
\hline SS 304 & 18 & 168 & 2.54 & 0.16 & 0.52 & 0.31 & No spiking \\
\hline SS $304^{21}$ & 32 & 155 & 0.5 & 1.2 & 2. & 0.60 & $\begin{array}{l}\text { Some spik- } \\
\text { ing }\end{array}$ \\
\hline $\begin{array}{l}20-6-9 \\
\text { Steel }\end{array}$ & 18 & 175 & 1.21 & 0.87 & 1.076 & 0.81 & $\begin{array}{l}\text { Spiking- } \\
\text { large }\end{array}$ \\
\hline $\begin{array}{l}20-6-9 \\
\text { Steel }\end{array}$ & 15 & 135 & 1.1 & 0.6 & 0.7 & 0.86 & $\begin{array}{l}\text { Spiking- } \\
\text { large }\end{array}$ \\
\hline $\begin{array}{l}\text { HY- } 180 \\
\text { Stee? }\end{array}$ & 18 & 174 & 2.54 & 0.28 & 0.55 & 0.51 & $\begin{array}{l}\text { Some spik- } \\
\text { ing }\end{array}$ \\
\hline
\end{tabular}

less note that no spiking results. When $S$ is in the vicinity of 0.5 , some spiking is evident. However, when $S$ is 0.8 , spiking is very severe and results in an unacceptable weld. It is, therefore, proposed that spiking will not be a problem for welds having a value of $S$ less than 0.5 ; and, consequently, when $S$ is greater than 0.5 the weid may be expected to exhibit unacceptable spiking.

The observed difference in the temperature distribution as a function of weld depth combined with experimental correlation of detrimental spiking with a large value of $S$ led to the possibility of predicting when spiking may be unacceptable. Estinating a weld depth using the 
procedure indicated by Tong and Geidt ${ }^{18}$ for a given set of weld parameters allows the cavity temperature distribution to be determined. Once the temperature is known, the cavity forces can be calculated and the location of the force imbalance in the cavity can be obtained. Finally, the stability parameter can then be estimated for this particular weld condition. Briefly, the procedure consists of the following steps.

1. Determine the penetration depth (Appendix D, Figure D-2).

2. Determine the cavity temperature from the dimensionless cavity temperature expression (Eq. 40).

3. Approximate the cavity shape to that of a cone with a spherical bottom.

4. Determine the surface tension pressure variation in the cavity as indicated in the Analysis Section.

5. Determine the vapor pressure variation in the cavity as indicated in the Analysis Section. If necessary, estimate the vapor pressure-temperature relationship as indicated in Appen$\operatorname{dix} C$.

6. Determine the imbalance location, $H$, as indicated in the Analysis Section.

7. Calculate the stability parameter, S.

This general method was used to calculate the stability parameter for a variety of weld parameters for several of the materials used in this study and one material, uranium, from the literature. The results of these calculations are to be found in Appendix $D$, the stability parameter is shown in Figure 44 . The stability parameter was calculated for the welds in this study for which the weld root region could be observed 


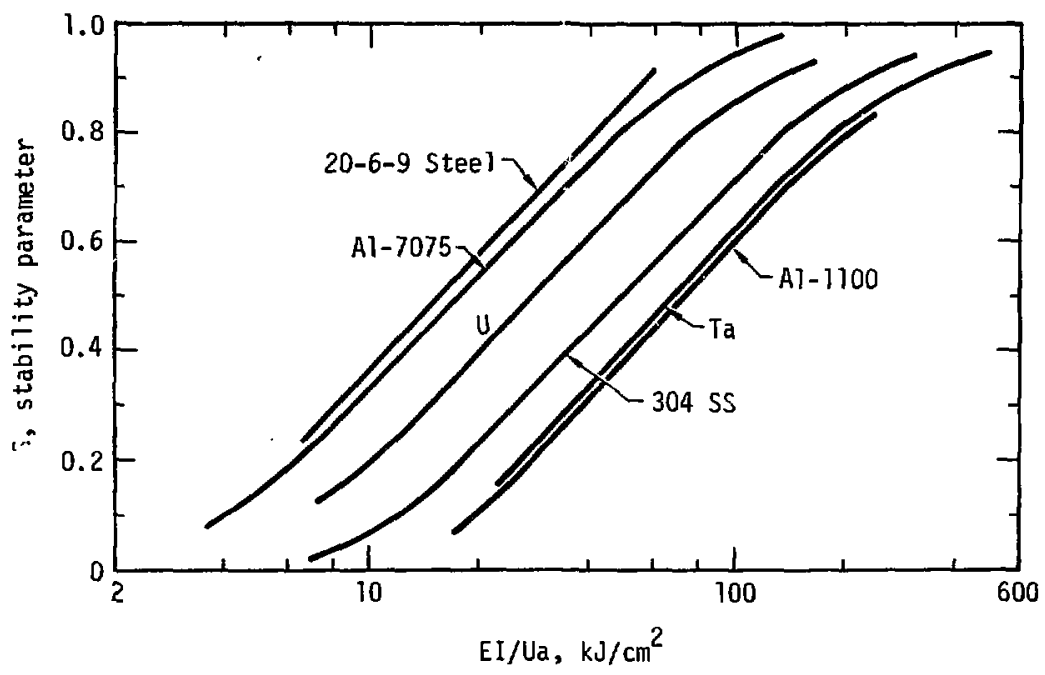

Figure 44. Stability parameter. 
from a post-weld macrosection. In all cases, the stability parameter, as determined using the above described general method, was greater than 0.5 for welds exhibiting unacceptable spiking and less than 0.5 for those welds with little or no spiking.

It is possible to determine whether a selected set of weld parameters may result in a weld with excessive spiking. Firsi, the penetration depth and beam power are specified, ther the product Ua can be determined. Next, the ratio EI/Ua is computed and the corresponding value for the stability parameter is determined from Figure 44 . If $S$ is greater than 0.5 spiking becomes more of a problem that if it is less than 0.5. After a few simple iterations, a set of weld parameters can be chosen that will result in a weld with a low probability of severe spiking. All of this can be done without performing a single test weld. 


\section{CONCLUSIONS}

1. For a specific material the peak cavity temperature is not dependent on weld penetration. This means that for various electron beam power settings or welding speed there is no measurable change in the peak cavity temperature for a specific material.

2. Comparison of temperature recordings with weld root sections indicated no correlation between spiking conditions and measured temperature level.

3. The strong variation of temperature from cavity top to bottom suggests that the vapor pressure will be greatest at the cavity bottom, and negligible near or at the cavity top.

4. Temperature measurements or the cavity after repeated weld passes indicate that when very small amounts of highily volatile elements are evaporated there is a substantial increase in temperature. This explains why the amount of volatile elements in an alloy can have a dramatic effect on ine behavior of the cavity during welding.

5. Utilizing the cavity temperature measurements in the analysis of the forces acting in the cavity indicated that a force imbalance occurs between the vapor pressure and surface energy forces along the cavity wall. It was postulated that at the imbalance location a liquid material projection is driven towards the cavity bottom. This action partially fills the cavity and is followed by the beam boring a hole in this molten liquid. These oscillations provide an explanation for the alternate partial filling and reforming of the cavity. Calculated oscillation frequencies agree favorably with experimentally determined frequencies. 
6. Cavity oscillations also appear at the cavity top but are not necessarily related to the oscillations at the cavity bottom. The oscillations at the top result in the freezing patterns on the weld bead surface. Calculated top oscillation frequencies agree well with those determined experimentally.

7. The measured temperature distributions were observed to exhibit a characteristic behavior as a function of weld depth. An expression is proposed for representing the temperature in the cavity as a function of the weld penetration depth. This dimensionless expression is also material dependent.

8. The cavity location at which the force imbalance occurred was shown to be related to the spiking tendency. A general method was presented that enabies the stability parameter to be calculated for numerous choices of weld parameters. This allows a determination to be made as to whether a set of weld parameters may lead to a condition exhibiting severe spiking.

\section{RECOMMENDATIONS}

1. Further investigation is required on the effect of volatile elements in alloys.

2. Temperature measurements should be obtained on these same materials on a higher voltage welder. It is possible that the maximum temperature level as well as the temperature distributions may also be machine dependent.

3. Emissivity measurements of liquid metals at temperatures well above melt are needed to increase the accuracy of the temperature measurements. 
4. The concept of the stability parameter should be pursued for additional materials. Also, welds performed on other welders should be analyzed to determine if machine differences are significant. 


\section{REFERENCES}

1. Schwartz, H., "Mechanics of High-Power-Density Electron Beam Penetration," 3. Applied Physics, Vo1. 37, (7), 1964, p. 2020.

2. Wells, 0. C., and Everhart, T. E., "A Note on the PhysicaT Principles Underlying the Formation of the Cavity in Electron Beam Welding," Fourth Annual Meeting Electron Beam Technology, Bakish, R. (ed.), pp. 105-122, March 1962.

3. Armstrong, R. E., "Control of Spiking in Partial Penetration Electron Bealn Welds," Welding Lournal, Vol. 49, (8), 1970.

4. Tong, H., Giedt, W. H., and Hong, Z., "Effects of Electrode Alignment of a Piece Type Gun on Beam Current Density Distribution," Fifth International Conference, Electron and Ion Beam Science and Technology, 1972, p. 321.

5. Hashimoto, T., and Matsuda, F., "Penetration Mechanism of WeTd Beads in Electron-Beam Welding - Studies on EB Weldings No. 6," Transactions of National Research Institute for Metals, Vol. 7, (5), 1965.

6. Tong, H., and Giedt, W. H., "Radiographs of the Electron Beam Welding Cavity," Review of Scientific Instruments, Vol. 40, (10), 1965.

7. Tong, H., and Giedt, W. H., "Interpretation of the Observed Oscillation of Electron Beam Welding Cavity, "Fourth International Conference Electron and Ion Beam, Science and Technology, 1970 , p. 148. 
8. Tong, H. and Gjedt, W. H., "A Dynamic Interpretation of Electron Beam," Welding Journal Research Supplement, June 1970.

9. Mara, G. L., "A Study of the Penetration Mechanism of Electron Beam Welding and the Spiking Phenomenon," Masters Thesis, Ohio State University, 1971.

10. Weber, C. M., "Direct Observation of the Penetration Mechanism of Partial Peneiration Electron Beam Welding, Fifth International Conference, Electron and Ion Beam Science and Technology, 1972, p. 307.

11. Arata, Y., Abe, E., and Fujisawa, M., "A Study on Dynamic Behaviors of Electron Beam Welding (Report I) - The Observation by a Fluoroscopic Method," Iransactions of JWRI, Vol. 5, (1), 1976.

12. Kennish, W. J., "Radiographic Study of Cavity Fluctuation, Interagency Mechanical Operations Group, Vol. 11, Electron Beam Welding Research, Jan. 1972, Report No. SC-DR-72-0637, Sandia Labs, Livermore, CA.

13. Ryzhkov, F. N., and Bashkatov, A. V., "Mechanism of Formation of Electron-Beam Welds," Welding Production, Vol. 19, (5), 1972.

14. 01 'Shanskii, N. A., et al., "Movement of Molten Metal During Electron-Beam Welding," Welding Production, Vol. 21, (9), 1974 .

15. Leskov, V. I., Trunov, E. N., and Zhivada, L. I., "Mechanism in Deep Weld Pools During Electron-Beam Welding," Automatic Welding, Vo1. 28, (1), 1975. 
16. Lupin, B. T., "A Correlation of Electron-Beam Welding Parameters," ASME Paper 66-WA/MËT-18.

17. Hashimoto, T. and Matsuda, F., "An Equation for Calculating Optimum Welding Conditions in Electron-Beam Welding," Transactions of National Research Institute for Metals, Vol. 9, (1), Japan, 1967.

18. Tong, H. and Giedt, W. H., "Depth of Penetration During Electron Beam Welding," Journal of Heat Transfer, Trans. ASME, Ser. C. Vol. 93, (2), 1971.

19. Langmuir, I., "The Vapor Pressure of Metal1 ic Tungsten," Physical Review, Vol. 2, (5), 1913.

20. Tong, H., "Heat Transfer and Cavity Penetration During ElectronBeam Welding," Ph.D. Dissertation, University of California, Dept. of Mechanical Engineering, Davis, California, Report No. 69-14, June 1, 1969.

21. Shintaku, S. M., "Temperature Distributions in Electron-Beam Welding Cavities," University of California, Dept. of Mechanical Engineering, Davis, California, Report No. 76-10, July 15, 1976.

22. Bonne11, D. W., Treverton, J. A., Valerga, A. J., and Margrone, J. L., "The Emissivities of Liquid Metals at Their Fusion Temperatures," Rice University, Houston, Texas, Dept. of Chemistry, Report NASA-CR-133521, 1971.

23. Weast, R. C., Handbook of Chemistry and Physics, 54th Edition, CRC Press, Cleveland, Onio, 1973. 
24. Touloukian, Y. S. (Ed.), Thermophysical Properties of High Temperature Solid Materials, MacMillan Co., New York, 1967.

25. Siegel, R., and Howe11, J. R., Thermal Radiation Heat Transfer, McGraw-Hi1l, ilew York, 1972.

26. Sparrow, E. M., and Cess, R. D., Radiation Heat Transfer, Brooks/ Cole Publishing Co., Eeïmont, California, 1966.

27. Sadykov, B. S., "Temperature Dependence of the Radiation Power of Metals," High Temperature, Vol. 3, (3), 1965, pp. 389394.

28. Lin, S. H., and Sparrow, E. M., "Radiant Interchange Among Curved Specularly Reflecting Surfaces - Application to Cylindrical and Conical Cavities," J. of Heat Transfer, C 87, 1965, pp. 299-307.

29. Honig, R. E., "Vapor Pressure Data for the Solid and Liquid Elements," RCA Review, Vol. 23, December 1962, pp. 567-586. 30. 01 'Shanskij, N. A., et al., "The Electron-Beam Welding of Thick Metals Using Low Voltage Beams," Automatic Welding, Vo]. 25, (11), 1972.

31. Santala, T., and Adams, C. M., Jr., "Kinetics and Themodynamics in Cortinuous Electron-Beam Evaporation of Binary Alloys," J. of Vacuum Science and Technology, Vol. 7, (6), 1970.

32. Foster, J. S., and Pfeifer, W. H., "Vacuum Deposition of Alloys Theoretical and Practical Considerations," J. of Vacuum Science and Technology, Vol. 9, (6), 1972. 
33. Andreini, R. J., and Foster, J. S., "Kinetics of Solute Removal During Electron-Beam and Vacuum-Arc Melting," $\underline{\mathrm{J}}$. of Vacuum Science and Technology, Vol. 11, (6), 1974.

34. Wilson, J. R., "The Structure of Liquid Metals and Alloys," Metallurgical Reviews, Vol. 10, (40), 1965.

35. Bunshah, R. F., "High-Rate Evaporational Depositioni Processes of Metals, Alloys, and Ceramics for Vacuum Metallurgical Applications," J. of Vacuum Science and Technology, Vol. 11, (4), 1974.

36. Stowe11, W. R., "Single Source Evaporation of a Niobium Based

Alloy Containing Volatile Constituents," $\mathrm{J}$. of Vacuum

Science and Technology, Vol. 10, (4), 1973.

37. Paton, B. E., et al., "Electron-Beam Welding in Different Welding Positions," Automatic Welding, Vol. 25, (6), 1972.

38. Shapiro, A. H., Dynamics and Thermodynamics of Compressible Fluid Flow, Ronald Press Co., New York, 1953. 
APPENDIX A

\section{Reflected Radiation Entering Probe from Other Cavity Surface Elements}

The pyrometer used measures all of the radiation leaving the target area. This is the sum of the emitted and reflected radiation. For radiation measurements in a conical cavity the magnitude of the reflected radiation must be determined, and if significant, the appropriate correction to the measured reading must be made.

The radiation, $q_{R}$, leaving an arbitrary location, $d A_{i}$, on the cavity wall can be represented as the sum of the emitted and reflected radiation. Referring to Figure $A-1$, radiation coming into surface $d A_{i}$ by reflection from surface $A_{S}$, is equal to $q_{I N, S}$ multiplied by the surface reflectivity, $\rho$. Equation $(A-1)$ defines the local heat flux leaving $\mathrm{d} A_{j}$ per unit time and per unit of $\mathrm{d} A_{i}$ as

$$
\begin{aligned}
& q_{R}=\varepsilon \sigma T^{4}+\rho q_{I N, S} \\
& q_{R}=\varepsilon \sigma T^{4}+(1-\varepsilon) q_{I N, S}
\end{aligned}
$$

The fraction of the emitted radiation from $\mathrm{d} A_{i}$ that reaches $\mathrm{d} A_{j}$ both directly and by specular interreflection defines the exchange factor, ${ }^{28} d E_{d A_{i}-d A_{j}}$, as

$$
d E_{d A_{i}-d A_{j}}=f_{1}+\rho f_{2}+\rho^{2} f_{3}+\ldots=\sum_{r=1}^{\infty} \rho^{n-1} f_{n}
$$

where $f_{n}$ is the diffuse angle factor. The radiation arriving at $d A_{i}$ by reflection from all elements $d A_{j}$ is, 


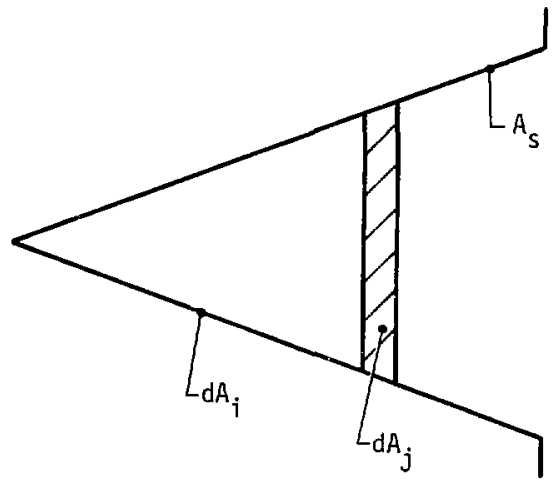

Figure A-1. Area definitions in concial cavity. 


$$
\varepsilon \sigma T^{4} \frac{d A_{j}}{d A_{i}} d E_{d A_{j}}-d A_{i}
$$

Usinc reciprocity, $d A_{j} d E_{d A_{j}-d A_{i}}=d A_{i} d E_{d A_{j}-d A_{j}}$, the incoming energy to $\mathrm{dA}_{i}$ by reflection and direct radiation from other elements on the cone surface is, ${ }^{28}$

$$
q_{i N, S}=\int_{A_{j}} \varepsilon \sigma T^{4} d E_{d A_{i}-d A_{j}}
$$

or

$$
q_{I N, S}=\varepsilon \sigma T^{4} E_{d A_{i}-A_{S}}
$$

where $E_{d A_{i}-A_{s}}$ is the fraction of energy emitted from $d A_{i}$ per unit of $d A_{i}$ that reaches the cone surface area, $A_{S}$. Substituting Eq. $(A-4)$ into Eq. (A-1) gives the local heat flux leaving $d A_{i}$ (per unit of $d A_{j}$ ) by emission and reflection as,

$$
a_{R}=\varepsilon \sigma T^{4}+(1-\varepsilon) \varepsilon \sigma T^{4} E_{d A_{i}-A_{s}}
$$

In terms of the local heat flux, $q_{R}$, the intensity of radiation leaving $d A_{i}$ in the direction of the probe is,

$$
i=\frac{q_{R}}{\pi}\left(d A_{i} \sin \beta\right) d \omega
$$

where dw is the solid angle subtended by the probe.

Equ ting the above radiation intensity leaving $d A_{i}$ to that entering the prose area, $d A_{p}$, by emission at the cavity temperature with an apparent emissivity, $\varepsilon_{a}$, gives

$$
\left(\frac{E_{2} \sigma T^{4}}{\pi}\right) \sin B d A_{i} d \omega=\frac{q_{R}}{\pi} d A_{i} \sin \beta d \omega
$$


The cavity geometry is defined in Figure $A-2$. Substituting Eq. (A-5) for $q_{R}$ into the above expression, and solving for $\varepsilon_{a}$, results in,

$$
\varepsilon_{a}=\varepsilon+(1-\varepsilon) \varepsilon E_{d A_{i}}-A_{s}
$$

To estimate $\varepsilon_{a}$, a value must be determined for $E_{d A_{j}-A_{s}}$ for typical measurement geometries. A value for $E_{d A_{i}}-A_{s}$ colild be calculated lising the equation given by $L$ in and Sparrow, ${ }^{28}$ but the evaluation is very unwieldy. It is easier to use the appropriate figures presented in the reference and the following relationship to solve for $E_{d A_{i}}-A_{S}$.

$$
\frac{q}{\sigma T^{4}}=\varepsilon-\varepsilon^{2} E_{d A_{i}-A_{s}}
$$

For a specific cone angle, $\theta$, axial location, $z$, and surface emissivity, the reference figures give a value for the left-most term in Eq. (A-9). This allows solution for $E_{d A_{j}-A_{s}}$ by use of $E q .(A-9)$. The above calculation sequence was performed for representative test configureations to arrive at the data compiled in Table A-1 for specular or diffuse radiation.

The target spot is approximately 0.020 inch in diameter and the cavity sizes for a conical cavity varied as shown in Table A-2. A shallow cavity typically had a cone angle of $45^{\circ}$, while a deep cavity had a cone angle of $10^{\circ}$ of less. Values for $E_{d A_{i}}-A_{s}$ from Table $A-1$ were substituted into Eq. $(A-B)$ and values of $\varepsilon_{a}$ were calculated and tabulated in Tabie A-3.

The increase in emissivity due to the interreflections from a deep cavity surface with $\varepsilon=0.5$ is 35 to $80 \%$. Because of the $45^{\circ}$ viewing angle of the probe relative to the work piece surface, it was not possible to view the cavity bottom of a deep weld. For a 


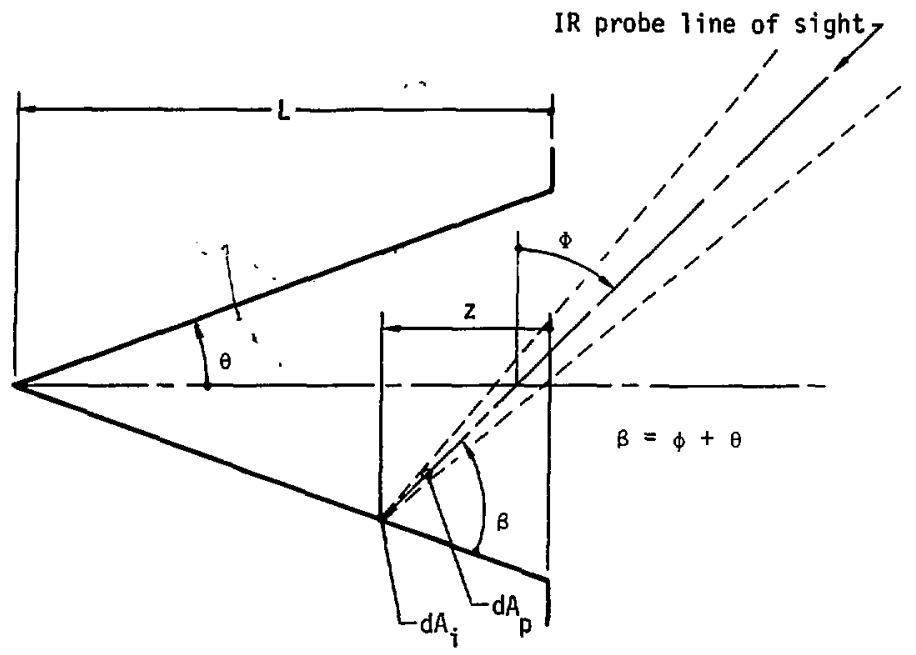

Figure A-2. Cavity representation showing relation between IR probe line of signt and cavity geometry. 
Tále A-1. Values of $E_{d A_{i}-A_{5}}$ for various typ:cal measurement parameters.

\begin{tabular}{|c|c|c|c|c|}
\hline$\varepsilon$ & $\theta$ & $z / L$ & E-Specular & E-Diffuse \\
\hline 0.1 & $10^{\circ}$ & 0.1 & 4.2 & 8.5 \\
\hline 0.1 & $10^{\circ}$ & 0.5 & 3.2 & 5.7 \\
\hline 0.1 & $10^{\circ}$ & 1.0 & 1.5 & 1.5 \\
\hline 0.5 & $10^{\circ}$ & 0.1 & 1.8 & 2.0 \\
\hline 0.5 & $10^{\circ}$ & 0.5 & 1.6 & 1.8 \\
\hline 0.5 & $10^{\circ}$ & 1.0 & 0.7 & 0.7 \\
\hline 0.1 & $20^{\circ}$ & 0.1 & 2.2 & 5.0 \\
\hline 0.1 & & 0.5 & 1.5 & 2.5 \\
\hline 0.1 & & 1.0 & 0.8 & 0.8 \\
\hline 0.5 & & 0.1 & 1.4 & 1.8 \\
\hline 0.5 & $\downarrow$ & 0.5 & 1.1 & 1.3 \\
\hline 0.5 & $20^{\circ}$ & 1.0 & 0.5 & 0.5 \\
\hline 0.1 & $45^{\circ}$ & 0.1 & 0.8 & 1.1 \\
\hline 0.1 & & 0.5 & 0.5 & 0.5 \\
\hline 0.1 & & 1.0 & 0.2 & 0.2 \\
\hline 0.5 & & 0.1 & 0.66 & 0.8 \\
\hline 0.5 & $\downarrow$ & 0.5 & 0.4 & 0.44 \\
\hline 0.5 & $45^{\circ}$ & 1.0 & 0.16 & 0.16 \\
\hline
\end{tabular}


Table A-2. Concial cavity values for a typical shallow or deep cavity.

\begin{tabular}{lll}
\hline & Shallow Cavity & Deep Cavity \\
\hline Depth, cm & 0.2 & 0.7 \\
Diameter, cm & 0.254 & 0.2 \\
Area, cm & 0.0945 & 0.222 \\
$\mathrm{dA}_{\mathrm{i}} / \mathrm{A}_{\mathrm{s}}$ & 0.021 & 0.0088 \\
\hline
\end{tabular}

Table A-3. Apparent Emissivity for shallow and deep cavities.

\begin{tabular}{lcccc}
\hline & Shallow $\left(\theta=45^{\circ}\right)$ & Deep & $\left(\theta=10^{\circ}\right)$ \\
\cline { 2 - 5 } $\begin{array}{l}\text { Cavity Measure- } \\
\text { ment Location }\end{array}$ & $\varepsilon=0.1$ & $\varepsilon=0.5$ & $\varepsilon=0.1$ & $\varepsilon=0.5$ \\
Top & 0.118 & 0.54 & 0.235 & 0.675 \\
Middle & 0.145 & 0.60 & 0.388 & 0.9 \\
Bottom & 0.172 & 0.665 & 0.478 & 0.95 \\
\hline
\end{tabular}

shallow weld with a surface $\varepsilon=0: 5$ the emissivity increase is 8 to $33 \%$. In either case, the amount of radiation entering the probe via reflection from other cavity surface elements can not be neglected. It is recommended that $E q .(A-8)$ be used to estimate the apparent emissivity. The majority of the temperature measurements in this study were obtained from shallow weld cavities with a range of surface emissivity of about 0.3 to 0.4 . Therefore, the emissivity increase over these surface values will vary between $10 \%$ near the top and $40 \%$ near the bottom. 


\section{APPENDIX B}

\section{Frequency of Weld Bead Ripples}

To determine the pressure buildup in the cavity the vapor mass must be known. The mass in the cavity at any time, $t$, is equal to some time averaged value at $t_{i}$ plus a transient amount due to time flucturations,

$$
m(t)=m\left(t_{i}\right)+\int_{t_{i}}^{t} \frac{d m}{d t} d t
$$

where $\mathrm{dm}$; dt represents the net amount of mass change per unit time. Assuming an average constant value for $\mathrm{dm} / \mathrm{dt}$ and approximating the time increment $\Delta \tau$ as $t-t_{i}$ allows the above expression to be written as,

$$
\begin{aligned}
& m(t)=m\left(t_{i}\right)+\frac{d m}{d t} t-\frac{d m}{d t} t_{i} \\
& m(t)=m\left(t_{i}\right)+\frac{d m}{d t} \Delta \tau
\end{aligned}
$$

If more mass is condensing on the cavity walls than is being evaporated in a small area, it is possible that $\mathrm{dm} / \mathrm{dt}$ could even be negative. However, that would not produce a pressure buildup. A pressure buildup can only arise when less mass is leaving than is being evaporated. Figure B-1 shows a cavity representation at some time. The electron beam is intensely evaporating the metal at rate $\dot{m}_{v}$ on area $A_{v}$ and the vapors leaving the cavity at rate $\dot{\mathrm{m}}_{e}$ through area $A_{E}$. The following expression described the rate of change of mass as,

$$
\frac{d m}{d t}=\dot{m}_{v} A_{v}-\dot{m}_{e} A_{E}
$$




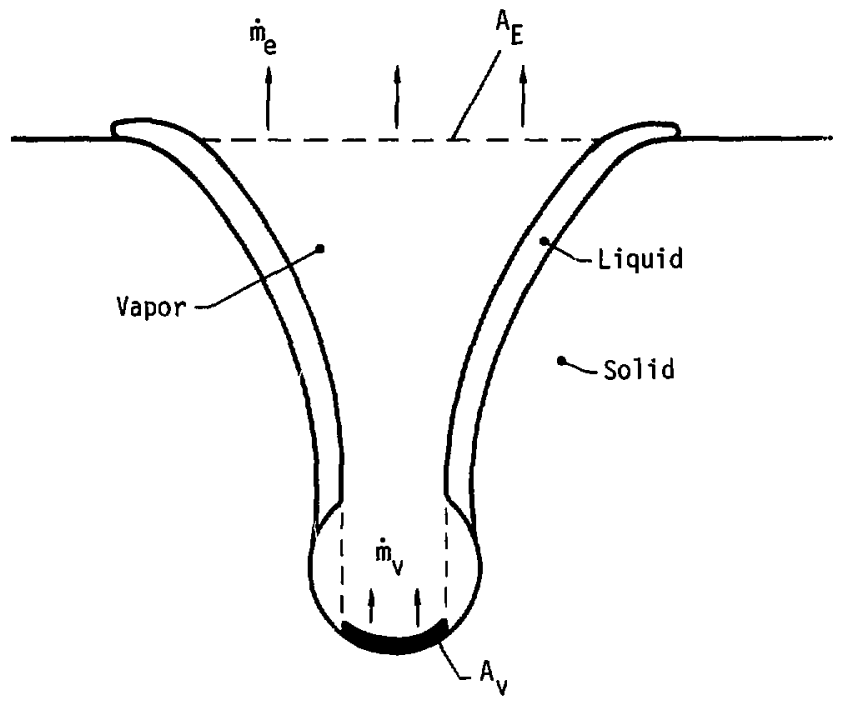

Figure B-1. Representation of cavity showing mass evaporating at cavity bottom and exiting through cavity top. 
An expression for the pressure buildup over some time averaged cavity pressure can be derived from the perfect gas law,

$$
p=\frac{m R_{u} T}{M V}
$$

where $M$ is the molecular weight, $V$ is the cavity volume, $T$ is the average cavity temperature, $m$ is the vapor mass in the cavity, $R_{u}$ is the universal gas constant, and $p$ represents the average cavity vapor pressure. Assuming the cavity temperature and volume to remain relatively constant over a small time increment, $\Delta \tau$, allows a differential pressure change, dp to be determined for a constant rate of mass change $\mathrm{dm} / \mathrm{dt}$ as,

$$
d p=\frac{R_{u}^{\top}}{M V} \frac{d m}{d t} \Delta \tau
$$

Estimating a value of $d m / d t$ from $E q .(B-3)$, the pressure buildup over some time averaged cavity pressure could be determined from Eq. (B-5). To determine how large this value actually is, it should be compared to the time averaged cavity pressure based on a time averaged cavity surface temperature. A value for the term $\dot{m}_{v}$ in $\mathrm{Eq}$. (B-3) can be estimated by using the Langmuir relationship, Eq. (23). For $\dot{m}_{e}$ one could take as a maximum flow rate that defined by choked flow which has the form ${ }^{38}$

$$
\mathrm{m}_{\mathrm{e}}=0.0011 \frac{\mathrm{p}}{\mathrm{T}^{1 / 2}} \frac{\mathrm{gm}}{\mathrm{cm}^{2} \mathrm{sec}}
$$

where $P$ is the average cavity pressure, dynes $/ \mathrm{cm}^{2}$, and $T$ is the cavity temperature, ${ }^{\circ} \mathrm{K}$. The magnitude of the pressure buildup defined by $\mathrm{Eq}$. $(B-5)$ can then be calculated by assuming a cavity volume, $V$, and time increment, $\Delta \tau$.

The liquid metal at the cavity top wants to flow back into the cavity with the he?p of the surface tension imbalance force as depicted in Figure 32. During welding the liquid is almost entirely behind the 
electron beam cavity as shown in Figure B-2. As the surface tension force tries to constrict the cavity into a smalier shape, the liquid metal will move into the cavity region, It is assumed that the magnitude of the liquid mass is approximately equal to the cavity volume multiplied by the liquid density,

$$
m=\rho \pi R^{2} h
$$

Then, under the influence of the surface tension force, the liquid will be accelerated in a direction opposite to the weld direction according to Newton's second law. Further, if it is assumed that the force is acting uniformly over a cavity surface area projected onto a vertical plane, $(h-H) 2 R$, from the imbalance location to the cavity top, one can write an expression for the surface tension force using Newton's second law.

$$
\text { Surface tension force }=\operatorname{mas} \frac{d^{2} x}{d t^{2}}
$$

For a surface tension pressure, P $_{S . T}$, the above is,

$$
P_{S . T .}(h-H) 2 R=\rho \pi R^{2} h \frac{d^{2} x}{d t^{2}}
$$

The solution to Eq. $(B-8)$ is

$$
x(t)=\frac{P_{S . T .}(h-H) 2}{\rho \pi R h} \frac{t^{2}}{2}+B t+C
$$

where boundary conditions

$$
\begin{aligned}
& x=0 \\
& t=0
\end{aligned} \quad \text { gives } c=0
$$

and

$$
\begin{array}{ll}
\frac{d x}{d t}=0 & \text { gives } B=0 \\
t=0 &
\end{array}
$$



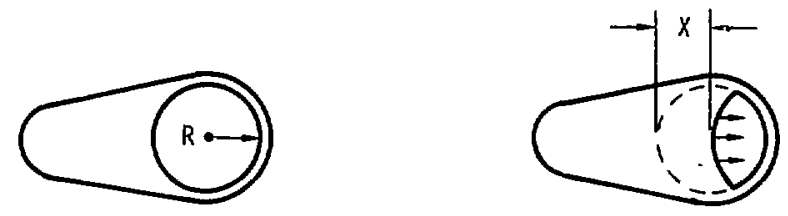

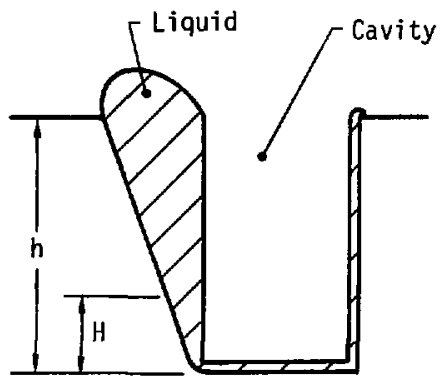

(a)

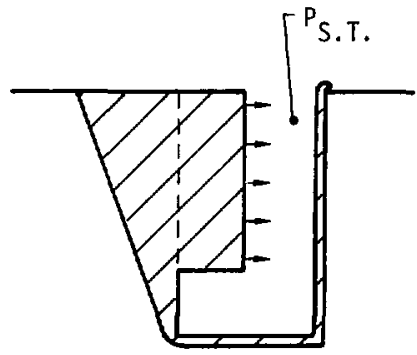

(b)

Figure B-2. Simulation of cavity before and after liquid metal flow resulting from the constricting effect of the surface tension. 
or

$$
x(t)=\frac{P_{S . T}(h-H) t^{2}}{\rho \pi R h}
$$

This solution will only apply as long as the pressure buildup is small and the surface tension pressure is uniform. Since the surface tension pressure actually increases as the hole diameter decreases, the above expression can only be used to estimate the time it will take to nearly close the cavity.

Now the necessary relations have been presented and a general estimate can be made for the dynamics at the cavity top. The time required to close up the top opening can be detemined from Eq. (B-10). For a typical weld in aluminum 3100 a 7 loy

$$
R=0.12 \mathrm{~cm}, \quad h \simeq 0.2 \mathrm{~cm}, \quad H=0.05 \mathrm{~cm}
$$

and

$$
\rho=2.7 \mathrm{gm} / \mathrm{cm}^{3},
$$

the surface tension pressure at the cavity top will be about 6000 dynes/ $\mathrm{cm}^{2}$. Therefore, the time required for the liquid to move a distance equal to the hole diameter, $2 R$, or $0.24 \mathrm{~cm}$ is from Eq. (B-10).

$$
\begin{aligned}
t & =r \sqrt{\frac{x \rho \pi R h}{P_{S . T .}(h-H)}} \\
& =\sqrt{\frac{(.24)(2.7) \pi(.12)(.2)^{\prime}}{(6000)(.2-.05)}}=0.0073 \mathrm{sec}
\end{aligned}
$$

Now, an estimate of the pressure buildup must be made. For the above weld, the cavity dimensions are $h=0.2 \mathrm{~cm}, \mathrm{R}=0.12 \mathrm{~cm}$, and the volume $\pi R^{2} h$, is the approximately $0.00905 \mathrm{~cm}^{3}$. Using an average for $T=2000^{\circ} \mathrm{K}$ and $M=27$, and substituting into Eq. (33), 


$$
\begin{aligned}
& \Delta P=\frac{8.3110^{7}}{27 \frac{\mathrm{gm}}{\mathrm{gm}-\mathrm{moTe}}} \frac{\text { ergs }}{\mathrm{gm}-\mathrm{mole}-{ }^{\circ} \mathrm{K}} \frac{2000^{\circ} \mathrm{K}}{0.00905 \mathrm{~cm}^{3}} \frac{\mathrm{dm}}{\mathrm{dt}} \Delta \tau \\
& \Delta P=6.810^{11} \frac{\mathrm{dm}}{\mathrm{dt}} \Delta \tau \quad\left[\frac{\text { dynes }}{\mathrm{cm}^{2}}\right]
\end{aligned}
$$

From the Langmuir equation for a single species the evaporation rate is,

$$
\dot{m}_{v}=4.3910^{-5} \mathrm{p}^{0}\left(\frac{M}{T}\right)^{1 / 2}
$$

and for

$$
\begin{aligned}
M & =27, \quad P^{0}-\text { dynes } / \mathrm{cm}^{2} \\
\dot{m}_{v} & =3.310^{-4} \frac{p^{0}}{T^{T / 2}}
\end{aligned}
$$

Comparing this with the maximum flow rate based on sonic flow, the evaporation rate is smalier for equal areas. Consequently, there will be no pressure buildup until the cavity tries to close. Therefore, as the cavity top tries to close, the rate of mass leaving the cavity can be approximated as

$$
\frac{d m}{d t}=3.310^{-4} \frac{P}{T^{1 / 2}} \pi R_{C}^{2}-1110^{-4} \frac{P}{T^{1 / 2}} \pi R_{T}^{2}
$$

And for a condition when the hole tries to close for a moment, the radius at the top $R_{T}$, may become slightly less than the effective evaporative radius at the cavity bottom, $R_{C}$. If $R_{C}=0.07 \mathrm{~cm}, R_{T}=0.03 \mathrm{~cm}$, aid using average temperature and pressure values $\left(2000^{\circ} \mathrm{K}, 13,300\right.$ dynes/ $\mathrm{cm}^{2}$ ) for the maximum flow rate term, and the measured bottom cavity temperature and the corresponding local vapor pressure $\left(2273^{\circ} \mathrm{K}, 72,000\right.$ dynes $/ \mathrm{cm}^{2}$ ) for the evaporation flow rate term allows Eq. $(B-14)$ to be evaluated as, 
$\frac{d m}{d t}=4.3910^{-6}(72,000)\left(\frac{27}{2273}\right)^{1 / 2}(.07)^{2} \pi-1110^{-4} \frac{(13,300)}{(2000)^{T / 2}}(.03)^{2} \pi$

$\frac{\mathrm{dm}}{\mathrm{dt}}=4.3710^{-3} \mathrm{~g} / \mathrm{s}$

Substituting this value in $E q,(B-12)$ the pressure increment is

$$
\begin{aligned}
& \Delta P=6.810^{11}\left(4.3710^{-3}\right) \Delta \tau \\
& \Delta P=2.9710^{9} \Delta \tau \quad \text { dynes } / \mathrm{cm}^{2}
\end{aligned}
$$

If the estimated average cavity pressure is $10 \operatorname{Torr}\left(13,300\right.$ dynes $\left./ \mathrm{cm}^{2}\right)$ and the opening at the cavity top is reduced from a radius of $0.07 \mathrm{~cm}$ to $0.03 \mathrm{~cm}$ for $10 \mu \mathrm{sec}$ (a minimum cycle time of $250 \mu \mathrm{sec}$ has been measured during welding and associated with cavity oscillation dynamics, 15 therefore, 10 jsec is indeed a very small time increment in comparison), the pressure increment established from Eq. (B-16) will be 29,700 dynes $/ \mathrm{cm}^{2}$. This is approximately twice as large as the estimated average cavity pressure and is certainly great enough to enlarge the opening very quickly. The pressure impulse will force the liquid at the cavity top to move towards the solidified weld bead region. As the liquid is being washed up onto the aiready solidified metal, surface tension forces will decelerate the liquid. Then some of the material may freeze as the surface tension force acts to reverse it's flow direction. This repetitive action could explain the freeze ring or ripple pattern on the weid bead. Approximating the cycle time to be twice the time estimated to nearly clase the cavity, yields the frequency. The calculated frequency for the above is $68 \mathrm{cycles} / \mathrm{sec}$ which compares to the measured value of 71 cycles/sec for this weld. The experimental frequency was determined by counting the number of freeze ridges per $\mathrm{cm}$ and multiplying by the weld speed in $\mathrm{cm} / \mathrm{sec}$. Table $\mathrm{B}-1$ contains values representative of four 
different test we?ds and the resulting estimated top weld bead frequencies.

Table B-1. Weld cavity data for several specific test welds and both experimental and calculated top weid bead frequencies.

\begin{tabular}{|c|c|c|c|c|}
\hline Material & $1100 \mathrm{Al}$ & $1100 \mathrm{A1}$ & Tantalum & S.S. 304 \\
\hline Beam Voltage, Kv & 15 & 17 & 17 & 18 \\
\hline Beam Current, ma & 140 & 210 & 240 & 154 \\
\hline Weld Speed, cm/s & 2.54 & 0.67 & 0.89 & 2.54 \\
\hline $\mathrm{R}, \mathrm{cm}$ & 0.12 & 0.25 & 0.1 & 0.06 \\
\hline$R_{c}, \mathrm{~cm}$ & 0.07 & 0.12 & 0.05 & 0.03 \\
\hline $\mathrm{R}_{T}, \mathrm{~cm}$ & 0.03 & 0.1 & 0.03 & 0.02 \\
\hline$x, \mathrm{~cm}$ & 0.24 & 0.25 & 0.2 & 0.12 \\
\hline h, cm & 0.2 & 0.55 & 0.19 & 0.54 \\
\hline $\mathrm{H}, \mathrm{cm}$ & 0.05 & 0.46 & 0.08 & 0.03 \\
\hline$P_{s t}$ dyn $/ \mathrm{cm}^{2}$ & 6000 & 2500 & 16400 & 15400 \\
\hline $\mathrm{T},{ }^{\circ} \mathrm{K}$ (ave) & 2000 & 2000 & 4273 & 1823 \\
\hline$P$, dyn $/ \mathrm{cm}^{2}$ (ave) & 13300 & 13300 & 7300 & 3300 \\
\hline$\dot{m}_{v}, g / 5-\mathrm{cm}^{2}$ & 0.344 & 0.344 & 0.481 & 0.954 \\
\hline$t, \sec$ & 0.0073 & 0.036 & 0.0105 & 0.00353 \\
\hline$f$, cycles/sec (calc.) & 68 & 14 & 48 & 142 \\
\hline f, experimental & 71 & 21 & $45-62$ & $127-178$ \\
\hline
\end{tabular}


Table B-1. Weld Cavity Data for Several Specific Test Welds and Both Experimental and Calculated Top Weld Bead Frequencies.

\begin{tabular}{|c|c|c|c|c|}
\hline Material & $1100 \mathrm{~A} 1$ & $1100 \mathrm{Al}$ & Tanta lum & S.S. 304 \\
\hline Beam Voltage, Kv & 15 & 17 & 17 & 18 \\
\hline Beam Current, ma & 140 & 210 & 240 & 154 \\
\hline Weld Speed, cm/s & 2.54 & 0.61 & 0.89 & 2.54 \\
\hline $\mathrm{R}, \mathrm{cm}$ & 0.12 & 0.25 & 0.1 & 0.06 \\
\hline $\mathrm{R}_{\mathrm{c}}, \mathrm{cm}$ & 0.07 & 0.12 & 0.05 & 0.03 \\
\hline$R_{T}, \mathrm{~cm}$ & 0.03 & 0.1 & 0.03 & 0.02 \\
\hline$X_{3} . \mathrm{cm}$ & 0.24 & 0.25 & 0.2 & 0.12 \\
\hline $\mathrm{h}, \mathrm{cm}$ & 0.2 & 0.55 & 0.19 & 0.54 \\
\hline $\mathrm{H}, \mathrm{Cm}$ & 0.05 & 0.46 & 0.08 & 0.03 \\
\hline$P_{\text {st }}$ dyn $/ \mathrm{cm}^{2}$ & 6000 & 2500 & 16400 & 15400 \\
\hline $\mathrm{T},{ }^{\circ} \mathrm{K}$ (ave) & 2000 & 2000 & 4273 & 1823 \\
\hline$P, d y n / \mathrm{cm}^{2}$ (ave) & 13300 & 13300 & 7300 & 3300 \\
\hline$\dot{m}_{v}, g / S-\mathrm{cm}^{2}$ & 0.344 & 0.344 & 0.481 & 0.954 \\
\hline$t$, sec & 0.0073 & 0.036 & 0.0105 & 0.0035 \\
\hline f, cycles/sec (calc.) & 68 & 14 & 48 & 742 \\
\hline$f$, experimental & 71 & 21 & $45-62$ & $127-178$ \\
\hline
\end{tabular}


APPENDIX C

Vapor Pressure - Surface Tension Pressure Relationship at the Cavity Bottom

The cavity temperature distribution and the vapor pressure-temperature data must be known before the vapor pressure variation in a weld cavity can be determined. This data is available for pure metals, but not for alloys. Therefore, the procedure described below was developed for estimating vapor pressure-temperature data for an alloy.

At the cavity bottom, the liquid surface temperature is at a maximum, and hence the vapor pressure is also at a maximum. The force balance at the cavity bottom presented in the analysis section resulted in,

$$
P_{v}=\frac{2 \gamma}{R_{B}}+\rho g h
$$

From the experimental weld sections, an estimate can be made for $R_{B}$. The magnitude of the term $2 \gamma / R_{B}$ can be determined after a value is calculated for $\gamma$ at the measured peak cavity temperature. The equilibrium vapor pressure corresponding to the peak cavity temperature can be determined from a curve such as given in Figure 8 or Figure 38 . At the cavity bottom, $P_{V}$ determined using the experimental peak cavity temperature was aiways substantially greater than $2 \gamma / R_{B}$. The hydrostatic head term, pgh, was small in comparison and was therefore neglected in the following discussion. The ratio of the remaining two pressure values can be calculated. This was done for several of the EB weld cavities in aluminum, steel, and tantalum, representing a broad range of weld parameters and the results plotted in Figure $\mathrm{C}-1$. At various 


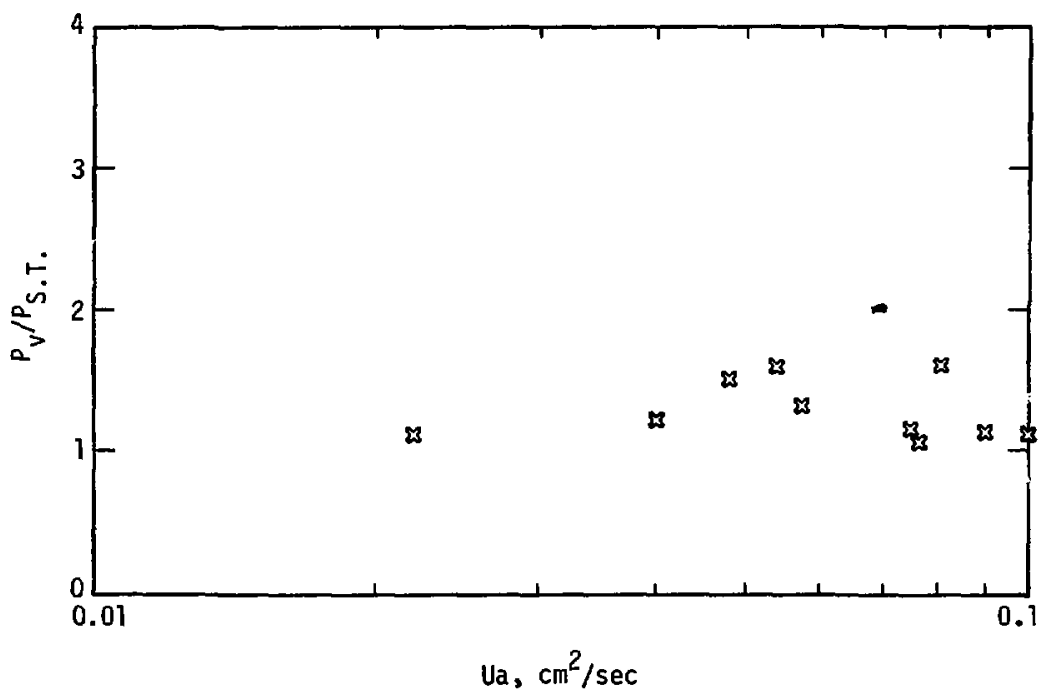

Figure $\mathrm{C}-1$. Pressure ratio calculated at cavity bottom over an extensive range of experimental conditions for welds in aluminum, steel and tantalum. 
weld speeds, U, cavity base radius, a, and therefore EB power, it can be observed that the pressure ratio, $\mathrm{P}_{\mathrm{v}} / \mathrm{P}_{\mathrm{S}}$.T.' at the cavity bottom is relatively constant. An average value of 1.2 appears to apply.

The significance of this observation is that it allows an estimate to be made for either the vapor pressure or the surface tension pressure if only one is known. Now for the aluminum alloys, 7075 , 6061 , and 5083 , it was not possible to caiculate a vapor pressuretemperature relationship. However, using the measured cavity base temperature, an estimated base cavity radius, and surface tension data, a value can be estimated for $2 \gamma / R_{B}$. Then, the vapor pressure at the cavity bottom can be determined by multiplying the value for $2 \gamma / R_{B}$ by the pressure ratio, 1.2 .

The above procedure was used to determine $2 \gamma / R_{B}$ and $P_{v}$ for 7075 aluminum. If the value of the vapor pressure thus determined for the 7075 aluminum alloy at its peak cavity temperature is placed on a vapor pressure-temperature curve, the result is an isolated point such as point $\mathrm{A}$ in Figure $\mathrm{C}-2$. In Figure $\mathrm{C}-2$, note that all of the curves have similar slopes and are only shifted to the right or left of each other. The vapor pressure of an alloy containing a highly volatile species, such as zinc in 7075 aluminum, will almost be totally dependent on the pressure exhibited by this volatile species. This was clearly demonstraced when a glass slide was located near the 7075 aluminum weld cavity during welding. The metal vapor deposited consisted of $90 \%$ zinc and $10 \%$ magnesium. Therefore, the alloy vapor pressure behavior as a function of temperature should be similar to that of zinc. 


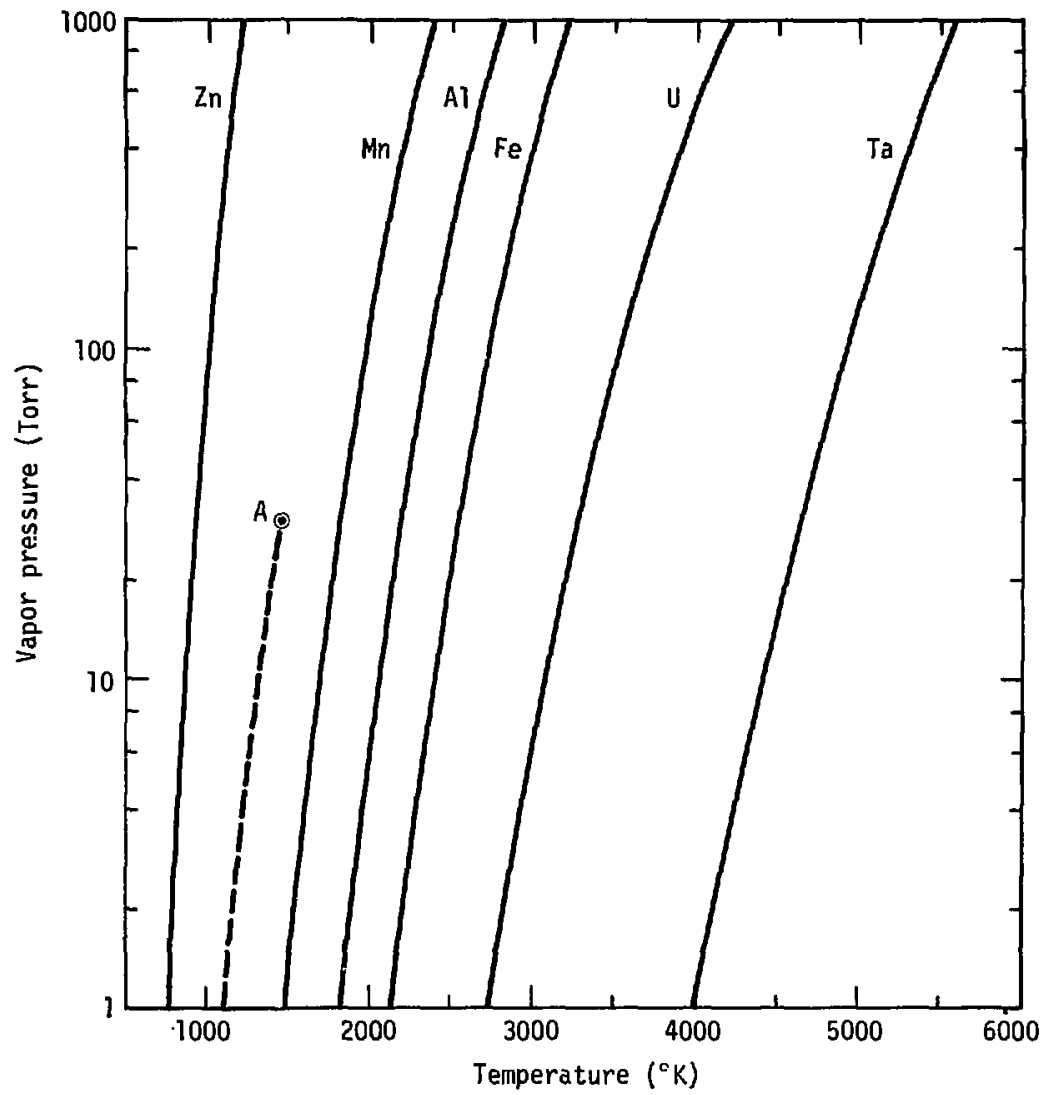

Figure C-2. Metal vapor pressure curves including es timated relationship for a 7075 aluminum alloy as indicated by the dashed line originating at point $A$. 
It is reasonable to assume that point $A$ is on a curve representing an alloy and that vapor pressure data at other temperatures could be estimated by sketching in a curve parallel to the other lines. This was done for 7075 aluminum and is shown in Figure C-2 as the dashed line. While surely not highly accurate, this procedure does allow a reasonable estimate to be made for the vapor pressure-temperature variation. The estimated relationship can then be used for calculating the vapor pressure in the 7075 aluminum cavity as a function of temperature and thus position. 


\section{APPENDIX D}

\section{Stability Parameter Calculations}

The following seven step procedure is proposed to determine the stability parameter, $S$, for any material:

1. Determine the depth of penetration $h$.

2. Determine the cavity temperature from the dimensionless temperature profile.

3. Approximate the cavity shape to be a cone with a spherical base.

4. Determine the surface tension pressure variation in the cavity.

5. Determine the vapor pressure variation in the cavity.

6. Determine the imbalance location, $H$.

7. Calculate the stability parameter, $\mathrm{S}=\mathrm{H} / \mathrm{h}$.

This procedure will now be explained in more detail in the following paragraphs.

Step 1. Determine the Depth of Penetration - A number of methods have been proposed for calculating penetration depth for specified power level and weld speed. The one proposed by Tong $^{18}$ is considered to be fundamentaliy more applicable and has been shown to be as accurate or more accurate than others. A constant temperature boundary condition was used to formulate a cavity model that allows the penetration depth to be predicted as a function of the material properties and weld parameters. Ideally, the surface temperature of the melt layer must be approximated. However, a first order estimate is to assume that the 
surface temperature is the same as the melting temperature of the material. With this approximation, the solution is given by,

$\frac{4.186 h}{n(E I)} \approx\left\{k\left(T_{m}-T_{\infty}\right)\left[\int_{0}^{\pi / 2} 2 D V(\theta, A) d \theta\right]+\left(4 \rho \alpha h_{f g}\right) A\right\}^{-1}$

where $A=U a / 2 \alpha$ and the value of the integral is determined from Figure $\mathrm{D}-1$. It is to be noted that an improved solution can be obtained by methods outlined in reference 18 . However, this is a lengthy procedure and for the purpose of determining the stability parameter is probably unnecessary. The value recommended for the efficiency, $n$, is 0.5. The material properties should be evaluated at the mean temperature. Values used in subsequent calculations are listed in Table D-1. The results of these calculations are presented in Figure D-2 for several materials. By selecting a set of weld parameters such as weld speed, $U$, beam power, $E I$, and beam radius, a, the penetration depth can be determined for a specific material.

Table D-1. Thermal properties at mean temperature.

\begin{tabular}{lcccccrr}
\hline & $\begin{array}{c}\rho \\
\mathrm{g} / \mathrm{cm}^{3}\end{array}$ & $\begin{array}{c}k \\
\mathrm{cal} / \mathrm{cm}- \\
\mathrm{sec}-{ }^{\circ} \mathrm{C}\end{array}$ & $\begin{array}{c}\mathrm{C}_{\mathrm{p}} \\
\mathrm{cal} / \mathrm{g}-{ }^{\circ} \mathrm{C}\end{array}$ & $\begin{array}{c}\alpha \\
\mathrm{cm}^{2} / \mathrm{sec}\end{array}$ & $\begin{array}{c}\mathrm{h}_{\mathrm{fg}} \\
\mathrm{cal} / \mathrm{g}\end{array}$ & \multicolumn{2}{c}{$\begin{array}{c}\text { Temperatures } \\
\left({ }^{\circ} \mathrm{C}\right) \\
\text { Melt }\end{array}$} \\
\hline $1100 \mathrm{Al}$ & 2.71 & 0.537 & 0.257 & 0.772 & 90 & 650 & 335 \\
$304 \mathrm{AA}$ & 8.0 & 0.059 & 0.148 & 0.0499 & 64.5 & 1425 & 722 \\
U D-38 & 19.1 & 0.089 & 0.044 & 0.1059 & 20.0 & 1133 & 577 \\
$7075 \mathrm{Al}$ & 2.79 & 0.29 & 0.23 & 0.452 & 93 & 532 & 276 \\
Ta & 16.6 & 0.13 & 0.036 & 0.218 & 41.3 & 2994 & 1507 \\
20-6-9 & 8.0 & 0.0496 & 0.15 & 0.042 & 64.5 & 1410 & 715 \\
Stee1 & & & & & & & \\
\hline
\end{tabular}




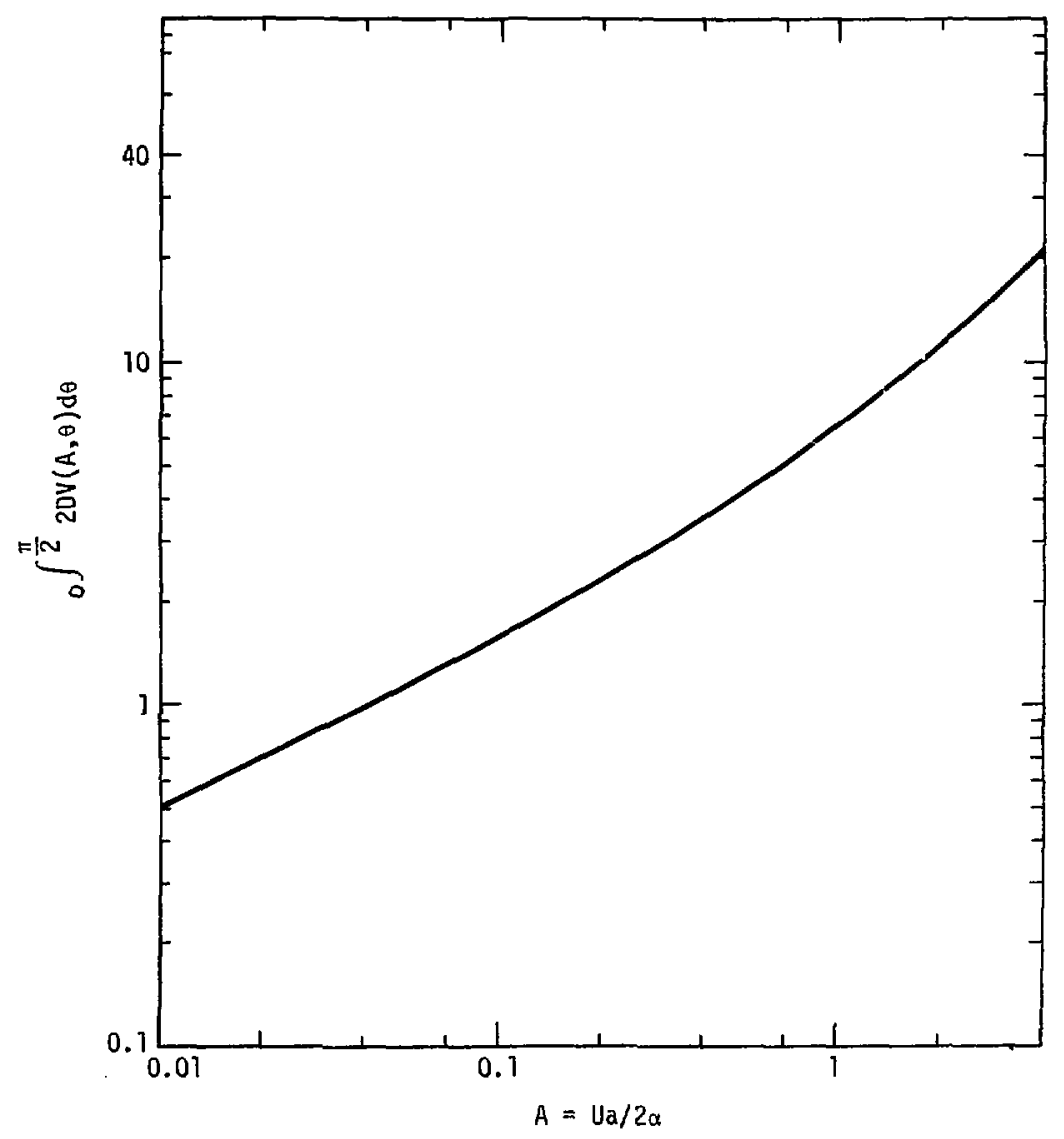

Figure $0-1$. Forward heat conduction parameter. 18 


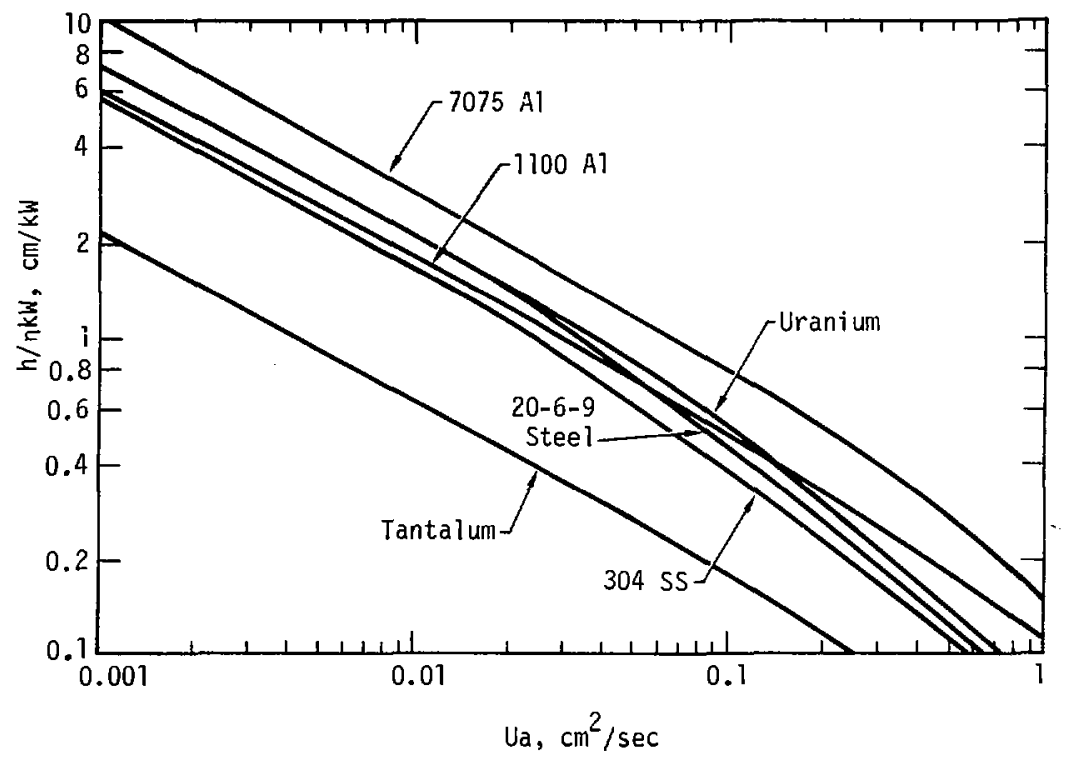

Figure $\mathrm{D}-2$. Depth of penetration parameter. ${ }^{18}$ 
Step 2. Determine the Cavity Temperature Variation - The cavity temperature profile can be calculated for a specified penetration depth and material by assuming,

$$
\theta=1-\left(\frac{x}{h}\right)^{c / h}
$$

as proposed in the Discussion Section, Eq. (40). For aluminum, a value of 0.35 is recommended for $C$. Then for any depth, $x$, the dimensionless temperature, $\theta$, can be calculated. To obtain the actual cavity surface temperature, $T(x)$, at location $x$ measured from the cavity top, $T_{T}$ and $T_{B}$ must be known. Then the following equation can be solved for $T(x)$.

$$
\theta=\frac{T_{B}-T(x)}{T_{B}-T_{T}}
$$

The experimentai temperature measurements indicated that the temperature at the top of the cavity is slightiy in excess of the melt temperature. Therefore, it is reasonable to assume that $T_{T}=$ melt temperature. For materials whose cavity temperatures have not been measured, the following approach is suggested to estimate the bottom temperature. The force balance at the cavity bottom presented in the Analysis Section resulted in,

$$
P_{V}=\frac{2 Y}{R_{B}}+\rho g h
$$

Since the vapor pressure is a strong function of temperature, a rough approximation of $P_{V}$ can be obtained by neglecting the hydrostatic term, $\rho g h$, in Eq. (12). The result

$$
P_{V} \approx \frac{2 y}{R_{B}}
$$


can be used to arrive at an estimate of the bottom temperature as follows. Substituting a surface tension value ${ }^{26}$ and a value of $R_{B}$ into (D-4) will yield an approximate value for the vapor pressure. Then the temperature corresponding to this pressure can be obtained from data such as shown in Figure $8 .^{29}$ For example, with a cavity radius of 0.05 $\mathrm{cm}, \gamma=830$. dynes $/ \mathrm{cm}$, the vapor pressure of aluminum is $\simeq 25$ Torr.

This pressure corresponds to a temperature of $\simeq 1890^{\circ} \mathrm{C}$ which can be used to approximate the bottom temperature, $T_{B}$. This compares favorably with the experimentally determined temperature of $1900 \pm 50^{\circ} \mathrm{C}$ for 1100 al uminum.

The radius $R_{B}$ can be approximated by measuring the weld width at the weld root from a post-weld macrosection. It should be noted that $R_{B}$ will generally vary for different machine settings or electron gun designs.

Step 3. Approximate Cavity Shape to that of a Cone with a Spherical Bottom - From observing many post-weld macrosections, the avove approximation is very close to that actually experienced. It is suggested that the dimensions to use for the cavity dimension be based on these macrosections. Approximate the bottom radius and the radius at the cavity opening by making measurements of a weld cross-section. In this investigation, it was observed that the top radius was generally 2 - 4 times the bottom radius. However, a welder that can focus to a smaller spot size may produce welds with a different ratio of radii.

Step 4. Determine Surface Tension Pressure - After the temperature distribution and cavity shape are determined, the surface tension pressure can be calculated as a function of cavity location. Since the 
force imbalance location will probably be along the conical sides of the cavity (rather than at the bottom), the following expression (Analysis Section) can be used to calculate the surface tension pressure at location $x$.

$$
P_{\text {S.T. }}=\frac{Y}{R_{X}}
$$

Surface tension is dependent on the temperature as well as the cavity location, as is $R_{x}$. Surface tension data compiled by Wilson ${ }^{34}$ can be used in evaluating Eq. (D-5).

Step 5. Determine the Vapor Pressure - If the material considered is of high purity, or contains alloying elements that are less volatile than the base material, then reliable vapor pressure-temperature data $^{29}$ is available. If the material is an alloy, the peak cavity temperature must be estimated or measured, then the procedure in Appendix $C$ for 7075 aluminum should be used to determine the vapor pressure relationship for the specific alloy. Finally, this relationship is then used to give the vapor pressure in the cavity that corresponds to the local cavity surface temperature determined in Step 2.

Step 6. Determine the Imbalance Location - This is simply determined by finding the cavity location at which the surface tension pressure is approximately equal to the vapor pressure. It is measured from the cavity bottom.

Step 7. Stability Parameter - The stability parameter, S, is calculated by dividing the magnitude of the imbalance location by the penetration depth. 
The above procedure was used to calculate the stability parameter for six materials. Table D-2 lists these materials and the data required to evaluate the stability parameter. The results of these calculations were used to derive the information contained in Figure 44 .

Table D-2. Data used in determining stability parameter.

\begin{tabular}{|c|c|c|c|c|c|}
\hline Material & $\begin{array}{c}\mathrm{T}_{\mathrm{T}} \\
\left({ }^{\circ} \mathrm{C}\right)\end{array}$ & $\begin{array}{c}T_{B} \\
\left({ }^{\circ} \mathrm{C}\right)\end{array}$ & $\stackrel{\gamma}{\text { (dynes/cm) }}$ & $\begin{array}{c}T^{T} \gamma \\
\left({ }^{\circ} \mathrm{C}\right)\end{array}$ & $\begin{array}{c}\mathrm{d} \gamma / \mathrm{dT} \\
\left(\text { dynes } / \mathrm{cm}-{ }^{\circ} \mathrm{C}\right)\end{array}$ \\
\hline $1100 \mathrm{~A} 1$ & 660 & 1900 & 914 & 660 & -0.135 \\
\hline $7075 \mathrm{~A} 1$ & 532 & 1180 & 914 & 660 & -0.135 \\
\hline $\begin{array}{l}304 \text { Stainless } \\
\text { Steel }\end{array}$ & 1425 & 2100 & 1850 & 1450 & -0.43 \\
\hline 20-6-9 Steel & 1410 & 1820 & 1850 & 1450 & -0.43 \\
\hline Tantalum & 3000 & 4440 & 2400 & 3000 & -0.25 \\
\hline Uranium & 1133 & 3427 & 1550 & $1 \div 0$ & -0.14 \\
\hline
\end{tabular}

Table D-3 lists the parameters for some of the materiais welded in this study, the corresponding condition of the weld root region as observed from post-weld macrosections, and the value of $r$ from Figure 44 . In all cases, the stability parameter is greater than 0.5 for welds exhibiting unacceptable spiking and is less than 0.5 for welds with little or no spiking.

The above observations suggest the foilowing approach in choosing a set of weld parameters. First it is dfsired to have $S \leq 0.5$ to reduce the chance of detrimental spiking. Generally, a weld requires a certain penetration depth such that Figure $0-2$ can be used to determine the other weld parameters. For example, suppose the penetration depth for a 7075 aluminum weld is specified to be $1.0 \mathrm{~cm}$. If EI $=4 \mathrm{~kW}$, then 
Table D-3. Calculated stability parameter for experimental weld conditions.

\begin{tabular}{|c|c|c|c|c|c|c|c|}
\hline Material & $\begin{array}{c}E \\
\text { Beam } \\
\text { Voltage } \\
(k v)\end{array}$ & $\begin{array}{c}\text { I } \\
\text { Beam } \\
\text { Current } \\
\text { (ma) }\end{array}$ & $\begin{array}{c}U \\
\text { Weld } \\
\text { Speed } \\
(\mathrm{cm} / \mathrm{sec})\end{array}$ & $\begin{array}{l}\quad \text { a } \\
\text { Bottom } \\
\text { Radius } \\
(\mathrm{cm})\end{array}$ & $\begin{array}{c}E I / U a \\
\left(\mathrm{~kJ} / \mathrm{cm}^{2}\right)\end{array}$ & $\begin{array}{c}\text { S } \\
\text { Fig. } 44\end{array}$ & $\begin{array}{l}\text { Held Roots } \\
\text { Comments }\end{array}$ \\
\hline $1100 \mathrm{Al}$ & 12.9 & 152 & 0.44 & 0.06 & 44 & 0.34 & No spiking \\
\hline $1100 \mathrm{Al}$ & 17 & 160 & 0.84 & 0.10 & 32 & 0.22 & No spiking \\
\hline $1100 \mathrm{Al}^{21}$ & 31 & 140 & 0.80 & 0.05 & 108 & 0.62 & Small spiking \\
\hline $7075 \mathrm{Al}$ & 13 & 120 & 0.42 & 0.055 & 68 & 0.88 & Some large spikin \\
\hline $7075 \mathrm{Al}$ & 17 & 155 & 2.11 & 0.05 & 25 & 0.60 & Spiking \\
\hline $\begin{array}{l}304 \text { Stain- } \\
\text { less Steel }\end{array}$ & 15 & 140 & 2.11 & 0.04 & 25 & 0.30 & No spiking \\
\hline $\begin{array}{l}304 \text { Stain- } \\
\text { less Steel }\end{array}$ & 18 & 168 & 2.54 & 0.04 & 30 & 0.35 & No spiking \\
\hline $\begin{array}{l}304 \text { Stain- } \\
\text { less Steel }\end{array}$ & 32 & 155 & 0.5 & 0.05 & 198 & 0.88 & Some spiking \\
\hline 20-6-9 Steel & 18 & 175 & 1.21 & 0.045 & 58 & 0.90 & Large spikes \\
\hline 20-6-9 Steel & 15 & 135 & 1.1 & 0.04 & 46 & 0.83 & Large spikes \\
\hline Uranium ${ }^{3}$ & 110 & 15 & 1.27 & 0.09 & 15 & 0.30 & No spiking \\
\hline Uranium $^{3}$ & 110 & 24 & 1.27 & 0.06 & 34 & 0.56 & Spiking \\
\hline Tantalum & 17 & 240 & 0.89 & 0.084 & 54 & 0.42 & No spiking \\
\hline
\end{tabular}


$h / \eta E I=1 /(0.5)(4)=0.5$ and from Figure $0-2 \mathrm{Ua}=0.016 \mathrm{~cm}^{2} / \mathrm{sec}$.

Then EI/Ua $=4 / 0.076=250 \mathrm{~kJ} / \mathrm{cm}^{2}$ and Figure 44 for 7075 aluminum yields a value of $S=1.0$. The result indicates that this choice of parameters will exhibit serious spiking. This method provides a means to quickly determine whether spiking will be a problem or not before considerable effort and time is expended actually performing trial welds. 